Prepared in cooperation with Midwest Region Initiative on Natural Sources of Fracture Sand

\title{
Suitability of River Delta Sediment as Proppant, Missouri and Niobrara Rivers, Nebraska and South Dakota, 2015
}

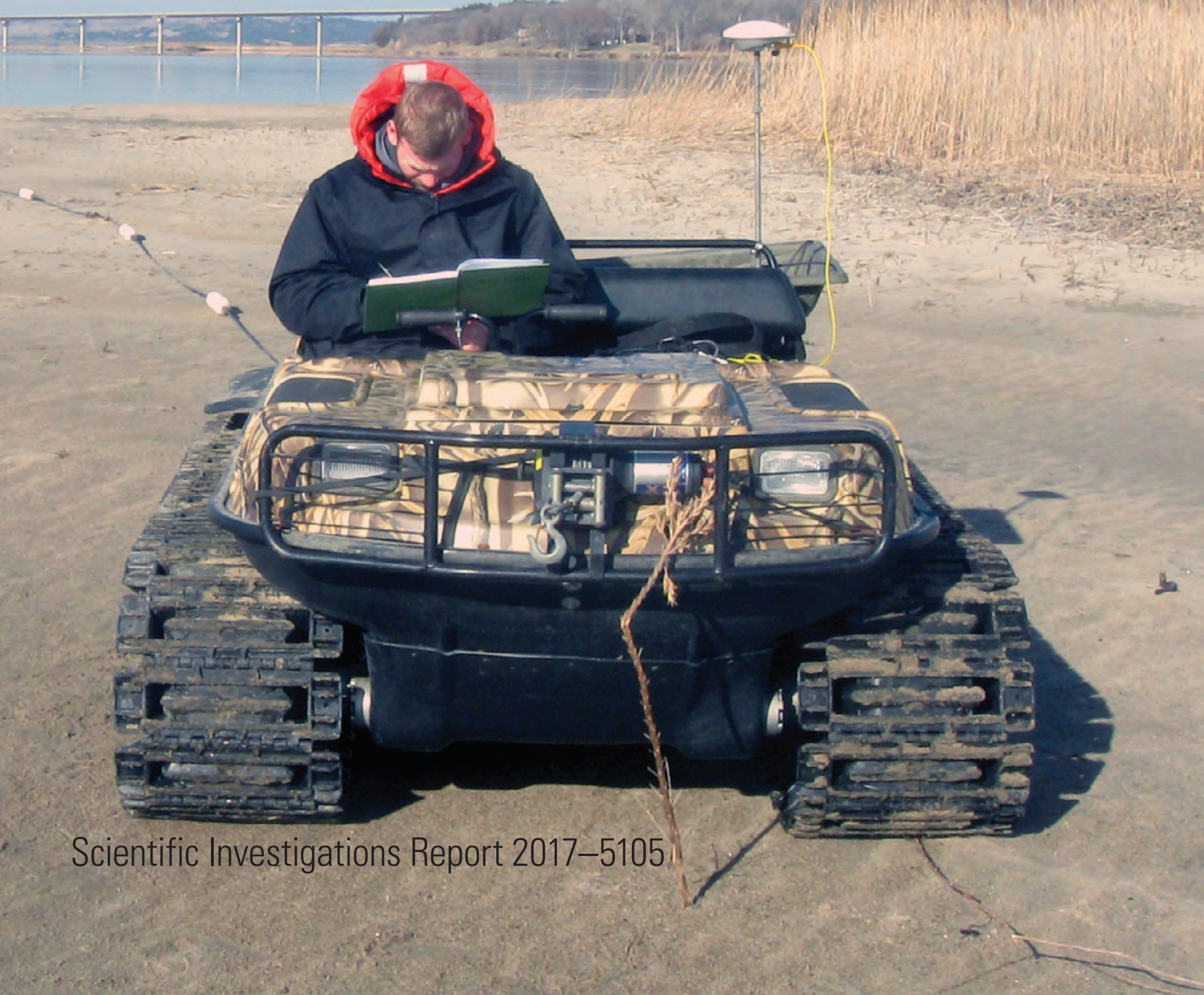

U.S. Department of the Interior

U.S. Geological Survey 
Cover. Collecting capacitively coupled resistivity data on a sandbar complex, Missouri River. View is looking upstream with Standing Bear Bridge shown in background. Photograph by Chris Hobza, U.S. Geological Survey. 


\section{Suitability of River Delta Sediment as Proppant, Missouri and Niobrara Rivers, Nebraska and South Dakota, 2015}

By Ronald B. Zelt, Christopher M. Hobza, Bethany L. Burton, Nathaniel J. Schaepe, and Nadine Piatak

Prepared in cooperation with Midwest Region Initiative on Natural Sources of Fracture Sand

Scientific Investigations Report 2017-5105 


\title{
U.S. Department of the Interior \\ RYAN K. ZINKE, Secretary
}

\section{U.S. Geological Survey William H. Werkheiser, Acting Director}

\author{
U.S. Geological Survey, Reston, Virginia: 2017
}

For more information on the USGS - the Federal source for science about the Earth, its natural and living resources, natural hazards, and the environment-visit https://www.usgs.gov or call 1-888-ASK-USGS.

For an overview of USGS information products, including maps, imagery, and publications, visit https://store.usgs.gov.

Any use of trade, firm, or product names is for descriptive purposes only and does not imply endorsement by the U.S. Government.

Although this information product, for the most part, is in the public domain, it also may contain copyrighted materials as noted in the text. Permission to reproduce copyrighted items must be secured from the copyright owner.

Suggested citation:

Zelt, R.B., Hobza, C.M., Burton, B.L., Schaepe, N.J., and Piatak, Nadine, 2017, Suitability of river delta sediment as proppant, Missouri and Niobrara Rivers, Nebraska and South Dakota, 2015: U.S. Geological Survey Scientific Investigations Report 2017-5105, 51 p., https://doi.org/10.3133/sir20175105.

ISSN 2328-0328 (online) 


\section{Contents}

Abstract

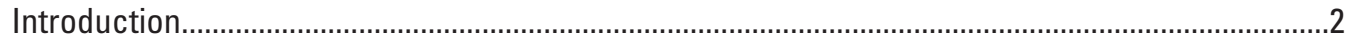

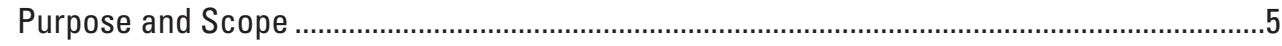

Description of the Study Area ...........................................................................................

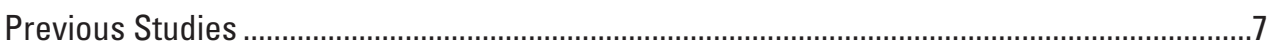

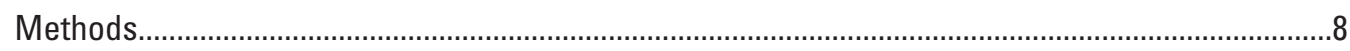

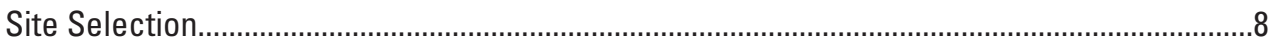

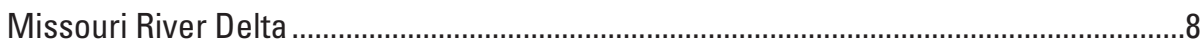

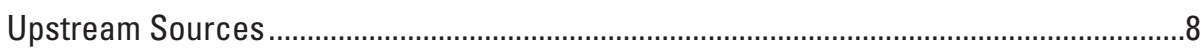

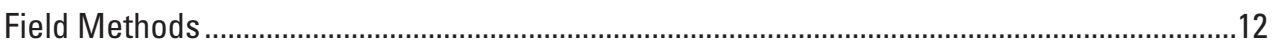

Surface-Geophysical Reconnaissance .....................................................................12

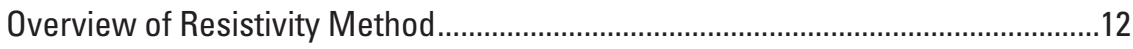

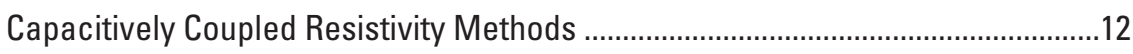

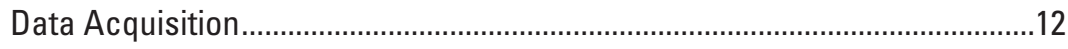

Data Processing and Inversion ......................................................................13

Missouri River Delta Sampling ....................................................................................

Sampling Upstream Sources of Sand .....................................................................14

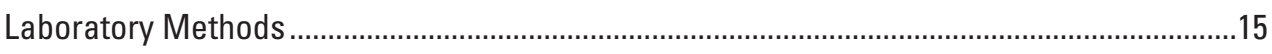

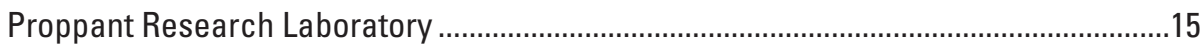

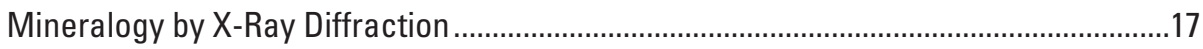

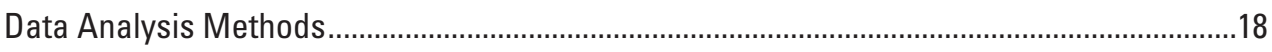

Proppant Size and Size Distribution ........................................................................18

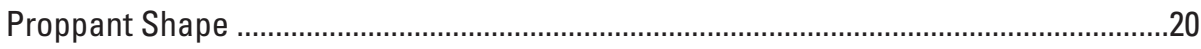

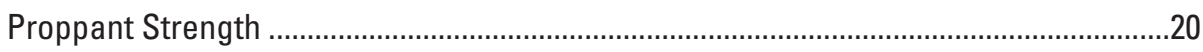

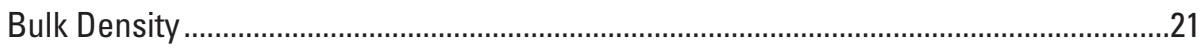

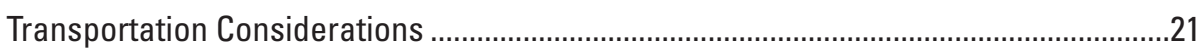

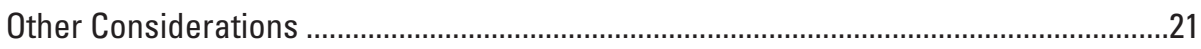

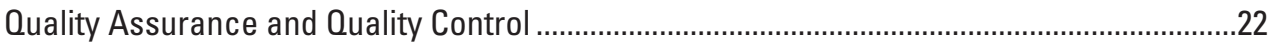

Methods for Interlaboratory Comparison .........................................................................22

Quality Assurance for U.S. Geological Survey Laboratory .......................................22

Quantification for Interlaboratory Comparison......................................................23

Uncertainty Estimates from Sampling Replicates ........................................................23

Uncertainty Estimates from Interlaboratory Comparisons ..............................................25

Other Quality-Assurance Review and Exploratory Data Analyses ..................................27

Suitability Assessment of River Delta Sediment ………............................................................27

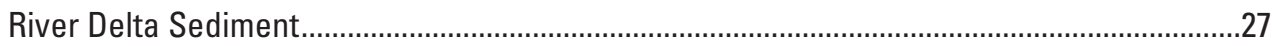

American Petroleum Institute 40/70 Dominant-Size Class .............................................29

American Petroleum Institute 70/140 Dominant-Size Class ...........................................29

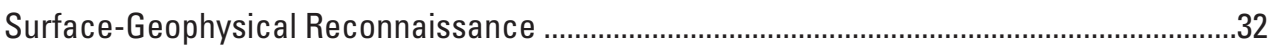

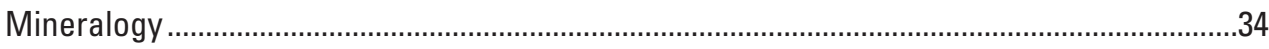


Suitability Assessment of Upstream Sources.................................................................................

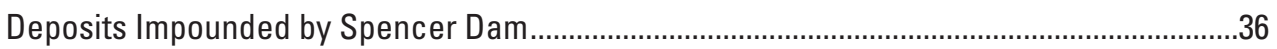

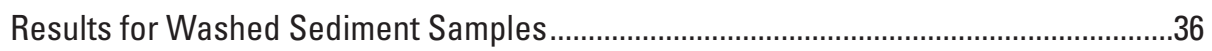

Results for Dominant Proppant Size Class ......................................................................37

Sandbar Deposits along the Lower Niobrara River Downstream from Spencer Dam ...........37

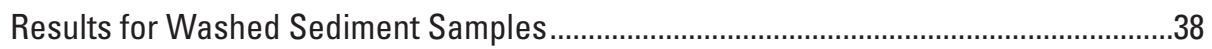

Downstream Trend from Spencer Dam to Eagle Creek................................................

Reach A-Where Medium Sand is Dominant ..................................................38

Reach B-Where Fine Sand is Dominant ....................................................40

Reach C—Between Eagle Creek and Streamgaging Station 06465500 .........40

Reach D-At the Niobrara River Mouth ......................................................40

Results for Dominant Proppant Size Class ..................................................................40

Reach A-Where Medium Sand is Dominant .................................................41

Reach B - Where Fine Sand is Dominant .......................................................41

Reach C—Between Eagle Creek and Streamgaging Station 06465500 .........41

Reach D-At the Niobrara River Mouth ............................................................42

Summary and Conclusions......................................................................................................

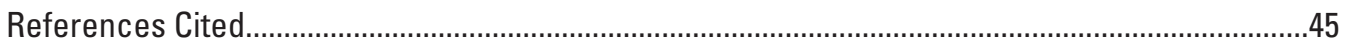

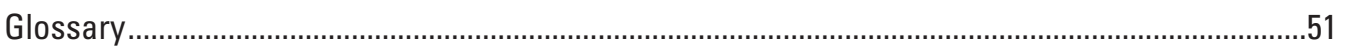




\section{Figures}

1. Map showing location of the study area, Missouri and Niobrara Rivers, and Lewis and Clark Lake, Nebraska and South Dakota.

2. Aerial photography showing sediment sample locations and surface-geophysical survey lines in the Missouri River delta near Running Water, South Dakota, 2015.

3. Map showing sediment sample locations in Spencer Dam vicinity, lower Niobrara River valley, Nebraska, 2015

4. Schematic illustration showing the capacitively coupled resistivity-system setup and geometry.

5. Photographs showing sandbar sample collection using bank-scrape method, Niobrara River, Nebraska, May 2015.

6. Plots showing particle-size distribution of selected sediment samples included in interlaboratory-comparison set showing results from dry-sieve method and optical imaging particle-size analyzer method for sediment samples collected late May 2015 at Niobrara River sites, Nebraska

7. Scatterplot showing results of interlaboratory comparison between dry-sieved whole sediment samples analyzed at U.S. Geological Survey lowa Sediment Laboratory and washed sediment samples analyzed by optical imaging particle-size analyzer method at Montana Tech

8. Scatterplot showing that particle roundness and sphericity were positively related and exceeded their respective minimum recommended values for suitability as proppant. Sediment samples collected from study area, Missouri River Delta, Nebraska and South Dakota, 2015

9. Boxplots showing sediment sample distributions by groups.

10. Vertical sections of surveyed lines showing surface-geophysical results from capacitively coupled resistivity and dominant American Petroleum Institute size class in boreholes, Missouri River delta sandbar complexes near Running Water, South Dakota, 2015

11. Graph showing frequency distribution of apparent resistivity values extracted from inverted capacitively coupled profiles at locations coincident with sediment samples from direct-push coring of Missouri River delta sandbar complexes, Nebraska and South Dakota, 2015

12. Graphs showing longitudinal distribution of percentiles of the particle-size distribution and percentage of washed raw material in American Petroleum Institute 40/70 size class, lower Niobrara River, Nebraska 


\section{Tables}

1. Data for sampling sites for upstream sand sources assessment, lower Niobrara River valley, Nebraska, 2015

2. Data for borehole sampled sites, Missouri River delta near Running Water, South Dakota, 2015

3. Typical properties of fracture sand-ISO 13503-2 industry standards, properties of 40/70 Ottawa sand, Preferred Sands of Genoa 40/70 Loup River sand, and average properties by group of samples collected in 2015 .

4. Particle-size distribution and particle shape results for replicate sediment samples collected in the study area in Nebraska and South Dakota, 2015

5. Summary of interlaboratory comparisons for six sediment samples, lower Niobrara River valley, Nebraska, May 2015

6. Summary of particle-size distribution and particle shape for sediment samples from direct-push river sandbar sediment cores, Missouri River delta, Nebraska and South Dakota, 2015

7. Statistical summary of resistivity values at specific depth intervals from inverted capacitively coupled resistivity profiles, Missouri River delta sandbars, Nebraska and South Dakota, 2015

8. Sediment sample mineralogy by $\mathrm{x}$-ray diffraction for selected sediment samples of deltaic or riverine sand deposits, Missouri and Niobrara Rivers, 2015.

9. Summary of particle-size distribution, bulk density, particle shape, and test results, upstream sand-sources assessment, lower Niobrara River valley, Nebraska, 2015......35 


\section{Conversion Factors}

International System of Units to U.S. customary units

\begin{tabular}{|c|c|c|}
\hline Multiply & By & To obtain \\
\hline \multicolumn{3}{|c|}{ Length } \\
\hline micron $(\mu \mathrm{m})$ & $3.937 \times 10^{-5}$ & inch (in.) \\
\hline centimeter $(\mathrm{cm})$ & 0.3937 & inch (in.) \\
\hline millimeter (mm) & 0.03937 & inch (in.) \\
\hline meter $(\mathrm{m})$ & 3.281 & foot (ft) \\
\hline kilometer (km) & 0.6214 & mile (mi) \\
\hline kilometer $(\mathrm{km})$ & 0.5400 & mile, nautical (nmi) \\
\hline \multicolumn{3}{|c|}{ Area } \\
\hline square meter $\left(\mathrm{m}^{2}\right)$ & 0.0002471 & acre \\
\hline square meter $\left(\mathrm{m}^{2}\right)$ & 10.76 & square foot $\left(\mathrm{ft}^{2}\right)$ \\
\hline square hectometer $\left(\mathrm{hm}^{2}\right)$ & 2.471 & acre \\
\hline square kilometer $\left(\mathrm{km}^{2}\right)$ & 0.3861 & square mile $\left(\mathrm{mi}^{2}\right)$ \\
\hline \multicolumn{3}{|c|}{ Volume } \\
\hline $\operatorname{liter}(\mathrm{L})$ & 0.2642 & gallon (gal) \\
\hline cubic meter $\left(\mathrm{m}^{3}\right)$ & 35.31 & cubic foot $\left(\mathrm{ft}^{3}\right)$ \\
\hline cubic meter $\left(\mathrm{m}^{3}\right)$ & 1.308 & cubic yard $\left(\mathrm{yd}^{3}\right)$ \\
\hline \multicolumn{3}{|c|}{ Flow rate } \\
\hline cubic meter per second $\left(\mathrm{m}^{3} / \mathrm{s}\right)$ & 70.07 & acre-foot per day (acre-ft/d) \\
\hline cubic meter per second $\left(\mathrm{m}^{3} / \mathrm{s}\right)$ & 35.31 & cubic foot per second $\left(\mathrm{ft}^{3} / \mathrm{s}\right)$ \\
\hline cubic meter per second $\left(\mathrm{m}^{3} / \mathrm{s}\right)$ & 22.83 & million gallons per day (Mgal/d) \\
\hline kilometer per hour $(\mathrm{km} / \mathrm{h})$ & 0.6214 & mile per hour $(\mathrm{mi} / \mathrm{h})$ \\
\hline \multicolumn{3}{|c|}{ Mass } \\
\hline gram $(\mathrm{g})$ & 0.03527 & ounce, avoirdupois (oz) \\
\hline kilogram (kg) & 2.205 & pound avoirdupois (lb) \\
\hline megagram (Mg) & 1.102 & ton, short $(2,000 \mathrm{lb})$ \\
\hline megagram (Mg) & 0.9842 & ton, long $(2,240 \mathrm{lb})$ \\
\hline \multicolumn{3}{|c|}{ Pressure } \\
\hline gram per square centimeter $\left(\mathrm{g} / \mathrm{cm}^{2}\right)$ & 0.0142 & pound per square inch $\left(\mathrm{lb} / \mathrm{in}^{2}\right)$ \\
\hline megapascal (MPa) & 145.0 & pound-force per square inch $\left(\mathrm{lbf} / \mathrm{in}^{2}\right)$ \\
\hline \multicolumn{3}{|c|}{ Density } \\
\hline gram per cubic centimeter $\left(\mathrm{g} / \mathrm{cm}^{3}\right)$ & 62.4220 & pound per cubic foot $\left(\mathrm{lb} / \mathrm{ft}^{3}\right)$ \\
\hline \multicolumn{3}{|c|}{ Frequency } \\
\hline hertz & 1 & cycle per second \\
\hline kilohertz $(\mathrm{kHz})$ & 1,000 & cycle per second \\
\hline \multicolumn{3}{|c|}{ Electrical Current } \\
\hline milliampere (mA) & 0.001 & watt per volt \\
\hline kilovolt (kV) & 0.001 & joule per coulomb \\
\hline
\end{tabular}

Temperature in degrees Celsius $\left({ }^{\circ} \mathrm{C}\right)$ may be converted to degrees Fahrenheit $\left({ }^{\circ} \mathrm{F}\right)$ as follows:

${ }^{\circ} \mathrm{F}=\left(1.8 \times^{\circ} \mathrm{C}\right)+32$ 


\section{Datums}

Vertical coordinate information is referenced to the North American Vertical Datum of 1988 (NAVD 88), except where otherwise noted.

Horizontal coordinate information is referenced to the North American Datum of 1983 (NAD 83).

Elevation, as used in this report, refers to distance above the vertical datum.

\section{Supplemental Information}

Concentrations of suspended sediment in water are given in milligrams per liter ( $\mathrm{mg} / \mathrm{L})$.

\section{Acronyms}

$\begin{array}{ll}\text { API } & \text { American Petroleum Institute } \\ \text { ISL } & \text { lowa Sediment Laboratory } \\ \text { PD } & \text { percent difference } \\ \text { PSD } & \text { particle-size distribution } \\ \text { RP19C } & \text { Recommended Practice 19C } \\ \text { RPD } & \text { relative percent difference } \\ \text { SD } & \text { standard deviation } \\ \text { UOG } & \text { unconventional oil and gas } \\ \text { USD } & \text { University of South Dakota } \\ \text { USGS } & \text { U.S. Geological Survey }\end{array}$




\title{
Suitability of River Delta Sediment as Proppant, Missouri and Niobrara Rivers, Nebraska and South Dakota, 2015
}

\author{
By Ronald B. Zelt, Christopher M. Hobza, Bethany L. Burton, Nathaniel J. Schaepe, and Nadine Piatak
}

\section{Abstract}

Sediment management is a challenge faced by reservoir managers who have several potential options, including dredging, for mitigation of storage capacity lost to sedimentation. As sediment is removed from reservoir storage, potential use of the sediment for socioeconomic or ecological benefit could potentially defray some costs of its removal. Rivers that transport a sandy sediment load will deposit the sand load along a reservoir-headwaters reach where the current of the river slackens progressively as its bed approaches and then descends below the reservoir water level. Given a rare combination of factors, a reservoir deposit of alluvial sand has potential to be suitable for use as proppant for hydraulic fracturing in unconventional oil and gas development. In 2015, the U.S. Geological Survey began a program of researching potential sources of proppant sand from reservoirs, with an initial focus on the Missouri River subbasins that receive sand loads from the Nebraska Sand Hills. This report documents the methods and results of assessments of the suitability of river delta sediment as proppant for a pilot study area in the delta headwaters of Lewis and Clark Lake, Nebraska and South Dakota. Results from surface-geophysical surveys of electrical resistivity guided borings to collect 3.7-meter long cores at 25 sites on delta sandbars using the direct-push method to recover duplicate, 3.8-centimeter-diameter cores in April 2015. In addition, the U.S. Geological Survey collected samples of upstream sand sources in the lower Niobrara River valley.

At the laboratory, samples were dried, weighed, washed, dried, and weighed again. Exploratory analysis of natural sand for determining its suitability as a proppant involved application of a modified subset of the standard protocols known as American Petroleum Institute (API) Recommended Practice (RP) 19C. The RP19C methods were not intended for exploration-stage evaluation of raw materials. Results for the washed samples are not directly applicable to evaluations of suitability for use as fracture sand because, except for particle-size distribution, the API-recommended practices for assessing proppant properties (sphericity, roundness, bulk density, and crush resistance) require testing of specific proppant size classes. An optical imaging particle-size analyzer was used to make measurements of particle-size distribution and particle shape.
Measured samples were sieved to separate the dominant-size fraction, and the separated subsample was further tested for roundness, sphericity, bulk density, and crush resistance.

For the bulk washed samples collected from the Missouri River delta, the geometric mean size averaged 0.27 millimeters $(\mathrm{mm}), 80$ percent of the samples were predominantly sand in the API 40/70 size class, and 17 percent were predominantly sand in the API 70/140 size class. Distributions of geometric mean size among the four sandbar complexes were similar, but samples collected from sandbar complex B were slightly coarser sand than those from the other three complexes. The average geometric mean sizes among the four sandbar complexes ranged only from 0.26 to $0.30 \mathrm{~mm}$. For 22 main-stem sampling locations along the lower Niobrara River, geometric mean size averaged $0.26 \mathrm{~mm}$, an average of 61 percent was sand in the API 40/70 size class, and 28 percent was sand in the API 70/140 size class. Average composition for lower Niobrara River samples was 48 percent medium sand, 37 percent fine sand, and about 7 percent each very fine sand and coarse sand fractions. On average, samples were moderately well sorted.

Particle shape and strength were assessed for the dominant-size class of each sample. For proppant strength, crush resistance was tested at a predetermined level of stress (34.5 megapascals [MPa], or 5,000 pounds-force per square inch). To meet the API minimum requirement for proppant, after the crush test not more than 10 percent of the tested sample should be finer than the precrush dominant-size class. For particle shape, all samples surpassed the recommended minimum criteria for sphericity and roundness, with most samples being well-rounded.

For proppant strength, of 57 crush-resistance tested Missouri River delta samples of 40/70-sized sand, 23 (40 percent) were interpreted as meeting the minimum criterion at 34.5 $\mathrm{MPa}$, or 5,000 pounds-force per square inch. Of 12 tested samples of 70/140-sized sand, 9 (75 percent) of the Missouri River delta samples had less than 10 percent fines by volume following crush testing, achieving the minimum criterion at 34.5 MPa. Crush resistance for delta samples was strongest at sandbar complex A, where 67 percent of tested samples met the 10-percent fines criterion at the $34.5-\mathrm{MPa}$ threshold. This frequency was higher than was indicated by samples 
from sandbar complexes B, C, and D that had rates of 50, 46, and 42 percent, respectively. The group of sandbar complex A samples also contained the largest percentages of samples dominated by the API 70/140 size class, which overall had a higher percentage of samples meeting the minimum criterion compared to samples dominated by coarser size classes; however, samples from sandbar complex A that had the API $40 / 70$ size class tested also had a higher rate for meeting the minimum criterion (57 percent) than did samples from sandbar complexes B, C, and D (50, 43, and 40 percent, respectively).

For samples collected along the lower Niobrara River, of the 25 tested samples of 40/70-sized sand, 9 samples passed the API minimum criterion at $34.5 \mathrm{MPa}$, but only 3 samples passed the more-stringent criterion of 8 percent postcrush fines. All four tested samples of 70/140 sand passed the minimum criterion at $34.5 \mathrm{MPa}$, with postcrush fines percentage of at most 4.1 percent.

For two reaches of the lower Niobrara River, where hydraulic sorting was energized artificially by the hydraulic head drop at and immediately downstream from Spencer Dam, suitability of channel deposits for potential use as fracture sand was confirmed by test results. All reach A washed samples were well-rounded and had sphericity scores above 0.65 , and samples for 80 percent of sampled locations met the crush-resistance criterion at the 34.5-MPa stress level. A conservative lower-bound estimate of sand volume in the reach A deposits was about 86,000 cubic meters. All reach B samples were well-rounded but sphericity averaged 0.63 , a little less than the average for upstream reaches A and SP. All four samples tested passed the crush-resistance test at $34.5 \mathrm{MPa}$. Of three reach B sandbars, two had no more than 3 percent fines after the crush test, surpassing more stringent criteria for crush resistance that accept a maximum of 6 percent fines following the crush test for the API 70/140 size class.

Relative to the crush-resistance test results for the API 40/70 size fraction of two samples of mine output from Loup River settling-basin dredge spoils near Genoa, Nebr., four of five reach A sample locations compared favorably. The four samples had increases in fines composition of 1.6-5.9 percentage points, whereas fines in the two mine-output samples increased by an average 6.8 percentage points.

\section{Introduction}

Fracture sand (hereinafter referred to as "frac sand") is a specialized sand added to the fluids that are injected into unconventional oil and gas (UOG) wells during hydraulic fracturing (fracking or hydrofracking), a process that enhances hydrocarbon extraction from low-permeability reservoirs. Dramatic growth in the production of the UOG sector since 2000 has heightened demand for frac sand (Anderson, 2011). Beyond the demand caused by UOG sector growth, which has slowed since late 2014, new and more efficient hydraulic fracturing techniques require more silica sand use per well
(Dolley, 2016). The United States is the world's leading producer and consumer of industrial sand and gravel, and in 2015, about 71 percent of total U.S. production of industrial sand and gravel was used as frac sand (Dolley, 2016).

Frac sand includes processed naturally occurring sand or industrially coated sand that meets strict mineralogical and physical specifications such that frac sand is effective as a proppant (a granular material used to keep induced fractures open), extending the duration and flow rate of hydrocarbon releases from fractured rock surfaces in contact with the wellbore (Benson and Wilson, 2015a). In recent analyses of the U.S. proppant industry, 78-93 percent of estimated national consumption of proppant was supplied by processed frac sand (Freedonia Group, 2015 [cited in Smart Sand, Inc., 2016] and PropTester, Inc., and KELRIK LLC, 2016 [cited in Oil, 2016]).

Hydraulic fracturing involves pressurized injection of water (approximately 95 percent of total volume), proppant (approximately 4.5 percent), and chemicals (commonly includes surfactants, scale inhibitor, clay stabilizers, corrosion/ precipitation inhibitors, $\mathrm{pH}$ adjusting agents, and biocides) into hydrocarbon-bearing strata to create or enhance fractures and then prop open the fractured formation to promote the flow of hydrocarbons (Beckwith, 2011; Esswein and others, 2013). In 2010, a typical UOG well might have used 2,040 megagrams ( $\mathrm{Mg}$ ) (2,250 tons) of proppant, and proppant use per well was increasing (Geiver, 2014). By 2014, an average UOG well consumed $3,700-4,500 \mathrm{Mg}(4,100-5,000$ tons) of proppant, and the amount of proppant used per unit distance for horizontal boreholes was expected to continue to climb with advances in fracturing technologies (Benson and Wilson, 2015a).

Proppants may be customized for each particular hydrocarbon reservoir, well, or treatment design. Despite the variability among specialized proppants, the physical properties of frac sand, as defined by the American Petroleum Institute (API), are quite specific. An optimal source of frac sand is unconsolidated silica sand or friable sandstone that has a nearly pure quartz composition, crush-resistant grains, high sphericity/roundness of grains, and a uniformly medium- to coarse-grain size (Zdunczyk, 2007). The international supply of natural frac sand, supplemented by alternative proppants such as resin-coated sand and engineered high-strength ceramic spheres, has been sufficient to meet the recent demand, but future depletion of sand sources is expected to increase costs and concerns about the environmental impacts of mining and handling of frac sand (Benson and Wilson, 2015a). As exploration of new sources of frac sand continues, nontraditional sources - deposits of eolian, glacial, and fluvial sands - have drawn renewed attention (Anderson, 2011; Zdunczyk, 2013; U.S. Army Corps of Engineers, 2013c; Courtney, 2014; Zdunczyk and Nicholls, 2014).

The U.S. Geological Survey's (USGS) mission has historically included resource assessments that locate and characterize potential domestic sources of economically valuable geologic and hydrologic resources for the Nation. Internally, 
USGS science planners engaged in the Midwest Region Energy and Mining Initiative (related to UOG production) had noted by 2014 the strong upsurge in mining and sales of frac sand, largely from Midwest sources, and formed a group tasked to assess interest in identifying other sand sources, such as in reservoirs or materials from dredging operations (USGS Midwest Region, written commun., October 24, 2014). Surface-water storage reservoirs impound water and fluvial sediment delivered from the upstream drainage basin. Such dams are intrinsically interrupting the longitudinal connectivity of the basin to the downstream water body and thereby altering greatly the regime of sediment flux (Jacobson and others, 2009). The beneficial uses of the reservoir and the disrupted river are affected by the sediment-trapping efficiency and capacity of the reservoir. Sediment management is a challenge faced by reservoir managers who have several potential options for mitigation of storage capacity lost to sedimentation, including dredging, hydraulic flushing, sediment bypass, and habitat construction (Coker and others, 2009; Jacobson and others, 2009; U.S. Army Corps of Engineers, 2013a, 2013b); however, older storage reservoirs designed before sustainable life-cycle management approaches were widely accepted typically lack systems to bypass sediment (Engineering and Hydrosystems, Inc., 2002).

As sediment is removed from reservoir storage, potential use of the sediment for socioeconomic or ecological benefit could potentially defray some costs of its removal. For example, reservoir sand deposits in Lewis and Clark Lake (fig. 1) have been used to construct sand islands to provide emergent sandbars as nesting habitat for migratory shore birds. Deltaic deposits of alluvial sand conceivably have potential as sources of proppant for hydraulic fracturing. Rivers that carry a sandenriched sediment load will deposit sand along a reservoirheadwaters reach where the current of the river slackens.

Previous studies have considered dredged alluvial sand sources for potential usability for hydraulic fracturing (U.S. Army Corps of Engineers, 2013c; Zdunczyk, 2013; Preferred Sands, 2016), but the authors believe this study is the first to assess a large-river delta deposit using sediment samples collected onsite (that is, prior to the major physical disturbance incurred during the dredging of an alluvial sediment deposit).

In 2015, the USGS began a program of researching potential sources of proppant sand from reservoirs, with an initial focus on the Missouri River subbasins that receive sand loads from the Nebraska Sand Hills or areas of friable sandstone geology (U.S. Geological Survey, Midwest Region, written commun., 2015). An initial pilot assessment for Lewis and Clark Lake - impounded by Gavins Point Dam (fig. 1) — was of particular interest because of the following reasons:

- Unpublished exploratory sampling data from Knox County (fig. 1) indicated that sand in the delta or lake may have some properties (roundness, grain size) favorable for use as a proppant (M. Cerny, Knox County Economic Development Agency, written commun., 2014).
- As of 2011, the lake had lost 26 percent of its total storage volume to sedimentation (U.S. Army Corps of Engineers, 2013b), and sand-size particles dominate the annual sediment deposits into the lake (Perkey and others, 2013).

- Sediment deposition at the head of the lake had caused flooding of roads and residential properties on the river bottoms, and estimated costs to raise Highway 12 roadbeds east and west of Niobrara, Nebraska, now exceed \$200 million (fig. 1; Nebraska Department of Roads, 2016). Removal of alluvial sand from this area could help alleviate this ongoing concern.

For the Missouri River Recovery Program and in response to elements of the biological opinions issued by the U.S. Fish and Wildlife Service (U.S. Fish and Wildlife Service, 2000, 2003), Federal reservoir managers are studying sediment-management alternatives to address sediment imbalances in the Missouri River (U.S. Army Corps of Engineers, 2001, 2013a). An ideal alternative would in part restore the connectivity of sediment transport and associated turbidity in river reaches downstream from several main-stem dams because the river below these lakes is sediment starved, which causes channel degradation and loss of critical habitats (U.S. Fish and Wildlife Service, 2003). The U.S. Army Corps of Engineers (2013a) has recommended that studies of costs of sustainably managing the reservoir sediment (that is, through dredging and reservoir flushing) be completed and has begun exploring the benefits and effects from restoring instream sediment availability downstream from Gavins Point Dam. Dredging for sand could resuspend some fine sediment for transport through the dam, and sale of the sand could potentially improve the cost-benefit ratio, which was estimated as 0.77 for dredging in 2001 (U.S. Army Corps of Engineers, 2001). Thus, a finding of suitability of delta sand deposits for use as proppant could lead to reanalysis of the cost-benefit ratio for dredging and potentially to proposals of dredging as a feasible reservoir sediment-management alternative. Moreover, if part of the dredged sand were used to augment the sediment supply in the Missouri River downstream from the dam, sediment augmentation could partially mitigate costs of mechanically constructing sandbar habitat as well as the financial and environmental costs of chemically controlling vegetation growth on constructed sandbars.

This USGS study of Lewis and Clark Lake was a pilot, reconnaissance-level study to test and refine an approach and methods and to provide a dataset for exploratory resource assessment. The results from this study could be used to generate interest in and provide methodologies for similar or more comprehensive studies at other impoundments across the basin, the Midwest region, and potentially around the Nation. A comprehensive resource assessment might follow later and could involve multidisciplinary expertise to identify and characterize the economic potential and mass of individual sand-source areas, provide material flow analysis, understand potential adverse effects such as release of contaminants from the sediment during removal, and estimate the renewable 

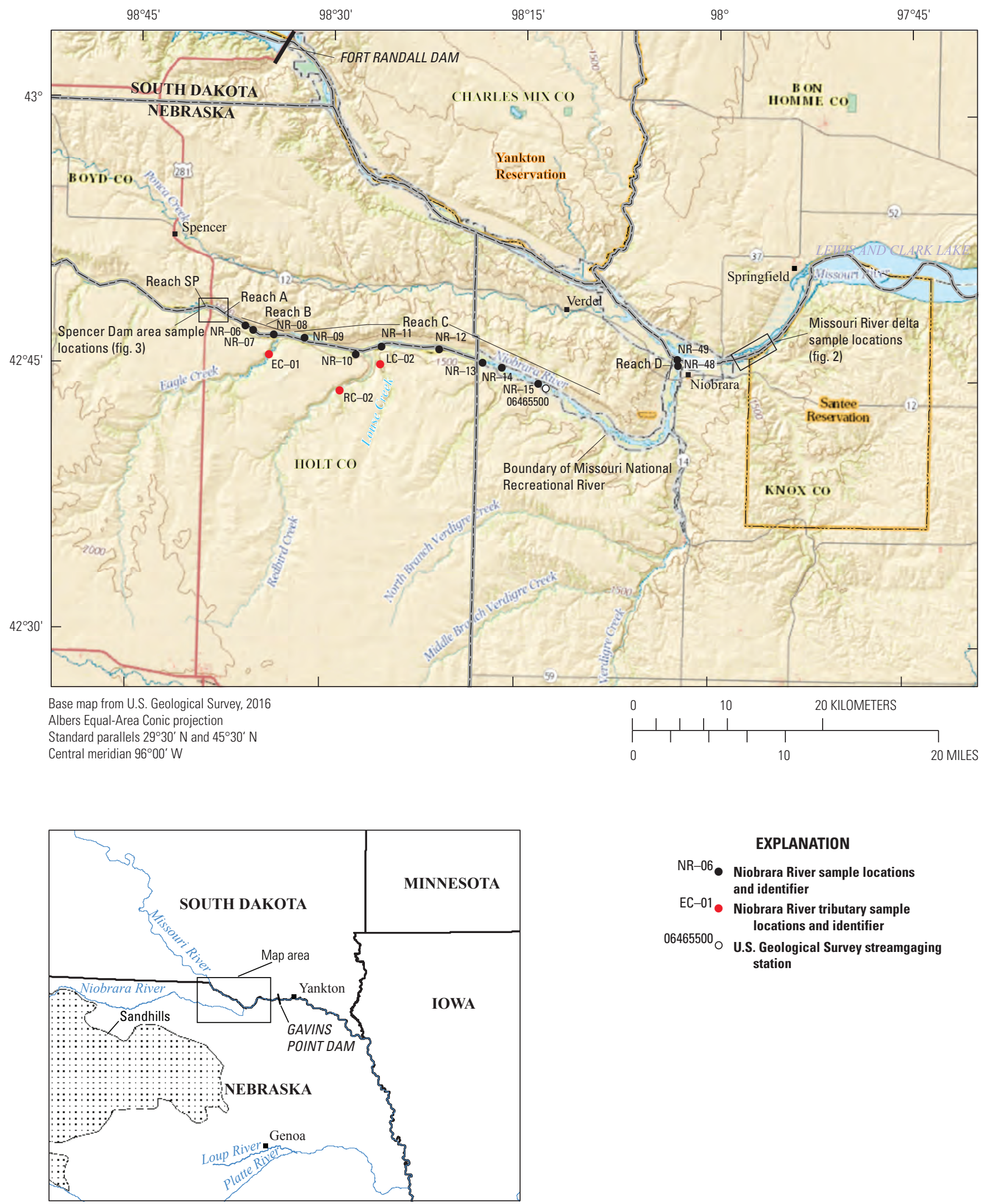

Figure 1. Location of the study area, Missouri and Niobrara Rivers, and Lewis and Clark Lake, Nebraska and South Dakota. 
capacity of the source from the load of sand delivered to a reservoir from its river basin.

Despite the nature of the study as a general reconnaissance-level study, one study goal was to fully test the methodology for assessing sand deposits as to physical suitability for proppant and selected factors affecting potential development of the resource. Study goals also included attainment of the following list of evaluation endpoints:

- comparison of resulting sand properties with those for sand suitable to be used as proppant, to include direct comparisons for the dominant-size fraction;

- distribution within each sand body of the analyzed physical properties of sediment to include particle-size distribution (PSD), roundness/sphericity, hardness (crush resistance), and stratigraphy; and

- estimation of the volume of evaluated sand bodies in the river delta, along with their estimated spatial extent.

\section{Purpose and Scope}

This report describes the physical characteristics and assesses the suitability of deltaic sand deposits at the head of Lewis and Clark Lake, Nebraska and South Dakota (fig. 1), for use as a proppant feedstock resource in unconventional oil or gas production. Additionally, the spatial extent and volume of selected, most-suitable sand bodies are estimated, and the Missouri River delta sand is compared with sand samples collected from selected upstream source areas along the lower Niobrara River valley from the Spencer Dam impoundment to the confluence with the Missouri River (fig. 1).

All sediment samples were collected in 2015, but given the large interannual variability in sediment deliveries to the lake (Cowman and others, 2013), the estimated extent of sand bodies may be time sensitive. Similarly, some of the upstream sand sources sampled for this study are deposits that appeared to be reworked annually in association with the typically semiannual sediment flushing from Spencer Dam. Thus, the physical properties measured in the study may represent the general character of sand bodies in the delta's headwaters area and selected upstream sources during April through May 2015, as opposed to being static properties of fixed formations.

\section{Description of the Study Area}

The study area includes the following two subareas: (1) the reach of the Missouri River within its delta at Running Water, South Dakota (fig. 2; hereinafter called the "Missouri River delta"), near the head of Lewis and Clark Lake and (2) the 63-kilometer $(\mathrm{km})$ segment of the lower Niobrara River extending from its mouth to the impoundment upstream from Spencer Dam, near Spencer, Nebr. (fig. 1; hereinafter called the "lower Niobrara River").
Within the 3.5-km (fig. 2) reach length of the Missouri River delta subarea, the river channel has multiple threads but generally strong currents, hence the river delta nomenclature. The Missouri River delta subarea is almost completely downstream from the Missouri National Recreational River (MNRR) segment but is within the Gavins Point Project administered by the U.S. Army Corps of Engineers (USACE), classified as either multiple-resource management land or open water when lake level is at the normal pool elevation (U.S. Army Corps of Engineers, 2004). The Missouri River delta subarea is within the USACE-defined approximate area of hypothetical dredging operations (U.S. Army Corps of Engineers, 2001, plate 2).

Lewis and Clark Lake (fig. 1) is the smallest and most downstream of the series of six large Federal reservoirs along the Missouri River and was formed by the closing in 1955 of 23-meter (m) (74-foot [ft]) tall Gavins Point Dam at river kilometer (rkm) 1,305 (river mile 811) near Yankton, S. Dak. (U.S. Army Corps of Engineers, 2013b). The rkm distances are measured upstream from the confluence of the Missouri and Mississippi Rivers (not shown). The incremental drainage area of the lake is 41,400 square kilometers $\left(\mathrm{km}^{2}\right.$; 16,000 square miles) out of its total upstream drainage area of 723,900 $\mathrm{km}^{2}$ (279,500 square miles) (U.S. Army Corps of Engineers, 2004). At Lewis and Clark Lake's maximum operating pool elevation (369 m, or 1,210 ft, above National Geodetic Vertical Datum of 1929), the lake extends for about $40 \mathrm{~km}$ (25 miles) upstream from the dam (U.S. Army Corps of Engineers, 2004).

The confluence of the Niobrara and Missouri Rivers is at rkm 1,358 (river mile 844) of the Missouri River and $914 \mathrm{~km}$ from the Niobrara River headwaters in eastern Wyoming (not shown). In contrast to the heavily regulated flows of the Missouri River main-stem reservoir system, the Niobrara River is free-flowing from Box Butte Dam in Dawes County, Nebr. (not shown; about $500 \mathrm{~km}$ upstream from the confluence with the Missouri River), where its mean annual flow is less than 1 cubic meter per second. Despite its free-flowing main stem, the streamflow of the Niobrara River is partially regulated by a storage reservoir on one of its largest tributaries and diversions into the associated irrigation-supply canal. A small hydroelectric dam near Spencer, Nebr. (fig. 1), also traps the coarsesediment load and periodically flushes stored sediment.

Sediment entering Lewis and Clark Lake from the Missouri and Niobrara Rivers, along with smaller deliveries from other streams, erosion of shoreline, and eolian deposition, is estimated to cause a present-day mean annual total sediment load of 4.7 million Mg (Engineering and Hydrosystems, Inc., 2002), corresponding to a combined mean annual loss of storage volume of 3.0-3.2 million cubic meters $(2,400$ 2,600 acre-feet; U.S. Army Corps of Engineers, 2011). The 1994-2006 annual sediment load transported past Yankton, S. Dak. (fig.1) (Jacobson and others, 2009), indicated that Lewis and Clark Lake is a 99.8-percent efficient trap for suspended sediment of all sizes. Moreover, all of the incoming sand-size load is trapped in the lake, and Gavins Point Dam 


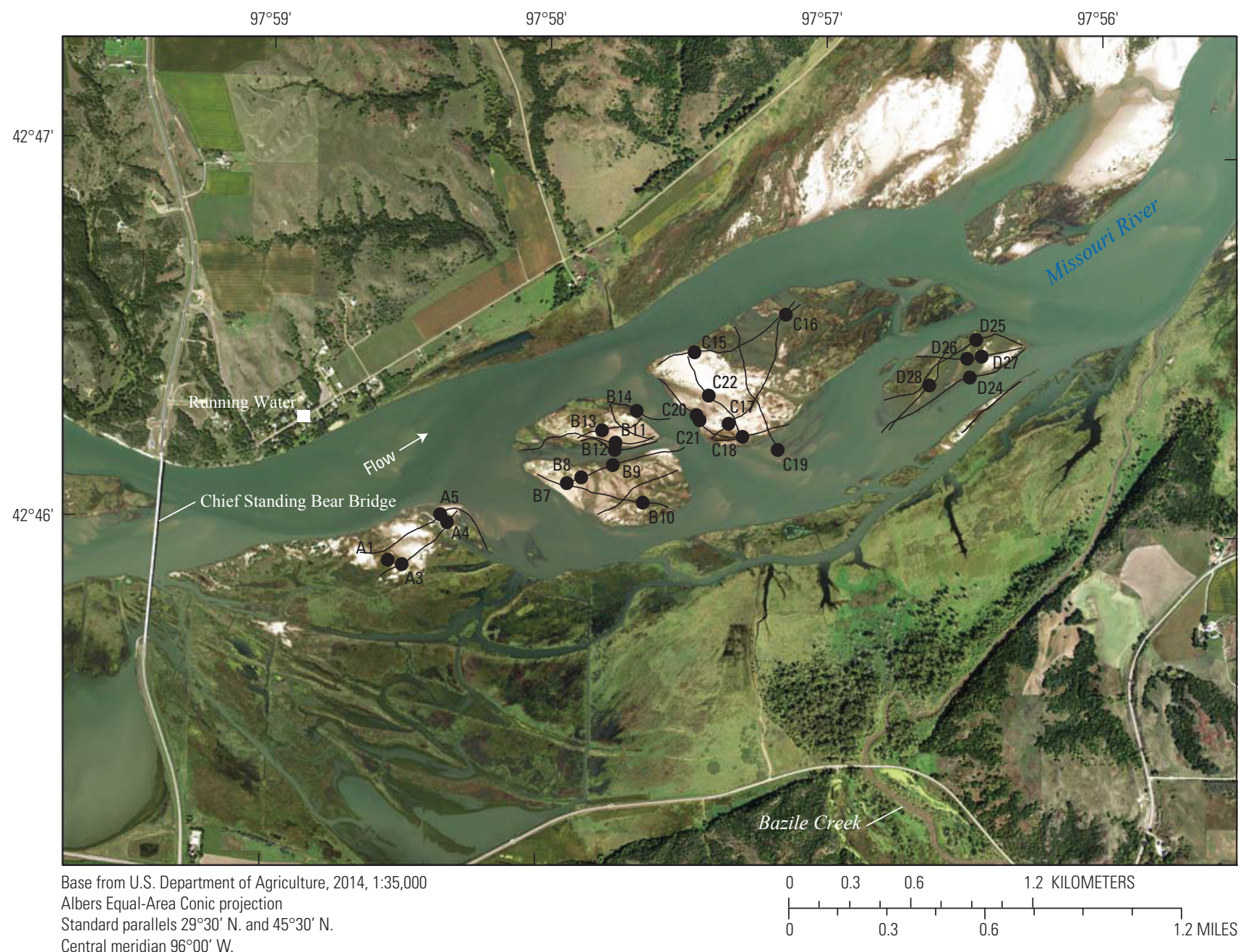

EXPLANATION

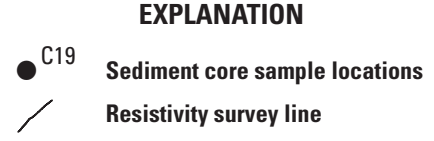

Figure 2. Sediment sample locations and surface-geophysical survey lines in the Missouri River delta near Running Water, South Dakota, 2015.

was not designed to bypass sediment. In such a reservoir that is, by design, being allowed to fill with sediment, reservoir storage volume has been classified as an exhaustible resource rather than a renewable resource (Kondolf and others, 2014). In the absence of reservoir sedimentation management in Lewis and Clark Lake, reservoir storage volume, once lost to sedimentation, is no longer available for use by future generations; however, the growth of the delta by 2005 had created about $46.5 \mathrm{~km}^{2}$ (11,500 acres) of wetland habitat within the area originally occupied by open water in 1956 aerial photography (U.S. Army Corps of Engineers, 2011). Much additional wetland habitat has resulted from sedimentation in areas upstream from and higher than the maximum pool elevation.

In addition to altering the natural hydrograph, the dam's sediment-trapping efficiency has profoundly altered the sediment regime downstream, causing losses of emergentsandbar nesting habitat that jeopardize the survival of two shore birds (least tern [Sternula antillarum] and piping plover [Charadrius melodus]), and has caused decreases in turbidity that may pose risks to the native fish species (U.S. Fish and Wildlife Service, 2003; Jacobson and others, 2009). Evacuating or bypassing much of the annual sediment load around Gavins Point Dam would not only extend the useful life of the lake, it would partly mitigate the downstream effects of the sediment deficit caused by the lake's efficiency as a sediment trap (Jacobson and others, 2009).

Most of the sand delivered to the lake from upstream is deposited within the deltaic reaches that extend from rkm 1,327 to 1,366 (river miles 825 to 849 ), or to about $8 \mathrm{~km}$ (5 miles) upstream from the Missouri-Niobrara confluence 
(U.S. Army Corps of Engineers, 2013a). At the lacustrine mouth of the Missouri River, the previously confined flow expands, decelerates, and deposits its sand load in the delta (Bridge, 2003, p. 303). The coarse bedload is deposited closest to the mouth, but the finer fractions of the suspended load are transported farther into the lake before settling onto the bed. Wind and waves subsequently erode, rework, and redeposit some delta sediment. The morphology of deltas reflects the balance among these contrasting aspects of delta formation and how, with time, the delta front has advanced and the upstream deltaic reaches aggraded (Bridge, 2003; U.S. Army Corps of Engineers, 2011). Because the incremental drainage basin of Lewis and Clark Lake includes the Niobrara River, which carries a large bed-material load and has a mouth near to the lake, the Niobrara River delta and the aggrading Missouri River delta that extends into the lake have become merged into a single depositional reach approaching $39 \mathrm{~km}$ (24 miles). The delta front has advanced into the lake by an average of $168 \mathrm{~m}(550 \mathrm{ft}$ ) annually since 1975 (U.S. Army Corps of Engineers, 2011). Cowman and others (2013) noted that sediment accumulated initially within the former main channel of the Missouri River (1955-65) but a visible delta became apparent in the 1970s.

\section{Previous Studies}

The hydraulic fracture treatment process involves multistage fracturing of as many as a few dozen stages, allowing for a large number of fractures to be created at specific locations within a single wellbore (Rock Products, 2012). Such treatment requires large quantities of frac sand for each well - the average 3,048-m (10,000-ft) horizontal well may use as much as $2,268 \mathrm{Mg}$ (2,500 tons) of proppant (Geiver, 2014). The principal sources for frac sand are those traditionally providing silica to the manufacturers of glass - ancient sandstones of the Midwest that are nearly pure silica. Additional factors beyond mineral purity that affect the economics of frac sand mining are accessibility of deposits at or near the surface, areal extent and thickness, textural uniformity, nearness to transportation routes and shipping terminals, and proximity to presently active plays of unconventional petroleum or natural gas (Benson and Wilson, 2015a).

Proppants presently include the following three chief types: (1) natural sand (frac sand) from either traditional, sandstone bedrock or nontraditional, unconsolidated deposits; (2) resin-coated proppant (RCP); and (3) engineered ceramic spheres. Traditional, bedrock sources of natural sand have well-rounded quartz grains with excellent sphericity and high crush resistance (Zdunczyk, 2013). Resin coating improves the effective strength by spreading the pressure load more uniformly and also helps trap pieces of proppant broken under the great pressure within fractures to keep such fines from entering the borehole (Beckwith, 2011). The RCP grains coated with a curable resin additionally adhere together under the pressure and temperature conditions within fractures, helping minimize the flowback of all emplaced proppants. The RCP is important for this study because (1) a substantial amount (perhaps 20 percent) of the frac sand produced from Loup River Power Canal dredge spoils receives resin coating at the Preferred Sands operation near Genoa, Nebr. (fig. 1) (S. Hyde, Preferred Sands of Genoa, oral commun., 2015) and (2) the Loup and Niobrara Rivers (fig. 1) drain large areas of Nebraska Sand Hills terrain (fig. 1) and transport large, sandy bedloads.

Ideal properties of frac sand include size distribution enriched in size ranges specified by the API, particle shape that is well-rounded and approximately spherical, hardness and crush resistance (usually correlated with high quartz mineral content), and only minimal presence of acid-soluble cement or minerals (such as calcite). In addition, for a sand deposit to be an ideal feedstock, the deposit will have minimal overburden, be friable (loose or poorly consolidated, poorly cemented), and be in proximity to a shipping terminal (rail or barge) within cost-effective distance of the place of use (UOG plays undergoing hydraulic fracturing).

In the mid-2000s, the recommended practices for testing proppant properties were developed for stated purposes of sampling and testing shipments of finished products, either at the supplier's facilities or at an unloading or end-use site (American Petroleum Institute and others, 2008). Such material has undergone several processing steps, typically including washing and sizing. Only a few studies have compared essentially raw material with API-recommended characteristics of finished products (for example, Marshall and others, 2014).

During the late 2000s, the supply of frac sand became limiting for the fracking industry, and smaller well-field services companies were unable to buy frac sand because the giant corporations of the well-field services industry bought most of the production (Zdunczyk, 2013). Some States (for example, North Dakota [Anderson, 2011], South Dakota [Marshall and others, 2014], and Montana's Survey of Native Proppant Resources [J.C. Getty and others, Montana Tech and Montana Bureau of Mines and Geology, written commun., 2016]) began field reconnaissance studies to identify potential sources of proppant among geologic materials of the State; however, those statewide assessments were focused mainly on sandstones and other bedrock formations, giving little attention to unconsolidated sand deposits. Anderson (2011) reported results for a single sediment sample of eolian dune sand. Marshall and others (2014) listed data for three sites where the Sand Hills Formation in Bennett County, S. Dak. (not shown), was sampled, indicating that the API 40/70 size class accounted for between about 39 and 63 percent of these sands, with all sediment samples having at least 33 percent of the tested sand finer than 0.212 millimeter $(\mathrm{mm})$ in size (U.S. number 70 sieve).

The importance of sediment management in Missouri River reservoirs has been long recognized (U.S. Army Corps of Engineers, 2001; Engineering and Hydrosystems, Inc., 2002; U.S. Fish and Wildlife Service, 2003; National Research 
Council, 2011). During the 1950s through 1970s, the river reach between Fort Randall Dam and Niobrara, Nebr., underwent severe erosion (Pacific GeoScience, 1998) and a net loss of 3,240 square meters per year per river kilometer (1.29 acres per year per river mile) to bank erosion since dam closure (U.S. Army Corps of Engineers, 1977). The USACE began the Lewis and Clark Lake Sediment Management Study in 2006 to examine alternatives for restoring a sediment balance across Gavins Point Dam (U.S. Army Corps of Engineers, 2012). Using USACE estimates, Coker and others (2009) reported that 4.5 million cubic meters (5.9 million cubic yards) per year of sediment was deposited within the lake, on the delta, or in the aggrading reaches of the Missouri and Niobrara Rivers upstream from their confluence. The largest single source of this sediment is the Niobrara River, which contributes 1.9 million cubic meters ( 2.5 million cubic yards) per year (Coker and others, 2009). Coker and others (2009, table A1) identified six principal sources of sediment entering Lewis and Clark Lake and presented data for the relative contribution and percent sand of each source. Those data indicate that about 74 percent of the sand load entering the lake comes from a single source- the Niobrara Riverand none of the other chief sources contributes more than about 6 percent on average.

Previous studies of potential new natural sources of proppant (Anderson, 2011; Marshall and others, 2014) have noted the challenge for economical use of a deposit containing a wide range of grain sizes - if present in substantial volumes, materials coarser or finer than those suitable for use as proppant would require markets or alternate uses (for example, ecological value for ecosystem services). Anderson (2011) envisioned sand sources that might not be suitable for development solely as frac sand, yet if demand exists for nearly all of the size fractions present, then such a deposit could be economical to mine in view of this "multiple markets approach."

\section{Methods}

One of the study objectives is to develop and test methods for exploration of reservoir sediment as a potential source of frac sand. The following sections describe the study methods and quality assurance methods in detail.

\section{Site Selection}

The following two subsections describe site selection for collection of sediment samples in each of the two subareas studied.

\section{Missouri River Delta}

Given that commercial viability of dredge spoils as a proppant source likely requires cooperation with the USACE for the costs of dredging, the primary area of study was delimited within the USACE "approximate location of hypothetical dredging operation" (U.S. Army Corps of Engineers, 2001, plate 2). Moreover, the most downstream $7.2 \mathrm{~km}$ of the USACE hypothetical dredge reach was defined as subarea 1, extending from Chief Standing Bear Bridge, Nebr.-S. Dak., to USACE river mile 834.8, about 2.5 miles downstream from Bazile Creek (fig. 2). The study area thus encompasses some of the coarsest deposits of sand within the Missouri River delta near the head of Lewis and Clark Lake, based on a presumption of typical downstream fining of deltaic deposition. Subarea 1, however, excludes the Niobrara delta that extends upstream from the mouth of the Niobrara River and downstream from the mouth to where it imperceptibly merges into the Missouri River delta upstream from Chief Standing Bear Bridge.

The four sandbar complexes that were sampled for this study are contained in a reach that extends from immediately south of Running Water, S. Dak., to $3.5 \mathrm{~km}$ downstream (fig. 2). The sandbar complexes are identified herein as A (most upstream) through D (most downstream). The "Field Methods" section of this report describes the use of surfacegeophysical surveys of these four sandbar complexes for reconnaissance and selection of 28 sites where sediment cores were to be collected later in 2015 .

\section{Upstream Sources}

Deltaic sediments generally are deposited episodically during periods of high transport from incoming sources, and these sources may carry sediment mixtures of differing composition and physical character. For this study, all sites sampled to characterize potential upstream sources were along the lower Niobrara River valley (subarea 2, reaches A-D, fig. 1), consistent with indications (Coker and others, 2009) that it is the source of nearly three-fourths of the sand load entering the Missouri River delta. However, a concurrent study by the University of South Dakota (USD), Missouri River Institute (Tim Cowman and Mark Sweeney, University of South Dakota, written commun., 2015) was assessing sediment characteristics of at least two of the other principal sources (Missouri River downstream from Fort Randall Dam [fig. 1] and selected small tributary streams in South Dakota).

Three types of upstream sand sources were identified as likely having contrasting physical characteristics and were targeted as separate strata for sampling - impounded mainstem sediment, downstream main-stem channel deposits, and channel deposits of selected tributary streams. The sediment impounded by Spencer Dam integrates many upstream sources and was selected to represent the composite sediment load originating from the drainage basin upstream from the dam. Three distributary channels of the Niobrara River were distinct within the impoundment (fig. 3), and a pair of sandbar locations was sampled along each distributary channel. Locations in the southern channel roughly correspond to a transect sampled near the south bank for a 2014 study of a sediment release (Schaepe and others, in press). 


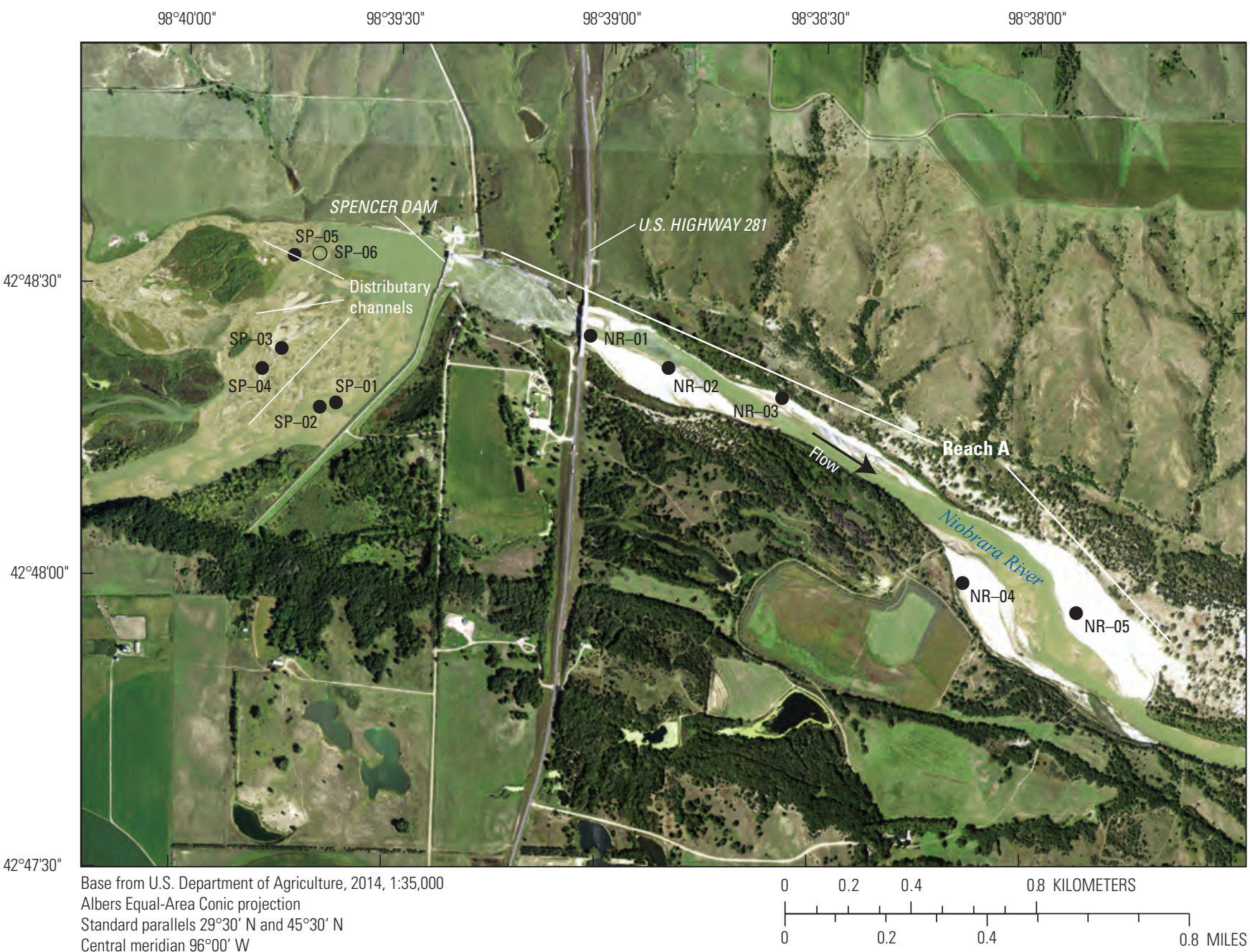

\section{EXPLANATION}

- NR-05 Niobrara River sample site and identifier

SP-03 Spencer Dam impoundment sample site and identifier

$\mathrm{O}^{\mathrm{SP}-06}$ Location of sample collected but not analyzed

Figure 3. Sediment sample locations in Spencer Dam vicinity, lower Niobrara River valley, Nebraska, 2015.

Channel deposits along the lower Niobrara River are built and maintained by natural and managed processes, including the typically twice-annual flushing of trapped sediment through the gates of Spencer Dam (fig. 3). The amount of aggradation during a sediment flush becomes attenuated with distance downstream from the dam, so sandbar sampling was weighted to be more closely spaced in the reaches near the dam and widely spaced in the reaches downstream from the confluence with Redbird Creek (fig. 1). Anticipating that the mission of the MNRR could effectively discourage mineral resources development within the MNRR administrative boundaries (fig. 1), few sediment samples of channel deposits were collected along the valley segment within Knox County,
Nebr. A total of 17 individual deposits of sand were sampled along the lower Niobrara River downstream from Spencer Dam (table 1).

Some tributaries to the lower Niobrara River drain part of the Nebraska Sand Hills and transport a sediment bedload dominated by sand. The dune sand of the Sand Hills ranges from very fine to medium sand (Gutentag and others, 1984). Tributaries entering the Niobrara from the south were selected on the basis of accessibility and the availability of suitable sand deposits within the channel. Sandbars were rare in tributary channels east of Eagle Creek (fig. 1); therefore, bed sediment samples were collected at only three tributary sites for this study (fig. 1; table 1). 
Table 1. Data for sampling sites for upstream sand sources assessment, lower Niobrara River valley, Nebraska, 2015.

[Field identifier prefix: SP, Spencer Dam pond; NR, Niobrara River; EC, Eagle Creek; RC, Redbird Creek; LC, Louse Creek; all sample textures were dominated by sand; --, not applicable; E, estimated value; ND, no data]

\begin{tabular}{|c|c|c|c|c|c|c|c|c|c|c|c|c|c|}
\hline Station identifier & $\begin{array}{c}\text { Field } \\
\text { identifier of } \\
\text { sample }\end{array}$ & $\begin{array}{c}\text { Date and } \\
\text { time } \\
\text { sampled }\end{array}$ & Sample type & $\begin{array}{c}\text { Collection } \\
\text { method }\end{array}$ & Fluvial form & $\begin{array}{c}\text { Core } \\
\text { length, } \\
\text { in meters }\end{array}$ & $\begin{array}{c}\text { Core } \\
\text { recovery, } \\
\text { in percent }\end{array}$ & $\begin{array}{l}\text { Vertical inter- } \\
\text { val sampled, } \\
\text { in centimeters } \\
\text { below sedi- } \\
\text { ment surface }\end{array}$ & $\begin{array}{c}\text { Number } \\
\text { of } \\
\text { intervals } \\
\text { in core }\end{array}$ & $\begin{array}{c}\text { Distance } \\
\text { from edge } \\
\text { of water, in } \\
\text { meters }\end{array}$ & $\begin{array}{l}\text { Distance } \\
\text { downstream } \\
\text { from station } \\
\text { to sample, in } \\
\text { meters }\end{array}$ & $\begin{array}{c}\text { Distance } \\
\text { upstream } \\
\text { from Niobrara } \\
\text { River mouth, in } \\
\text { kilometers }\end{array}$ & $\begin{array}{c}\text { Sample } \\
\text { texture, } \\
\text { subdominant } \\
\text { class }\end{array}$ \\
\hline 424800098403701 & SP-01 & $5 / 28 / 2015$ & Regular & Core sample & Delta, impounded & 0.37 & 76 & $11-34$ & 2 & 75 & 1,466 & 63.825 & -- \\
\hline 424800098403701 & SP-02 & $5 / 28 / 2015$ & Replicate & Core sample & Delta, impounded & 0.45 & 80 & $0-43$ & 1 & 107 & 1,413 & 63.863 & -- \\
\hline 424800098403701 & SP-02-R & $5 / 28 / 2015$ & Replicate & Core sample & Delta, impounded & 0.34 & 81 & $0-30$ & 1 & 107 & 1,413 & 63.863 & -- \\
\hline 424800098403701 & SP-03 & $5 / 28 / 2015$ & Replicate & Core sample & Delta, impounded & 0.27 & 91 & $0-27$ & 1 & 312 & 1,423 & 63.786 & -- \\
\hline 424800098403701 & SP-03-R-010 & $5 / 28 / 2015$ & Replicate & Core sample & Delta, impounded & 0.38 & 100 & $0-30$ & 1 & 312 & 1,423 & 63.786 & -- \\
\hline 424800098403701 & SP-04-012 & $5 / 28 / 2015$ & Regular & Core sample & Delta, impounded & 0.58 & 100 & $0-37$ & 3 & 271 & 1,335 & 63.903 & -- \\
\hline 424800098403701 & SP-04-017 & $5 / 28 / 2015$ & Regular & Core sample & Delta, impounded & 0.58 & 100 & $37-52$ & 3 & 271 & 1,335 & 63.903 & $\begin{array}{l}\text { Organic-rich } \\
\text { silt }\end{array}$ \\
\hline 424800098403701 & SP-05 & $5 / 28 / 2015$ & Regular & Core sample & Delta, impounded & 0.39 & 91 & $12-37$ & 2 & E 91 & 1,597 & 63.580 & -- \\
\hline 424800098403701 & SP-06-013 & $5 / 28 / 2015$ & Regular & Core sample & Delta, impounded & 0.40 & 100 & $32-40$ & 3 & E 116 & 1,640 & 63.553 & -- \\
\hline 424800098403701 & SP-03-R-013 & $5 / 28 / 2015$ & Regular & Core sample & Delta, impounded & 0.38 & 96 & $30-38$ & 2 & 312 & 1,423 & 63.786 & -- \\
\hline 06465000 & NR-01-A & $\begin{array}{l}5 / 29 / 2015 \\
9: 50\end{array}$ & Intra-deposit pair & Core sample & Shelf & 0.12 & E 90 & $0-12$ & 1 & 1 & 25 & 62.699 & -- \\
\hline 06465000 & NR-01-B & 5/29/2015 10:00 & $\begin{array}{l}\text { Primary of intra- } \\
\text { deposit pair }\end{array}$ & Bank scrape & Shelf & 0.56 & 100 & 56 & 1 & 0.6 & 25 & 62.699 & -- \\
\hline 06465000 & NR-02 & 5/29/2015 10:15 & Regular & Bank scrape & Shelf & 0.61 & 100 & 61 & 1 & 3.9 & 290 & 62.408 & -- \\
\hline 06465000 & NR-03 & 5/29/2015 10:40 & Regular & Core sample & Shelf & 0.11 & E 90 & $0-11$ & 1 & 14 & 727 & 62.038 & -- \\
\hline 424801098380801 & NR-04 & 5/29/2015 11:00 & Regular & Bank scrape & Shelf & 0.47 & 100 & 47 & 1 & 15 & 0 & 61.240 & -- \\
\hline 424758098375201 & NR-05 & 5/29/2015 11:15 & Regular & Bank scrape & Shelf & 0.50 & 100 & 50 & 1 & 0.5 & 0 & 60.879 & -- \\
\hline 424723098362001 & NR-06 & 5/29/2015 11:45 & Regular & Core sample & Submerged medial bar & 0.22 & 91 & $0-22$ & 1 & 17 & 0 & 58.383 & -- \\
\hline 424709098354401 & NR-07-A & 5/29/2015 12:00 & Replicate & Core sample & Medial bar & 0.17 & 59 & $0-17$ & 1 & 18 & 0 & 57.411 & -- \\
\hline 424709098354401 & NR-07-B & 5/29/2015 12:15 & Replicate & Core sample & Medial bar & 0.20 & 70 & $0-20$ & 1 & 18 & 0 & 57.411 & -- \\
\hline 424655098340601 & NR-08 & $5 / 29 / 2015 \quad 12: 45$ & Regular & Bank scrape & Medial bar & 0.24 & 100 & 24 & 1 & 0.1 & 0 & 54.874 & -- \\
\hline 424647098314501 & NR-09 & 5/29/2015 13:30 & Regular & Core sample & Medial bar & 0.21 & 70 & $0-21$ & 1 & 39 & 0 & 51.511 & -- \\
\hline 424615098263201 & NR-10 & 5/29/2015 14:20 & Regular & Core sample & Medial bar & 0.21 & E 70 & $0-21$ & 1 & 230 & $-1,750$ & 45.604 & -- \\
\hline 424624098254601 & NR-11 & 5/30/2015 11:00 & Regular & Bank scrape & Medial bar & 0.24 & 100 & 24 & 1 & 49 & 0 & 42.796 & -- \\
\hline 424618098211601 & NR-12-A & 5/30/2015 12:10 & Replicate & Bank scrape & Medial bar & 0.29 & 100 & 29 & 1 & 44 & 0 & 36.322 & -- \\
\hline 424618098211601 & NR-12-B & 5/30/2015 12:20 & Replicate & Bank scrape & Medial bar & 0.29 & 100 & 29 & 1 & 44 & 0 & 36.322 & -- \\
\hline 424538098175201 & NR-13 & $\begin{array}{ll}5 / 30 / 2015 & 13: 20 \\
\mathrm{PM} & \end{array}$ & Regular & Core sample & Medial bar & 0.21 & ND & $0-21$ & 1 & 120 & 0 & 31.394 & -- \\
\hline 424522098162301 & NR-14-A & $\begin{array}{l}\text { 5/30/2015 } \\
\text { PM }\end{array}$ & $\begin{array}{l}\text { Composited with } \\
\text { NR-14-B }\end{array}$ & Bank scrape & Medial bar & 0.23 & 100 & 23 & 1 & 165 & 0 & 29.305 & -- \\
\hline 424522098162301 & NR-14-B & $\begin{array}{l}\text { 5/30/2015 14:10 } \\
\text { PM }\end{array}$ & $\begin{array}{l}\text { Composited with } \\
\text { NR-14-A }\end{array}$ & Core sample & Submerged medial bar & 0.28 & 85 & $0-28$ & 1 & 161 & 0 & 29.305 & -- \\
\hline
\end{tabular}


Table 1. Data for sampling sites for upstream sand sources assessment, lower Niobrara River valley, Nebraska, 2015._Continued

[Field identifier prefix: SP, Spencer Dam pond; NR, Niobrara River; EC, Eagle Creek; RC, Redbird Creek; LC, Louse Creek; all sample textures were dominated by sand; --, not applicable; E, estimated value; $\mathrm{ND}$, no data]

\begin{tabular}{|c|c|c|c|c|c|c|c|c|c|c|c|c|c|}
\hline Station identifier & $\begin{array}{c}\text { Field } \\
\text { identifier of } \\
\text { sample }\end{array}$ & $\begin{array}{c}\text { Date and } \\
\text { time } \\
\text { sampled }\end{array}$ & Sample type & $\begin{array}{l}\text { Collection } \\
\text { method }\end{array}$ & Fluvial form & $\begin{array}{c}\text { Core } \\
\text { length, } \\
\text { in meters }\end{array}$ & $\begin{array}{c}\text { Core } \\
\text { recovery, } \\
\text { in percent }\end{array}$ & $\begin{array}{c}\text { Vertical inter- } \\
\text { val sampled, } \\
\text { in centimeters } \\
\text { below sedi- } \\
\text { ment surface }\end{array}$ & $\begin{array}{c}\text { Number } \\
\text { of } \\
\text { intervals } \\
\text { in core }\end{array}$ & $\begin{array}{c}\text { Distance } \\
\text { from edge } \\
\text { of water, in } \\
\text { meters }\end{array}$ & $\begin{array}{c}\text { Distance } \\
\text { downstream } \\
\text { from station } \\
\text { to sample, in } \\
\text { meters }\end{array}$ & $\begin{array}{l}\text { Distance } \\
\text { upstream } \\
\text { from Niobrara } \\
\text { River mouth, in } \\
\text { kilometers }\end{array}$ & $\begin{array}{c}\text { Sample } \\
\text { texture, } \\
\text { subdominant } \\
\text { class }\end{array}$ \\
\hline 06465500 & NR-15 & $\begin{array}{l}\text { 5/30/2015 } 15: 00 \\
\text { PM }\end{array}$ & Regular & Core sample & Medial bar & 0.20 & 90 & $0-20$ & 1 & 65 & -250 & 25.030 & -- \\
\hline 06465500 & NR-16-A & 10/13/2015 10:30 & Regular & Core sample & $\begin{array}{l}\text { Lateral bar in separation } \\
\text { eddy }\end{array}$ & 0.05 & 100 & $0-5$ & 2 & 1 & 15 & 24.756 & -- \\
\hline 06465500 & NR-16-B & 10/13/2015 10:30 & Regular & Core sample & $\begin{array}{l}\text { Lateral bar in separation } \\
\text { eddy }\end{array}$ & 0.08 & 87.5 & $5-12$ & 2 & 1 & 15 & 24.756 & -- \\
\hline 06466000 & NR-45 & 10/15/2015 16:30 & Regular & Core sample & Medial bar at tail of island & 0.20 & 95 & $0-20$ & 1 & 44 & -75 & 2.524 & -- \\
\hline 06466000 & NR-48-A & 5/29/2015 13:30 & $\begin{array}{l}\text { Composited as } \\
\text { NR- } 48^{1}\end{array}$ & Core sample & Shelf & 0.18 & 83 & $39-57$ & 2 & 136 & 2,240 & 0.125 & -- \\
\hline 06466000 & NR-48-B & 5/29/2015 13:30 & $\begin{array}{l}\text { Composited as } \\
\text { NR-48 }\end{array}$ & Bank scrape & Shelf & 0.39 & 100 & $0-39$ & & & & & \\
\hline 06466000 & NR-49-A & 5/29/2015 13:57 & Intra-deposit pair & Bank scrape & Shelf & 0.29 & 100 & 29 & 1 & 7 & 2,395 & 0.000 & -- \\
\hline 06466000 & NR-49-B & 5/29/2015 14:10 & Intra-deposit pair & Bank scrape & Shelf & 0.38 & 100 & 38 & 1 & 6 & 2,396 & 0.000 & -- \\
\hline 06465310 & EC-01 & 5/29/2015 11:45 & Regular & Bank scrape & $\begin{array}{l}\text { Medial bar (part of bar } \\
\text { complex) }\end{array}$ & 0.28 & 100 & 28 & 1 & 6.9 & -14 & 54.628 & -- \\
\hline 424353098285601 & RC-02 & 5/30/2015 8:20 & Regular & Bank scrape & Medial bar tail & 0.15 & 100 & 15 & 1 & 4 & -14 & 44.649 & Gravel \\
\hline 424524098255101 & LC- 02 & 5/30/2015 9:40 & Regular & Bed scoop & Point bar & 0.04 & ND & 4 & 1 & 0.3 & 0 & 43.502 & -- \\
\hline
\end{tabular}

${ }^{1}$ Composited in field and submitted for analysis as a single composite sample. 


\section{Field Methods}

This section of the report details the field methods used to describe the physical characteristics and assesses the suitability of Missouri River delta deposits at the head of Lewis and Clark Lake as viable proppant feedstock. The sampling approach used to assess the Missouri River delta deposits and upstream sources also is discussed.

\section{Surface-Geophysical Reconnaissance}

A geophysical reconnaissance was completed from March 25 to 27, 2015, to help strategically target sampling locations to determine the lithologic characteristics of the selected Missouri River delta sandbar complexes. The geophysical reconnaissance was intended to help identify and differentiate sand bodies that could be potentially viable proppant feedstock from lenses of clay-to-silt-size sediment and depositional pockets of organic detritus in the subsurface. The geophysical data also were collected to support interpolation between coring locations and to help estimate the spatial extent and volumes of underlying sand bodies.

The capacitively coupled (CC) resistivity method was chosen as the primary surface-geophysical tool for the reconnaissance survey because of the ability of the technique to collect shallow resistivity data rapidly at the land surface. Soil boring locations were selected for collection of soil cores on the basis of trends or anomalies observed in the CC resistivity sections to capture variability. Because the $\mathrm{CC}$ resistivity data were used as a reconnaissance tool, the cores were located in a more logical, strategic manner rather than a random sampling. A strategic coring plan ensured that the lateral variability observed in the resistivity profiles could be verified at core locations and interpreted accordingly. Targeting locations in this manner would potentially allow a "calibration" of the CC resistivity data that could be used to describe the lithologic characteristics and spatial extent of the underlying sand bodies for this site. Included in this section are an overview of the resistivity method and a brief explanation of data acquisition, processing, and inversion of the data.

\section{Overview of Resistivity Method}

Resistivity is an intrinsic material property that is defined by resistance to the flow of electric current in that material. Measurements of this property are made by injecting a known current into the subsurface using two current electrodes and measuring the resulting voltage difference between two potential electrodes. Based on Ohm's Law, the resistance is computed by taking the ratio of the measured voltage and the transmitted current. The apparent resistivity of the material, expressed in ohm-meters, can then be determined by multiplying each resistance value by the corresponding geometric factor, which is based on the electrode geometry and spacing.
The main factors that affect the resistivity of a material are the amount of interconnected pore water present, the water quality (level of total dissolved solids [TDS]), and the amount of mineralogical clay present. In the unsaturated zone, if no mineralogical clay is present, a fine-grained material (for example, silt or fine sand) generally will retain more interconnected pore water because of capillary forces than does a coarse-grained material (for example, coarse sand or gravel). The fine-grained material, therefore, will have a lower resistivity compared to coarse-grained materials. Water quality is an important factor because the concentration of ions in the water affects its ability to conduct electricity. Materials containing water with high TDS will have a lower resistivity compared to materials containing water with low TDS. The presence of even a small amount of clay minerals can dramatically decrease the overall bulk resistivity of a material because current is conducted through the pore fluids (electrolytically) and through cation exchange (electronically). Because of the relation between grain size and resistivity, the resistivity method can be a useful tool in differentiating grain size variations and providing a better estimate of volume of potential frac sand feedstock. More detailed descriptions of the resistivity method and resistivity values for common geologic materials are provided in Butler (2005), Reynolds (1997), and Sharma (1997).

\section{Capacitively Coupled Resistivity Methods}

This section describes the capacitively coupled resistivity methods used to physically characterize and assess the suitability of Missouri River delta deposits near the head of Lewis and Clark Lake as a potential source of natural sand proppant. A discussion of the data acquisition and data processing and inversion procedures are discussed in the subsections that follow.

\section{Data Acquisition}

The CC resistivity data were acquired with the Geometrics OhmMapper TR5 (Geometrics, Inc., San Jose, California) towed behind an amphibious tracked all-terrain vehicle (fig. 4). This dipole-dipole array system consisted of five receiver dipoles, equivalent to five potential electrode pairs, and one transmitter dipole, equivalent to a current electrode pair (fig. 4). Each dipole consisted of a 5-m cable attached to each end of an electronics unit, yielding dipole lengths of $10 \mathrm{~m}$. The resultant towed array length was about $50 \mathrm{~m}$.

The transmitter, at the rear of the array, was attached to the receivers by a nonconductive rope $(5 \mathrm{~m}$ long for this survey) and transmitted an alternating current at a frequency of 16.5 kilohertz. Current was transmitted into the ground through the use of capacitance, which negates the need for the electrodes to be in direct contact with the ground and thus allows for more efficient and faster data acquisition. With the wire in each dipole cable and the ground acting as the opposing conductor "plates" of a capacitor, the insulating sheath enclosing the wire and the air space between the dipole cable and the ground functioned as the insulator between the plates (Geometrics, 2001). 


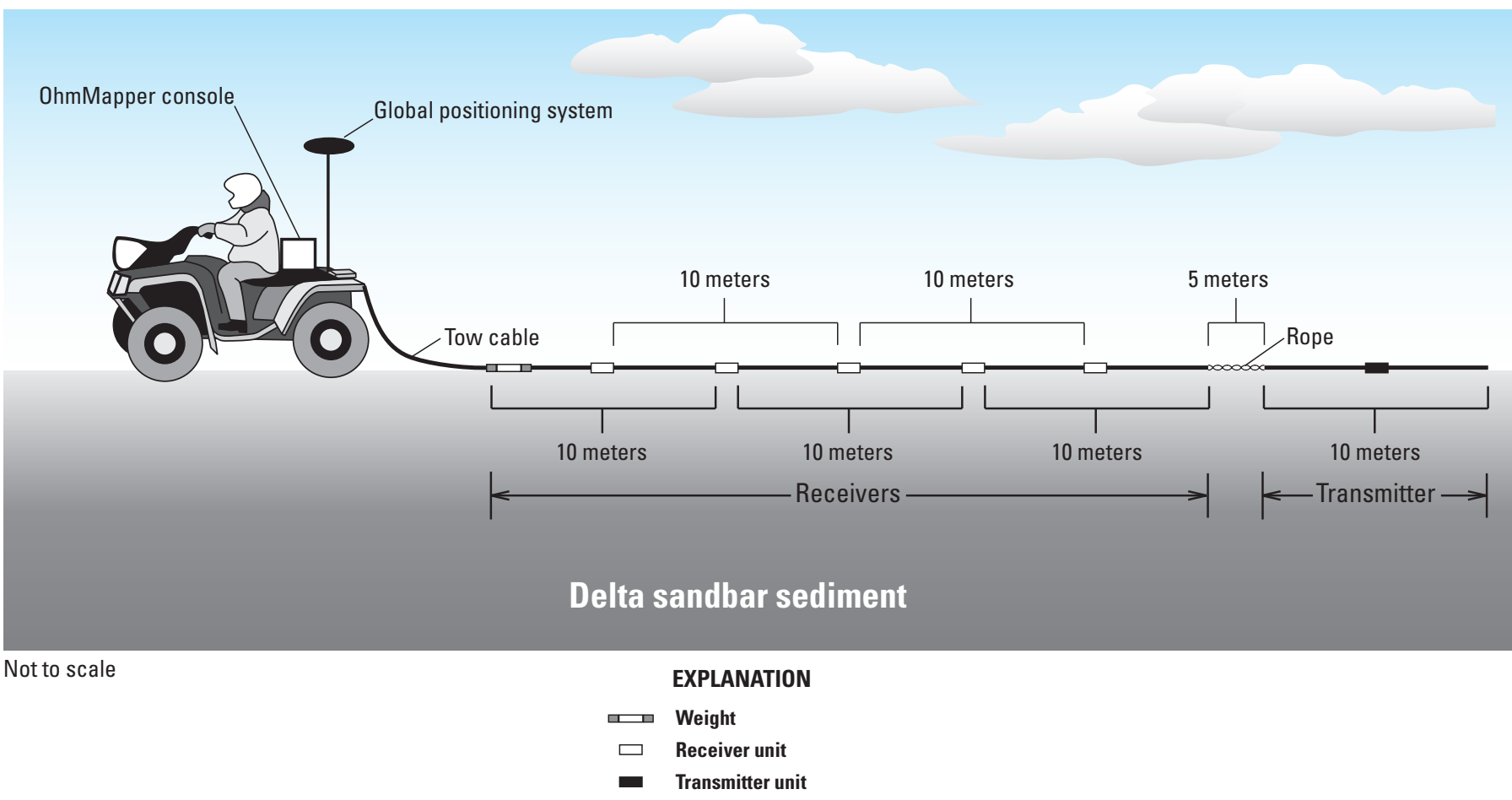

Figure 4. Schematic illustration showing the capacitively coupled resistivity-system setup and geometry.

Each receiver dipole sampled the subsurface to a particular depth based on its length and distance from the transmitter dipole. To attain the survey objective, the survey was designed for the optimal compromise between vertical and horizontal resolution and maximum depth of investigation by varying the geometry (dipole and rope lengths) of the array. The CC resistivity and differential global positioning system (DGPS) data were acquired at a rate of 1 hertz with the all-terrain vehicle traveling from 3 to 5 kilometers per hour. For further details on the $\mathrm{CC}$ resistivity method and acquisition system, refer to Ball and others (2006), Geometrics (2001), Lucius and others (2008), and Timofeev and others (1994).

All CC resistivity data were acquired using an integrated DGPS. All DGPS data were collected with a Trimble DSM 232 (Trimble Navigation Ltd., Sunnyvale, Calif.) using the OmniSTAR ${ }^{\circledR}$ (OmniSTAR, Inc., Houston, Texas) high performance (OmniSTAR HP) service for real-time differential correction (http://www.omnistar.com/SubscriptionServices/ OmniSTARHP.aspx). The vertical and horizontal accuracies expected by using the OmniSTAR HP service typically are 15 and 10 centimeters (cm), respectively (OmniSTAR, 2005).

Data collection generally was limited to flat, open areas of bare sand or sparsely vegetated areas, which produced higher quality data with a greater signal than when the dipoles were raised off the land surface (for example, by being draped over thick vegetation). Thick vegetation, such as patches of Phragmites (a reed), resulted in a loss of signal between the transmitter at the rear of the array and the five receivers. Abrupt changes in elevation also were avoided. Towing the array over steep inclines, such as those created by recently deposited windblown dunes, caused a gap between the dipole array and land surface resulting in poor signal quality. Areas with standing water also were avoided during data collection because the transmitter, receivers, and connections for the OhmMapper system are not sealed or water tight.

\section{Data Processing and Inversion}

The raw binary data files were downloaded from the OhmMapper instrument using Geometrics MagMap 2000 software, version 4.94 (Geometrics, 2009). The binary files were imported into a pair of unpublished USGS Global Positioning System (GPS) and OhmMapper data-processing software programs (GPSpathtool and OhmBin, respectively; Joseph Vrabel, written commun., 2012). Upon initial import of a raw binary file, GPSpathtool allowed the user to enter the GPS antenna height, define the nature of the survey (for example, a single pass with a single geometry or multiple passes over the same line with multiple geometries), and edit the array geometry (for example, GPS-array offset, dipole lengths, or rope length). The geographic coordinates in the binary file were automatically projected to the appropriate Universal Transverse Mercator zone, with elevations as heights above the North American Vertical Datum of 1988, expressed in meters, and the position and elevation of the center of each transmitter-receiver pair for every measurement was interpolated and extrapolated from the DGPS data stream. Poor locational data were rejected based on the GPS quality factor and by graphically selecting data points. A single path was then fitted to the accepted GPS data. The discrete points were mapped, or projected, to the path fit. The typical processing procedure 
used was to selectively remove data with a GPS quality factor of 2 (indicative that DGPS location had not converged to a horizontal accuracy less than $30 \mathrm{~cm}$ ) based on position relative to the general path trend. A quality factor of 4 is the optimal GPS quality factor, indicating that horizontal accuracy ranges from 5 to $30 \mathrm{~cm}$.

Outputs from GPSpathtool were imported into the OhmBin program, where the resistivity data were viewed and processed. Within the OhmBin program, all data can be viewed either as horizontal, down-distance line plots for each receiver or as contoured pseudosections of the apparent resistivity, measured voltage, calculated resistance (millivolts per milliamp), and transmitted current levels. The data were processed by (1) automatically removing data spikes using a single data-point-spike width and factor of $1.5,(2)$ manually removing data spikes in the voltage and resistance data, and (3) binning (or averaging) the data to a 5-m horizontal bin size. A single data-point-spike factor is defined as the ratio of a data point with its neighboring points. If a preset threshold is exceeded, then the point is removed. A single data-point-spike width and factor of 1.5 was chosen based on the high-frequency noise characteristics observed in the data. These parameters in combination function as a low-pass filter that allowed for removal of the higherfrequency noise created by the movement of the system during acquisition. The 5-m bin size was chosen as a good compromise between the lateral heterogeneity expected in the subsurface in the survey area and the practical lateral resolution of CC resistivity measurements acquired with a 5-m half-dipole length.

The binned data were exported in a RES2DINV (Loke, 2009) file format that also can be read into the EarthImager 2D (Advanced Geosciences, Inc., 2008) inversion program. All CC resistivity data were inverted using the robust, finiteelement inversion method in EarthImager 2D (version 2.4.0, build 617; Advanced Geosciences, Inc., 2008). The robust method is based on the assumption of exponentially distributed errors and minimizes the combination of the data misfit and model instability (L1-norm parameter). This method resolves abrupt changes in resistivity (lithology) (Advanced Geosciences, Inc., 2008), which are common in alluvial systems. The inverted resistivity sections were then imported into Encom Profile Analyst (Pitney Bowes Software, North Sydney, Australia, http://www.pitneybowes.com/pbencom/ products/Geophysics/encom-pa.html).

The CC resistivity data were used to select soil boring locations for collection of cores. Locations were chosen so as to sample representative and anomalous resistivity structure along each of the $\mathrm{CC}$ resistivity profiles and included sampling the full range of resistivity values observed. Of the 28 locations selected, 25 locations actually were cored because water levels controlled accessibility by the tractor-mounted coring rig to the selected locations at the time of borings, along with cost and time considerations (table 2). Once the soil borings were described lithologically and laboratory analyses of sediment samples were completed, these data were imported into Profile Analyst and displayed along with the $\mathrm{CC}$ resistivity data for further analysis and interpretation.

\section{Missouri River Delta Sampling}

Missouri River delta sediment samples were collected with a tractor-mounted coring rig (Model 54TR, Geoprobe Systems, Salina, Kansas). Prior to coring, location coordinates were typed into a handheld GPS that allowed field personnel to collect cores within $3 \mathrm{~m}$ of the intended target location. At each location, two cores (3.8-cm diameter) were collected to a depth of $3.7 \mathrm{~m}$. Each set of cores was collected approximately $0.5 \mathrm{~m}$ apart. Collecting two cores at each location ensured enough sediment material was available to allow for lithologic description, laboratory analyses, and archiving. Once cores were collected, they were capped, labeled, and visually inspected for fine-grained organic-rich sediments. If an interval contained organic-rich fine sediments, the interval was cut from the core, capped, labeled, and frozen immediately to preserve for potential future chemical analyses. One set of cores remained intact for lithologic description at the USGS Nebraska Water Science Center, whereas the other core from each pair was reserved for quality-control sampling or to offset any deficiency in sample mass from thin intervals of the logged core. The location, elevation, and field identifier of each of the borehole sites where sediment core pairs were collected are listed in table 2. Cores were lithologically described noting sediment grain size, sorting, color, presence of organic material, and mineralogy. Core description intervals were based on abrupt changes in lithologic character that generally coincided with sediment sample intervals. Through visual inspection and description, the presumed "best" sediment samples were selected for further analyses. These samples were generally well-sorted, fine- to medium-grained sand, with few fines. Selected sediment samples were shipped to Montana Tech Proppant Research Laboratory in Butte, Montana, for further analyses.

\section{Sampling Upstream Sources of Sand}

Spencer Dam impoundment was sampled using a Universal push corer to bore into the deltaic deposit to a target depth ranging from about 0.4 to $0.6 \mathrm{~m}$. Bore depth was limited by refusal or by the $0.7-\mathrm{m}$ length of open core barrel affixed to the sampler head. When core recovery commenced, a check valve closed the top of the core barrel to produce a vacuum seal allowing an improved recovery of noncohesive material (typically 80 percent or more of the core was recovered). The bottom end of the core barrel was capped prior to lifting the core barrel completely above the water surface, and the top end was capped afterward. Cores of bottom sediment from the impoundment behind Spencer Dam were collected from sandbars along three distributary channels across the impoundment. Each cluster of two coring locations does not refer to replicate cores; rather the pair was within a sandbar complex in one of three distinct distributary channels (fig. 3; table 1). However, two of the clusters were selected as sites where a replicate core also was collected (see "Quality Assurance and Quality Control" section). Of the six coring locations, one 
Table 2. Data for borehole sampled sites, Missouri River delta near Running Water, South Dakota, 2015.

[Elevation in meters above North American Vertical Datum of 1988 (NAVD 88); horizontal coordinate information referenced to Universal Transverse Mercator projection, zone 14; *, indicates that a replicate sample was analyzed]

\begin{tabular}{|cccccc}
\hline Station identifier & $\begin{array}{c}\text { Field } \\
\text { identifier }\end{array}$ & $\begin{array}{c}\text { Date } \\
\text { bored }\end{array}$ & $\begin{array}{c}\text { Easting, } \\
\text { in meters }\end{array}$ & $\begin{array}{c}\text { Northing, } \\
\text { in meters }\end{array}$ & $\begin{array}{c}\text { Elevation, } \\
\text { in meters }\end{array}$ \\
\hline 424554097583301 & A1* & $4 / 13 / 2015$ & 583801 & 4735226 & 369.2 \\
\hline 424553097583001 & A3 & $4 / 13 / 2015$ & 583872 & 4735208 & 369.0 \\
\hline 424600097582001 & A4 & $4 / 13 / 2015$ & 584087 & 4735418 & 369.3 \\
\hline 424601097582201 & A5* & $4 / 13 / 2015$ & 584053 & 4735457 & 369.0 \\
\hline 424607097575401 & B7 & $4 / 15 / 2015$ & 584674 & 4735628 & 369.7 \\
\hline 424608097575101 & B8* & $4 / 15 / 2015$ & 584745 & 4735658 & 369.0 \\
\hline 424610097574401 & B9 & $4 / 15 / 2015$ & 584899 & 4735724 & 368.8 \\
\hline 424604097573801 & B10 & $4 / 15 / 2015$ & 585053 & 4735546 & 368.2 \\
\hline 424613097574401 & B11* & $4 / 15 / 2015$ & 584908 & 4735836 & 369.1 \\
\hline 424612097574401 & B12 & $4 / 15 / 2015$ & 584905 & 4735800 & 368.4 \\
\hline 424615097574701 & B13 & $4 / 15 / 2015$ & 584840 & 4735892 & 369.7 \\
\hline 424618097573901 & B14 & $4 / 15 / 2015$ & 585008 & 4735993 & 368.4 \\
\hline 424628097572701 & C15 & $4 / 14 / 2015$ & 585285 & 4736291 & 369.6 \\
\hline 424634097570701 & C16 & $4 / 14 / 2015$ & 585731 & 4736486 & 368.2 \\
\hline 424617097571901 & C17 & $4 / 14 / 2015$ & 585464 & 4735944 & 369.7 \\
\hline 424615097571601 & C18* & $4 / 14 / 2015$ & 585536 & 4735882 & 368.7 \\
\hline 424613097570801 & C19 & $4 / 15 / 2015$ & 585712 & 4735824 & 368.2 \\
\hline 424618097572601 & C20 & $4 / 14 / 2015$ & 585303 & 4735981 & 369.4 \\
\hline 424617097572601 & C21* & $4 / 14 / 2015$ & 585320 & 4735958 & 368.7 \\
\hline 424621097572401 & C22 & $4 / 14 / 2015$ & 585361 & 4736080 & 369.3 \\
\hline 424625097562701 & D24* & $4 / 16 / 2015$ & 586651 & 4736209 & 368.1 \\
\hline 424631097562601 & D25 & $4 / 16 / 2015$ & 586675 & 4736392 & 368.1 \\
\hline 424628097562801 & D26 & $4 / 16 / 2015$ & 586633 & 4736300 & 368.3 \\
\hline 424628097562401 & D27 & $4 / 16 / 2015$ & 586705 & 4736315 & 368.2 \\
\hline 424623097563601 & D28 & $4 / 16 / 2015$ & 586450 & 4736164 & 368.5 \\
\hline & & & & & \\
\hline 4 & & & & \\
\hline 4 & & & & \\
\hline
\end{tabular}

location (SP-06, fig. 3) did not yield a sufficient mass of sandsized material for submittal to the laboratory; therefore, laboratory results are available only for five of the cored locations.

Sediment samples of channel sand deposits were collected chiefly from medial bars and sand shelves, which differ visibly only with respect to whether the feature was surrounded by flowing threads of the wetted channel. Sediment sample collection used one of two methods dependent on whether the hand-pushed corer could penetrate to softer, fully saturated sand near the water level in the sandbar. The first method, used when the sampled interval was mostly saturated material, was to manually push an open, plastic-core barrel vertically down into the deposit, either to refusal or to

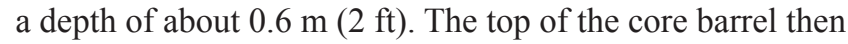
was closed, usually with an expanding rubber test plug (Oatey 75-mm Gripper ${ }^{\circledR}$ ). Closure of the barrel top allowed retrieval with suction, so the core was retrieved and core length was measured; then the barrel top was reopened and the sample containerized in a resealable plastic bag. For the second method, used to sample unsaturated material, sediment samples were collected using a trowel or scoop as a bank scrape (figs. 5A-F; Schaepe and Alexander, 2011). Bank scrapes integrated the sediment grains of a freshly exposed (cleaned with trowel or scoop) vertical section along either the sandbar margin or an excavated pit because in such samples all strata are represented in approximate proportion to their thickness at the exposed section (Schaepe and Alexander, 2011).

Tributaries were sampled from sandbar deposits, which were either medial or point bars. Sediment samples were collected using the bank scrape method (Schaepe and Alexander, 2011) from the downstream end of medial bars at Eagle and Redbird Creeks and by using a scoop to sample the barely submerged surface of a point bar at Louse Creek (fig. 1).

Sediment samples representing upstream sources of sand generally were not weighed prior to submittal to the laboratory because moisture content was highly variable. A few sediment samples that were air dried and weighed ranged from 1.25 to 1.75 kilograms.

\section{Laboratory Methods}

Exploratory analysis of natural sand for determining its suitability as a proppant involved application of a subset of the standard protocols known as API Recommended Practice (RP) 19C (API RP19C; American Petroleum Institute and others, 2008), also known as International Organization for Standardization (ISO) 103403-2. The standard protocols are used routinely to evaluate samples of natural or manufactured proppant material for potential use in hydraulic fracturing operations.

\section{Proppant Research Laboratory}

In the report on a survey of native proppant resources in Montana (Getty and others, 2016), a section on laboratory methods details the procedure, illustrates the procedure with a flowchart, and notes that the RP19C methods were not intended for exploration-stage evaluation of raw materials, but the methods were used to guide protocol development for evaluating raw materials. For this study, the Proppant Research Group (PRG) at Montana Tech analyzed the sediment samples using the following (modified API RP19C) protocol (John Getty, Montana Tech, written commun., 2015, 2016). 

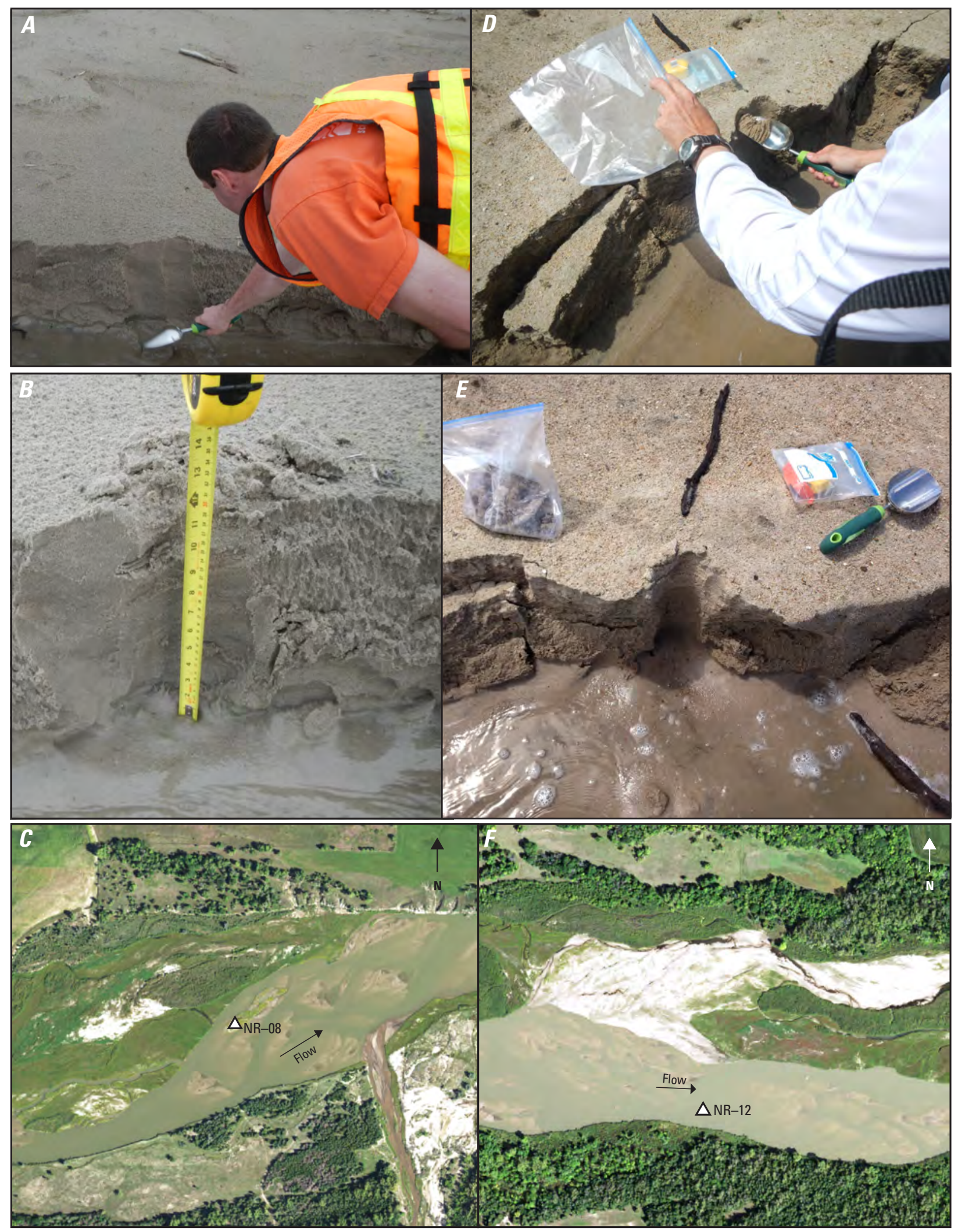

Figure 5. Sandbar sample collection using bank-scrape method, Niobrara River, Nebraska, May 2015. $A$, cleaning vertical bank prior to sampling; $B$, measuring sampled thickness; $C_{r}$ aerial view of NR-08 and site of photographs $A$ and $B$; $D$, scraping the bank face; $E$, containerized sample; and $F$, aerial view of NR-12 and site of photographs $D$ and $E$. U.S. Geological Survey photographs by Hillary Stoll and R.B. Zelt; aerial photos from Google, dated April 20, 2014. 
1. Log the sediment sample into the laboratory information management system. Weigh, prepare for analysis (wash, dry, and sieve), and reweigh the sediment sample. During the sieving procedure, attempt to disaggregate material coarser than $2 \mathrm{~mm}$ (retained on U.S. Number 10 sieve) and discard remaining individual particles of this size class (gravel). Using an optical microscope, determine if the sediment sample appears to be primarily crystalline quartz.

2. Use the Camsizer ${ }^{\circledR}$ XT (Retsch Technology, 2015) optical imaging particle-size analyzer (OPSA) to determine the continuous size distribution of the sediment sample. The OPSA uses dynamic digitalimage processing (ISO 13322-2) to analyze the size and shape of particles moving through a $20-\mathrm{mm}$ field-of-view analysis area. This OPSA uses two light-emitting diodes as light sources with a twocamera system collecting more than 275 images per second of dispersed particle shadows to achieve 1-micron resolution and, for this study, the particles required no artificial dispersion; that is, gravity dispersion (free fall) was used with the dry, pourable sediment samples. Using this dispersion option, the OPSA's measurement range includes particles from 10 microns to $8 \mathrm{~mm}$ in diameter (Retsch Technology, 2015), which includes the full range of sand sizes $(0.0625-2 \mathrm{~mm})$. The OPSA resolved particles using numerous size classes to summarize the full PSD graphically, but tabular output of only selected points of the PSD was specified for delivery. Class boundaries for numerical summarization were selected for this study to be equivalent to sizes of the U.S. Standard Sieve Series, wherein size classes are designated by sieve number and the coarser the grain, the smaller the sieve number (ASTM International, 2004; Beckwith, 2011).

Particle size may be measured by a variety of techniques and each is associated with a characteristic definition of particle size (Abireddy and Clayton, 2009). Imaging techniques, such as the OPSA used at the PRG, define particle size as the minimum length of the projected image of a particle. Thus, a mixture of randomly oriented particles imaged by the OPSA will measure particle sizes that include a mixture of intermediate and minimum diameters of individual particles. The use of particle-size methods other than standard sieve analysis is allowed for proppant evaluations, provided that the alternate methods are correlated with the standard sieving methods (American Petroleum Institute and others, 2008). The PRG reported that the OPSA used to measure size and shape characteristics for this study had been calibrated to results from the set of sieves used at the PRG at the time of the OPSA initial setup (J. Getty, Montana Tech, oral commun., 2015).
3. From the OPSA data, determine the dominant-size fraction from among the standard particle-size classes for proppant specified in API RP19C. The washed sediment sample was split to retain a mass of $80-120$ grams and sieved to separate the dominantsize fraction using a sieve stack including the first and second primary sieves for the selected dominantsize fraction. The separated sediment subsample was used in additional testing, whereas the remainder of the sediment sample was archived.

4. The size distribution of the sieved sediment subsample was verified and the sphericity and roundness were determined, all by using the OPSA.

5. Using microscopy, the sediment subsample was reevaluated to provide an image of the target material, determine the ratio of particle clusters to individual particles, and confirm the mineralogy determination (from step 1).

6. Bulk density was measured, provided that sediment subsample mass was sufficient. For this study, loosepack bulk density was determined for the sediment subsamples as part of the crush-resistance test procedure; that is, for sediment subsamples consisting of the dominant API size class. Bulk density was not measured for the washed raw material. To measure bulk density, a known volume was filled with dry proppant and weighed (American Petroleum Institute and others, 2008, ISO 13503-2; Getty, 2013).

7. A representative aliquot of 40 grams of sediment subsample was tested for crush resistance. The tested level of stress applied to each sediment subsample was determined after the initial 25 sediment samples had been tested at 34.5 megapascals (MPa), or 5,000 pounds-force per square inch $\left(\mathrm{lbf} / \mathrm{in}^{2}\right)$. The resulting material was reweighed and its PSD reanalyzed using the OPSA. The fraction of the material smaller than the second primary was reported as the percent fines, an indication of the percentage that was not crush resistant at the tested stress level.

All of the numerical data collected on each sediment sample were exported from the laboratory information management system into spreadsheet-formatted tables for delivery to the USGS. Digital images and computer-generated tabulargraphical reports on the PSD of each analyzed sediment sample that were provided by the PRG laboratory in standard file formats are available as a USGS data release (Hall and Hobza, 2017).

\section{Mineralogy by X-Ray Diffraction}

High-purity quartz (99-percent silica) content is a hallmark of premium frac sand. Impurities such as feldspar, garnets, amphiboles, and other minerals tend to break down 
under the fracture-closure pressure exerted as the hydraulic fracking pressure is relaxed. Previously, the requirement for high purity of quartz composition had precluded most eolian, glacial, and fluvial deposits from further consideration as frac sand sources; however, lower-cost "fit-for-purpose" sands that do not meet premium silica and crush-resistance specifications have been and are being used increasingly for some fracking operations (Zdunczyk, 2013; KELRIK LLC and PropTester, Inc., 2016; Preferred Sands, 2016).

A subset of 12 sediment samples collected for this study was submitted for mineralogy analysis by $\mathrm{x}$-ray diffraction (XRD) at the USGS Powder XRD Laboratory, Reston, Virginia. The XRD peaks result from the scattering of $\mathrm{x}$-rays from each set of crystal lattice planes in a sample. A characteristic set of peaks and peak intensities provides a fingerprint of crystalline and amorphous phases. Software enables spectral pattern processing, phase identification, crystallographic analysis, semiquantitative mineralogical analyses by Rietveld refinement (Rietveld, 1969), and structure determination (Piatak and others, 2014). Eight Missouri River delta sediment samples were chosen randomly, and the corresponding replicate core was used to provide sediment samples for XRD mineralogy. Four sediment samples from upstream sources also were submitted; these were sediment samples that had not been submitted for analysis by the PRG, although one sample (SP-03R-013) was a short interval from a core that also contributed a PRG-analyzed sediment sample. Sediment samples were analyzed for percentages of quartz, plagioclase feldspar, alkali feldspar (includes potassium feldspar), pyroxene, clays, and micas. Splits of sediment samples were pulverized in alcohol in a McCrone micronizer. Pulverized sediment samples placed into side-loaded aluminum holders were analyzed by XRD using a PANalytical X'Pert PRO automated powder diffractometer with $\mathrm{CuK \alpha}$ radiation at 45 kilovolts and 40 milliamperes. $\mathrm{Cu} K \alpha$ radiation is defined as the emission resulting when an electron transitions from the " $\mathrm{L}$ " shell to the " $\mathrm{K}$ " shell in a copper atom. Sediment samples were scanned for scattering angle, $2 \theta$, ranging from 3 to 80 degrees at a step size of 0.02 degrees of arc distance with a counting time of $30 \mathrm{sec}-$ onds per step. Quantification of mineral phases was done using a Rietveld procedure (X'Pert HighScore Plus software) and standard reference patterns. The accuracy of the quantitative results is within 10 percent by weight of the amount present, based on prepared mixtures of minerals.

\section{Data Analysis Methods}

Assessment of suitability for frac sand was based on the standards for proppants promulgated by the API and the ISO. The current (2015) API/ISO standards for proppants (including frac sand) are defined in "Measurement of Properties of Proppants Used in Hydraulic Fracturing and Gravel-Packing Operations" (RP19C/ISO13503-2; American Petroleum Institute and others, 2008), which modified and superseded RP 56 and RP 60 (American Petroleum Institute, 1983, 1989). These frac sand standards were modeled after the properties of the "Ottawa" or "Northern White" sand and the "Brady Brown" sand (Zdunczyk, 2013). A comparison of samples of 40/70 Ottawa sand and 40/70 PSG Loup River sand with the API/ ISO specifications for frac sand is listed in table 3.

\section{Proppant Size and Size Distribution}

Proper sizing of proppants is a key factor affecting the permeability of proppant-filled fractures (Houseworth, 2014). A narrow range of particle sizes is desirable for proppant, but grain diameters generally are within the range from 0.1 to $2 \mathrm{~mm}$. Uniformly coarse sand-sized particles allow the greatest permeability, but fracture length is more important than fracture conductivity for gas wells in tight reservoirs (Reinicke and others, 2010a). Consequently, the ability of the proppant to be transported by the fracking fluid depends in part on the particle size and density (Houseworth, 2014). Greater transportability is desirable to facilitate delivery of proppant deep into fractures. Proppants that are smaller and have a lower density are more easily transported (Economides and others, 2013).

The API size class consisting of particles passing U.S. Number 20 standard mesh but retained on U.S. Number 40 mesh (known as the 20/40 size class), along with the $30 / 50$ size class, have been the gradations in most demand historically (Beckwith, 2011). The API designates grainsize ranges by notations, such as 20/40,30/50, 40/70, and so forth, which indicate the bounding mesh sizes that enclose a minimum 90 percent of the sample. In the case of 20/40 sand, at least 90 percent of the sand passes through the U.S. Number 20 -mesh $(0.850-\mathrm{mm})$ sieve and is retained by the U.S. Number 40-mesh (0.425-mm) sieve (Zdunczyk, 2013; Benson and Wilson, 2015b). The API 20/40 and 30/50 size classes are popular for fracking oil wells, whereas the $40 / 70$ and 70/140 size classes are commonly used to stimulate well productivity for gas wells (Beckwith, 2011; Zdunczyk, 2013). Fracking engineers typically select the proppant size class to use for each well, or each stage of a multistage stimulation, by taking into account fluid viscosity, down-hole conditions, and well design.

The PSDs were characterized by a suite of summary statistics that include the central tendency or average size, measures of the spread of sizes around the average (sorting parameters), and measures of size in the tails of the frequency distribution of sizes to each side of the average. The mathematical moments of the distribution are greatly affected by outliers in the tails of the PSD and are not reliable unless the size distribution is fully known (McManus, 1988), which was not the case for the washed raw materials analyzed for this study. Formulas for the geometric variant (Blott and Pye, 2001; as implemented in GRADISTAT) of the graphical method proposed by Folk and Ward (1957) were used to characterize the PSD of whole or washed raw samples collected for this study. 
Table 3. Typical properties of fracture sand-ISO 13503-2 industry standards, properties of 40/70 0ttawa sand, Preferred Sands of Genoa 40/70 Loup River sand, and average properties by group of samples collected in 2015 (modified from U.S. Silica, 2014; Benson and Wilson, 2015a).

[ISO, International Standards Organization; API, American Petroleum Institute; 40/70, API size class for which at least 90 percent of material is finer than U.S. standard sieve 40 and coarser than U.S. standard sieve number 70 ; --, no data; $\geq$, greater than or equal to; $\mathrm{mm}$, millimeter; $\leq$, less than or equal to]

\begin{tabular}{|c|c|c|c|c|c|c|c|c|c|c|c|c|c|c|}
\hline $\begin{array}{r}\text { Property, test result, or } \\
\text { (weighted-average value of each is } \mathrm{g} \\
\text { indicated sample gr }\end{array}$ & $\begin{array}{l}\text { statistic } \\
\text { given in table bo } \\
\text { roup) }\end{array}$ & ody for & $\begin{array}{c}\text { Industry } \\
\text { standard for } \\
\text { frac sand, ISO } \\
13503-2 \text { (API } \\
\text { and others, } \\
2008 \text { ) }\end{array}$ & $\begin{array}{l}\text { U.S. Silica } \\
40 / 70 \\
\text { Ottawa sand' }\end{array}$ & $\begin{array}{l}\text { Preferred Sands } \\
\text { of Genoa mine } \\
\text { output (Loup Riv- } \\
\text { er), } 40 / 70 \text { sand } \\
\text { subsamples }\end{array}$ & $\begin{array}{c}\text { Preferred Sands } \\
\text { of Genoa (Loup } \\
\text { River) plant } \\
\text { output, } 40 / 70 \\
\text { sand }^{2}\end{array}$ & $\begin{array}{l}\text { Missouri River } \\
\text { delta, washed } \\
\text { raw sand, } \\
\text { 40/70-dominated } \\
\text { samples }\end{array}$ & $\begin{array}{c}\text { Missouri } \\
\text { River delta, } \\
\text { 40/70 sand } \\
\text { subsamples }\end{array}$ & $\begin{array}{c}\text { Missouri } \\
\text { River delta, } \\
70 / 140 \text { sand } \\
\text { subsamples }\end{array}$ & $\begin{array}{c}\text { Lower } \\
\text { Niobrara im- } \\
\text { pounded reach } \\
\text { SP, } 40 / 70 \text { sand } \\
\text { subsamples }\end{array}$ & $\begin{array}{l}\text { Lower Niobrara } \\
\text { River reach } \\
\text { A, } 40 / 70 \text { sand } \\
\text { subsamples }\end{array}$ & $\begin{array}{c}\text { Lower } \\
\text { Niobrara } \\
\text { River reach } \\
\text { B, 70/140 sand } \\
\text { subsamples }\end{array}$ & $\begin{array}{c}\text { Lower } \\
\text { Niobrara } \\
\text { River reach } \\
\text { C, } 40 / 70 \text { sand } \\
\text { subsamples }\end{array}$ & $\begin{array}{c}\text { Lower } \\
\text { Niobrara } \\
\text { River reach } \\
\text { D, } 40 / 70 \text { sand } \\
\text { subsamples }\end{array}$ \\
\hline Number of samples averaged & & & -- & -- & 2 & -- & 50 & 50 & 12 & 8 & 5 & 4 & 9 & 3 \\
\hline Particle shape (Krumbein and Sloss, 1963) & & & & & & & & & & & & & & \\
\hline Roundness & & & $\geq 0.6$ & 0.7 & 0.77 & 0.8 & 0.71 & 0.73 & 0.67 & 0.76 & 0.77 & 0.73 & 0.76 & 0.76 \\
\hline Sphericity & & & $\geq 0.6$ & 0.7 & 0.66 & 0.8 & 0.64 & 0.65 & 0.62 & 0.65 & 0.66 & 0.63 & 0.65 & 0.65 \\
\hline Bulk density, grams per cubic centimeter & & & -- & ${ }^{3} 1.46-1.58$ & 1.53 & 1.51 & -- & 1.48 & 1.42 & 1.50 & 1.50 & 1.48 & 1.51 & 1.51 \\
\hline Mean particle diameter, in mm (API) & & & -- & 0.298 & 0.334 & 0.336 & 0.301 & 0.307 & 0.169 & 0.307 & 0.314 & 0.174 & 0.325 & 0.312 \\
\hline Median particle diameter, in mm & & & -- & 0.29 & 0.322 & -- & 0.269 & 0.294 & 0.172 & 0.295 & 0.299 & 0.183 & 0.311 & 0.298 \\
\hline $\begin{array}{c}\begin{array}{c}\text { Particle-size distribution } \\
\text { (average value for indicated sample } \\
\text { group) }\end{array} \\
\end{array}$ & $\begin{array}{l}\text { Mesh nomi- } \\
\text { nal size, } \\
\text { in mm }\end{array}$ & $\begin{array}{c}\text { U.S. } \\
\text { sieve } \\
\text { number }\end{array}$ & $\begin{array}{l}\text { Percent by } \\
\text { weight }\end{array}$ & $\begin{array}{l}\text { Percent by } \\
\text { weight }\end{array}$ & $\begin{array}{l}\text { Percent by } \\
\text { volume }\end{array}$ & $\begin{array}{l}\text { Percent by } \\
\text { weight }\end{array}$ & $\begin{array}{l}\text { Percent by } \\
\text { volume }\end{array}$ & $\begin{array}{l}\text { Percent by } \\
\text { volume }\end{array}$ & $\begin{array}{l}\text { Percent by } \\
\text { volume }\end{array}$ & $\begin{array}{l}\text { Percent by } \\
\text { volume }\end{array}$ & $\begin{array}{l}\text { Percent by } \\
\text { volume }\end{array}$ & $\begin{array}{l}\text { Percent by } \\
\text { volume }\end{array}$ & $\begin{array}{l}\text { Percent by } \\
\text { volume }\end{array}$ & $\begin{array}{l}\text { Percent by } \\
\text { volume }\end{array}$ \\
\hline Percent retained, indicated sieve & 0.850 & 20 & -- & 0 & 0 & -- & 1.7 & 0 & 0 & 0 & 0 & 0 & 0 & 0 \\
\hline Percent retained, indicated sieve & 0.600 & 30 & $\leq 0.1$ & 0 & 0 & -- & 2.6 & 0 & 0 & 0 & 0 & 0 & 0 & 0 \\
\hline Percent retained, indicated sieve & 0.425 & 40 & -- & 1.3 & 8.2 & 1.8 & 8.1 & 4.5 & 0 & 3.9 & 4.3 & 0 & 6.4 & 4.2 \\
\hline Percent retained, indicated sieve & 0.355 & 45 & -- & 13.7 & -- & -- & -- & -- & -- & -- & -- & -- & -- & -- \\
\hline Percent retained, indicated sieve & 0.300 & 50 & -- & 32.3 & 54.15 & -- & 24.2 & 40.3 & 0.1 & 40.9 & 45.0 & 0.1 & 49.8 & 43.9 \\
\hline Percent retained, indicated sieve & 0.250 & 60 & -- & 26.3 & 24.75 & -- & 19.8 & 32.0 & 1.9 & 34.0 & 33.2 & 2.2 & 28.3 & 32.5 \\
\hline Percent retained, indicated sieve & 0.212 & 70 & -- & 23.4 & 10.15 & -- & 17.1 & 17.8 & 13.9 & 16.6 & 13.9 & 17.9 & 12.2 & 15.4 \\
\hline Percent retained, indicated sieve & 0.150 & 100 & -- & 2.9 & -- & 0.0 & -- & -- & -- & -- & -- & -- & -- & -- \\
\hline Percent retained, indicated sieve & 0.106 & 140 & $\leq 1.0$ & 0 & 2.65 & $\leq 1.0$ & 25.4 & 5.4 & 81.5 & 4.54 & 3.52 & 78.9 & 3.1 & 4.0 \\
\hline & Total & & -- & 99.9 & 99.9 & 100 & 98.9 & 100 & 97.4 & 100 & 99.9 & 99.1 & 99.8 & 100 \\
\hline Percent composition, indicated size & $40 / 70 \mathrm{~s}$ & size & $\geq 90$ & 95.7 & 89.05 & 98.2 & 60.6 & 90.0 & -- & 91.5 & 92.1 & -- & 90.3 & 91.8 \\
\hline Percent composition, indicated size & $70 / 140$ & size & -- & -- & -- & -- & -- & -- & 81.5 & -- & -- & 78.9 & -- & -- \\
\hline Crush resistance & Stress ap & pplied & & & & & & es component $f$ & lowing crush & & & & & \\
\hline $\begin{array}{c}\text { Test result or statistic } \\
\text { (average value for indicated sample } \\
\text { group) }\end{array}$ & Kilopascals & $\begin{array}{l}\text { Pounds- } \\
\text { force per } \\
\text { square } \\
\text { inch }\end{array}$ & $\begin{array}{l}\text { Percent by } \\
\text { weight }\end{array}$ & $\begin{array}{l}\text { Percent by } \\
\text { weight }\end{array}$ & $\begin{array}{l}\text { Percent by } \\
\text { volume }\end{array}$ & $\begin{array}{l}\text { Percent by } \\
\text { volume }\end{array}$ & $\begin{array}{l}\text { Percent by } \\
\text { volume }\end{array}$ & $\begin{array}{l}\text { Percent by } \\
\text { volume }\end{array}$ & $\begin{array}{l}\text { Percent by } \\
\text { volume }\end{array}$ & $\begin{array}{l}\text { Percent by } \\
\text { volume }\end{array}$ & $\begin{array}{l}\text { Percent by } \\
\text { volume }\end{array}$ & $\begin{array}{l}\text { Percent by } \\
\text { volume }\end{array}$ & $\begin{array}{l}\text { Percent by } \\
\text { volume }\end{array}$ & $\begin{array}{l}\text { Percent by } \\
\text { volume }\end{array}$ \\
\hline Percent composition, indicated test & 34,500 & 5,000 & $\leq 10$ & -- & 9.5 & -- & 11.5 & 11.5 & 7.6 & 9.5 & 8.5 & 3.3 & 11.2 & 11.6 \\
\hline Percent composition, indicated test & 55,200 & 8,000 & $\leq 10$ & 9.6 & -- & -- & -- & -- & -- & -- & -- & -- & -- & -- \\
\hline Percent composition, indicated test & 62,100 & 9,000 & $\leq 10$ & 13.3 & -- & -- & -- & -- & -- & -- & -- & -- & -- & -- \\
\hline $\begin{array}{l}\text { Maximum stress level passed, in mega- } \\
\text { pascals (K-value) }\end{array}$ & -- & -- & ${ }^{4} 13.8-34.5$ & (8k) 55.2 & (5k) 34.5 & (7k) 48.3 & -- & -- & (5k) 34.5 & (5k) 34.5 & (5k) 34.5 & (5k) 34.5 & - & -- \\
\hline $\begin{array}{l}\text { Maximum stress level passed, in pounds- } \\
\text { force per square inch }\end{array}$ & -- & -- & $2,000-5,000$ & 8,000 & 5,000 & ${ }^{5} 7,000$ & -- & -- & 5,000 & 5,000 & 5,000 & 5,000 & -- & -- \\
\hline
\end{tabular}

U.S. Silica (2014).

${ }^{2}$ Preferred Sands (2015b).

${ }^{3}$ Tibor (2014).

${ }^{4}$ Minimum-maximum crush stress-level guidelines for fracture sand classes of proppant (API and others, 2008).

${ }^{5}$ Preferred Sands (2016) lists $7 \mathrm{k}$ as the crush resistance of its 40/70 product, but notes that k-values are subject to variability. 
Minimum specifications do not exist for the mean or median particle diameter, but some documents indicate that a high-strength, premium proppant will have medium to coarse sand-size grains (Benson and Wilson, 2015b). For this study, percentages by volume were provided by the OPSA for each standard particle-size class, along with selected percentiles of the size distribution. These OPSA results were used as input to the GRADISTAT calculations of summary statistics for washed raw material, and OPSA-reported percentiles were used directly for washed raw sediment samples and also for sieved sediment subsamples representing the dominant proppant size class present.

\section{Proppant Shape}

Useful properties for characterizing new sources of frac sand include two parameters of particle shape-roundness and sphericity. Proppant materials should be a wellsorted mix of rounded or nearly round sand grains and grains that are spherical or nearly spherical (American Petroleum Institute and others, 2008; Zdunczyk, 2013). Grain shape specifications were based on the index developed by Krumbein and Sloss (1963), in which the API-recommended values for roundness and sphericity of frac sand must equal or exceed 0.6 dimensionless units; however, some authors (Anderson, 2011; Bennetts, 2013) indicated that high-strength proppants are recommended to have sphericity and roundness values of 0.7 or greater. When grains are well-rounded and nearly spherical, porosity through the proppant-filled fracture will be maximized and the hydrocarbons allowed to flow freely.

Sphericity corresponds to how well a particle shape compares with a sphere (American Petroleum Institute and others, 2008) and thus is concerned with basic particle shape. Additionally, a resin-coated sphere gains some deformability that increases the contact area between grains and decreases the density of closure stress (Reinicke and others, 2010a). By contrast, roundness is independent of basic shape and depends only on the sharpness of edges and corners (Powers, 1953). At least two scales used to classify particle roundness use a "rounded" grade for roundness scores from about 0.50 to 0.70 , and particles scoring above 0.70 are graded as "well-rounded" (Powers, 1953).

Proppant shape, in combination with particle size, has implications for considerations beyond hydraulic conductivity. Mobility or transportability within the fracture are an important consideration that favors smaller particles (Reinicke and others, 2010b). Frac sand grains need to roll deep into the finest fractures commensurate with their size. A resin coating on proppant typically improves roundness and allows grains to adhere to one another, thereby resisting being backwashed out of the fractures when the fracking fluid is backflushed. Uniformity of proppant shape also affects the stress distribution within the proppant particles packing a fracture.

\section{Proppant Strength}

Proppant strength affects the ultimate fracture permeability and is viewed as the most important mechanical proppant property (Tibor, 2014) because proppant strength directly relates to closure stress, or fracture-closure pressure, which is defined as the pressure that closes the fracture after the hydraulic fracturing pressure is relieved (Holditch, 2007). After proppant is pumped into fractures, closure stress typically subjects proppant to pressures of $27.6 \mathrm{MPa}(4,000 \mathrm{lbf} /$ $\mathrm{in}^{2}$ ) or more (Zdunczyk, 2013). If the closure stress of the fracture exceeds the compressive strength of the proppant, the proppant grains will be crushed (Houseworth, 2014) and resulting small debris (fines) will fill intergranular pore spaces. Proppant disintegration diminishes the effective proppant size and consequently lowers the permeability of the fracture.

Reinicke and others (2010b) classified proppants with respect to their strength and noted that each type was available with resin coating. Natural sands (frac sand) are the weakest class, suitable for applications where closure stress is less than $40 \mathrm{MPa}$. Intermediate-strength proppants include fused ceramic or sintered bauxite spheres, suited to closure stresses between 30 and $65 \mathrm{MPa}$. High-strength proppants (sintered bauxite) are needed for closure stresses exceeding $65 \mathrm{MPa}$ (Reinicke and others, 2010b).

Crush-resistance tests were used to assess the relative strength of standard size-class sediment subsamples of the sand deposits sampled for this study; therefore, only the material isolated as the dominant size-class sediment subsample is being referenced in this and other sections of this report that deal with crush-resistance testing or test results.

The API minimum guidelines (American Petroleum Institute and others, 2008, p. 26) specify testing sand proppants at crush-stress levels from 13.8 to $34.5 \mathrm{MPa}$ and reporting of the proppant type, size designation, crush-stress level, and percentage crushed; however, the guidelines indicate intent to revise the selection of pressures to a determination of the stress level at which 10-percent fines are generated. Crush resistance was tested for this study using a single crush-stress level at $34.5 \mathrm{MPa}\left(5,000 \mathrm{lbf} / \mathrm{in}^{2}\right)$. The American Petroleum Institute and others (2008, p. 24) description of the crushresistance test further stipulates that tests are to use proppant samples that have been sieved such that "all particles tested are within the specified size range." However, recognizing the apparent bias in the sieving of samples for this study (see "Quality Assurance and Quality Control" section) led to a modification in assessing the results from crush tests of environmental exploratory samples tested with a procedure designed for finished proppants. The following two test outcomes were evaluated as thresholds for potential passage of the crush test:

1. First, if the percent finer than the second primary sieve (that is, finer than the U.S. Number 70 mesh for a proppant of API 40/70 size) is less than 10 percent of the tested mass undergoing the crush test, the sediment 
sample was designated for this study as passing the "fines-percentage threshold."

2. The second threshold, or "fines relative-increase threshold," was defined by presuming that all samples from an operational frac sand supplier would be sieved to tolerances such that no more than 5.5 percent of tested material would be finer than the specified size range (that is, such material is defined as "fines" even before undergoing the crush test). Consequently, the threshold of allowable proportional increase for a sample that had 5.5-percent fines prior to crush testing was determined by a simple calculation to be an allowable 80 -percent increase of the fines percentage. (Because 10 percent is 81.8 percent larger than 5.5 percent, an 80 -percent increase in fines allows passage of the crush test at less than 10 -percent fines composition.)

In addition to the API guidance, some in the proppant industry have suggested more stringent criteria for evaluation of crush resistance. For example, Bennetts (2013) indicated that the fines-percentage threshold should vary with mesh size. Accordingly, when using the stringent criteria, the maximum acceptable percentage of fines following the crush test is 10 percent for the API 30/50 size class, 8 percent for API 40/70 size class, and 6 percent for API 70/140 size class.

\section{Bulk Density}

Bulk density describes the mass of proppant that fills a unit volume that includes proppant and porosity (American Petroleum Institute and others, 2008). Bulk density is an important physical property of frac sand because bulk density determines the mass of a proppant needed to fill a fracture, rail car, or storage tank of nominal volume.

No standard numerical criteria exist for bulk density of proppants; rather, this property was used by the laboratory in determining the mass of proppant material needed for each crush-resistance test (American Petroleum Institute and others, 2008). However, bulk density values that are similar to those for high-purity silica sand indicate a sample having high quartz content (Benson and Wilson, 2015b).

\section{Transportation Considerations}

Since 2012, several new producers of frac sand have begun operations and former producers have opened operations at new locations. Trucks are the primary mode used by these new mines to transport raw material from mine sites to processing plants (Zdunczyk, 2013). Most processing plants are located where rail facilities are located, but for some plants, trucks are used to transport the finished product to a rail terminal (Zdunczyk, 2013). Air emissions of particulate matter are a common environmental issue faced by mines or plants where truck traffic is heavy, and this traffic generates many of the complaints involving new mines (Zdunczyk, 2013).

Although railway service was available in the study area historically, railway service is not available at the present time (2017). For example, by 1882 the rails had connected Running Water, S. Dak., to Springfield, S. Dak., and thence to main lines farther northeast (Chicago and North Western Railway, 1882). Parts of the former railroad infrastructure, such as concrete box culverts, still stand along the former route on the bottomland east of Running Water, but the aggrading delta has made that exact route too wet for modern use. On the Nebraska side, Niobrara was connected from the south in 1901 (Houston, 1938), and although the old railroad bridge across the Niobrara River still serves to connect recreational foot paths, the rails have long been gone. To assess the feasibility of redeveloping rail transportation infrastructure in the study area is beyond the scope of this study.

The closest commercial-navigation waterway ends at rkm 1,181 (river mile 734) of the Missouri River, $175 \mathrm{~km}$ downstream from the Missouri River delta study reach. Generally shallow channels, numerous sandbars and shoals in primary channels, and especially the lack of a passage at the Gavins Point Dam prevent barge transportation of sand products without first trucking to a terminal downstream from the dam.

\section{Other Considerations}

A particular health and workplace safety concern that has been prominent in the industrial sand industry for decades is respirable airborne silica (Zdunczyk, 2013). Silica dust is emitted during mining, processing, transport, and transfer of frac sand. About three-fourths of sampled airborne silica dust was between 0.5 and 5 microns in size, and respirable dust includes sizes up to 10 microns (Esswein and others, 2013). Inhalation of fine, crystalline silica particles can cause silicosis, lung cancer, and other disorders (Esswein and others, 2013). None of the data collected for this study, however, are useful for addressing possible unsuitability of the sampled sediment as proppant based on potential for airborne dust emission because the sample preparation wash removed nearly all of the fine dust. Moreover, the finest size class analyzed (finer than $0.106 \mathrm{~mm}$ ) includes larger particles - up to one order of magnitude larger - than the reported maximum size of respirable dust.

Specifications such as acid solubility and turbidity are somewhat less important than particle size, shape, strength, and mineralogy (Zdunczyk, 2013). Carbonates in the sand had little effect on fracking operations in 2015, although in previous periods more acidic chemicals were used and carbonate content of frac sand was a concern to the extent that carbonate would dilute the performance of such chemicals (Zdunczyk, 2013). Washing the proppant-mine output at the processing plant using attrition cells that scour particles to liberate clays can resolve turbidity (Zdunczyk, 2013). On the basis of these considerations, no data were collected for acid solubility and turbidity characteristics of the samples collected for this study. 


\section{Quality Assurance and Quality Control}

As a reconnaissance-level pilot study, limited quality assurance was implemented, consisting of replication of field sampling at a 10-percent minimum rate, interlaboratory/intermethod comparison of PSD for six of the upstream sediment samples, cross verification of the delivered tables of laboratory results, and exploratory data analysis.

All of the direct-push cores were collected in duplicate to provide sufficient sediment sample mass for any thin-lens deposits targeted for sampling and to allow replicate sediment samples to be collected from paired-replicate cores. Of the 71 sediment samples collected from the direct-push cores in the Missouri River delta, 7 were replicate sediment samples collected from the replicate core, paired with a primary-core sediment sample (table 2 ). The replicate pair presumably came from the same sedimentary facies.

Except where otherwise noted, replicate sediment samples collected at sites along the lower Niobrara River were collected using the same sampling method at a point $1 \mathrm{~m}$ from the paired primary sampling location. Of the 30 OPSA-analyzed sediment samples collected from lower Niobrara River sand deposits (table 1), 4 were field-replicate sediment sample pairs from within the same vertical layer of a sand deposit. In addition, two pairs of sediment samples (NR-01 and NR-49) provide some insight on within-deposit variability. Both of these pairs were collected with different sampled thicknesses; moreover, one pair (NR-49-A and NR-49-B) was collected about $2 \mathrm{~m}$ apart, at points where the land surface was about $10 \mathrm{~cm}$ different in height. Consequently, neither of the sediment sample pairs collected at NR-01 or NR-49 were included when estimating the uncertainty associated with sampling imprecision.

\section{Methods for Interlaboratory Comparison}

Interlaboratory comparisons were made on the basis of PSD for six sediment samples, but recognizing that the laboratories used different technologies for particle-size analysis and that sediment samples were prepared differently in advance of PSD measurement. The API recommendations for proppant testing (American Petroleum Institute and others, 2008) allow use of particle-size methods other than by standard sieve analysis, provided that the alternate methods are correlated with the standard sieving methods. The six interlaboratory-comparison sediment samples were sent first to the USGS Iowa Sediment Laboratory (ISL) at Iowa City, Iowa, and analyzed using a standard dry sieve analysis (Guy, 1969) that resulted in size-class percentages finer than each of 10 particle-diameter (sieve) sizes, ranging from 0.0625 to $31.5 \mathrm{~mm}$. Each of these six sediment samples was recombined and returned to the authors, who then submitted them with the other field sediment samples for analyses at Montana Tech's PRG, including measurement of the PSD by the OPSA method.

Ideally, both laboratories would have analyzed the whole raw sediment sample so that analytical technology would be the only variable other than laboratory. As noted in the
"Laboratory Methods" section, however, the sediment sample preparation procedure followed by the PRG (and consistent with standard testing of frac sand) involved washing the sediment sample prior to measuring the PSD. The PRG weighed sediment samples before and after the washing, and these data along with the OPSA and sieve results allowed a reconstruction of the prewash PSD to be attempted. Also for an ideal comparison, quality-assurance data would document the quality of the benchmark sediment samples for the full range of particle sizes involved in the study. As the following summary of those quality-assurance data indicates, most of the available data pertain to the sizes finer than sand.

\section{Quality Assurance for U.S. Geological Survey Laboratory}

The data collected for the USGS quality-assurance studies of 2015 (U.S. Geological Survey, Branch of Quality Systems, 2014, 2015) did not include PSD results for sizes coarser than $0.031 \mathrm{~mm}$ except for the percent sand. Sand content in the reference samples analyzed for PSD by ISL for the respective quality-assurance studies was $0.62 \mathrm{~g}$ (13.0 percent) in 2014 study $2,0.21 \mathrm{~g}$ (4.8 percent) in 2015 study 1 , and $0.40 \mathrm{~g}$ (9.1 percent) in 2015 study 2 . The percent difference (PD; the deviation of measured value from actual value for the reference sample, expressed as a percentage of the actual value) for the percent-sand value averaged 4.0 percent for nine samples analyzed by the USGS ISL. For the percent by weight finer than $0.031 \mathrm{~mm}$, the actual value was not reported; however, the median value determined among all laboratories participating in each study is herein assumed to represent the probable actual value. The median absolute PD of nine USGS ISL analyses was 2.5 percent of the probable actual value, and mean PD was -1.0 percent. Also for percent finer than $0.031 \mathrm{~mm}$, the ISL's precision was indicated by the relative standard deviation (RSD; the ratio of standard deviation among repeated measures to the mean value) and F-pseudosigma ( $F p s$; a nonparametric approximation of the standard deviation of traditional statistics when the frequency distribution of the data is Gaussian). The Fps, which has units of the summarized variable, in this case percent finer than $0.031 \mathrm{~mm}$, averaged 1.4 percent for the three studies. The RSD for the three quality-control studies (three samples per study) in 2014-15 averaged 2.7 percent and was within 1.2, 2.3, and 0.3 percentage points, respectively, of the median RSD for all labs participating in each study.

Despite the small sample mass of the analyzed reference samples, the small uncertainty and negligible bias indicated by these results for percent sand and for the PSD of coarse silt allow modest confidence in this laboratory's reliability. Gordon and others (2000), reporting earlier USGS qualityassurance studies, stated that the laboratory-median relative percent difference (RPD) for sand-size material mass was the most variable physical sediment property measured, ranging up to 26.4 percent; however, most USGS laboratories participating in Gordon and others (2000) had median RPD no greater than 3 percent of actual sand-size material mass. Later 
USGS quality-assurance studies (U.S. Geological Survey, Branch of Quality Systems, 2015) continued to include results for determinations of mass of sand-size material in sediment mixtures containing sand, silt, and clay. For the two USGS quality-assurance studies of 2015, the USGS ISL had precision within 2.6 percent of actual sand mass for at least seven of nine blind sediment samples per study and an overall average precision within 2.0 percent of the actual sand mass. As a measure of bias, the USGS ISL's 2015 median RPD of the sand-size mass determinations was 0.17 percent larger than the actual value, and the 25 th through 75 th percentiles of RPD only ranged from -0.08 to 0.66 percent. Sieve results from 2015 for the USGS ISL generally are reliable for use as the standard for interlaboratory comparison; however, as with all environmental data, the USGS sediment data can be expected to contain some errors larger than the averages, as indicated by the maximum RPD among the individual sand-size mass determinations by the USGS ISL for the two USGS qualityassurance studies of 2015-6.6 and 10.1 percent, respectively.

\section{Quantification for Interlaboratory Comparison}

Interlaboratory comparisons were made for several statistics of the PSD - mean and median particle sizes, compositional percentage in each of four standard sand-size fractions and each of two API proppant-size classes, and at the 10th and 90th percentiles of the empirical cumulative-frequency distribution (ECFD). The OPSA and dry-sieving methods did not report percentages for a common set of particle sizes, with the exception of $0.25 \mathrm{~mm}$. Thus, the results from both laboratories were processed using the GRADISTAT spreadsheet tool (Blott and Pye, 2001; Blott, 2010) to estimate the values of the tested statistics, with the following exception. To estimate percentage composition in each of the two API proppant-size classes, the PSD results from dry sieving were plotted as ECFDs in logprobability graph space and percentages finer than the standard sieve sizes for proppant (American Petroleum Institute and others, 2008) were visually interpolated from the plotted ECFDs (figs. $6 A-C$ ).

To quantify the interlaboratory comparisons, correlation strength was measured using two of the three correlation coefficients in common use (Helsel and Hirsch, 2002). Pearson's product-moment correlation coefficient $(R)$ is a measure of linear correlation, whereas Kendall's rank-correlation coefficient (tau) measures all monotonic associations, including nonlinear relations. As a nonparametric statistic, tau is resistant to effects of outliers and more suitable for small or skewed datasets; however, tau will take on lower values than Pearson's $R$ for linear associations of the same strength. In addition, the PD (American Petroleum Institute and others, 2008) was calculated for corresponding statistics of the six pairs of PSDs. Because of the conventional usage and advantages of Krumbein's (1938) phi scale for analysis of sediment size, which typically is log-normally distributed, correlation and PD were computed using sizes logarithmically transformed to the phi scale.

\section{Uncertainty Estimates from Sampling Replicates}

Overall median RPD summarized across 11 pairs of replicate sediment samples was not greater than 3.4 percent for 6 summary statistics of particle size and shape - that is, 3 percentiles and the mean for particle size, and 2 summary indices of particle shape (table 4, available for download as a Microsoft Excel ${ }^{\circledR}$ file at https://doi.org/10.3133/sir20175105). For upstream source sediment samples, quality-control results for the four pairs of sampling replicates that were collected using an identical sampling method at a sample-separation distance of $1 \mathrm{~m}$ (table 4) produced a median RPD of less than 15 percent for all calculated points of the cumulative PSD between 0.106 and $1.18 \mathrm{~mm}$, and the median RPD was no more than 5 percent for summary statistics of particle size and shape listed in table 4 (that is, the aforementioned six summary statistics plus standard deviation of particle size). However, the median RPD for percent finer than $0.106 \mathrm{~mm}$ was 24 percent, but this fraction of the PSD was depleted by the sample-preparation wash and contained no more than 1.7 percent of the sample volume for any of the replicate sediment samples.

For Missouri River delta direct-push cores, results for the seven pairs of replicate sediment samples (table 4) produced a median RPD of 14 percent or less for all calculated points of the cumulative PSD between 0.106 and $1.18 \mathrm{~mm}$, and median RPD was less than 8 percent for all summary statistics of particle size and shape, except standard deviation, as listed in table 4 . The RPD of 14 percent for standard deviation of particle size is indicative of inherently greater spatial variability in coarseness of the sediment deposits in the delta environment relative to the well-sorted riverbed sediment in sandbars of the lower Niobrara River. The median RPD for percent finer than $0.106 \mathrm{~mm}$ was 18 percent, but again, this fraction of the PSD was depleted by the sample-preparation wash, and no more than 1.2 percent of the sample volume was of this size class for any of these seven pairs of replicate sediment samples. For individual pairs of replicate sediment samples, RPDs tended to be less than 30 percent for size classes that contained at least 10 percent of sample volume, but RPD increased substantially for infrequent particle-size classes.

Only one sediment sample pair was submitted for laboratory analyses for which spatial variability should not have been a contributor to the RPD, but sampling error still was associated because the sediment samples were not collected using a sediment-splitting apparatus. These replicate sediment subsamples came from a single 19-liter bulk sediment sample of the Preferred Sands of Genoa (PSG) mine output and were obtained as cores from a cylindrical bucket after the contents had been stirred thoroughly prior to collection of each sediment sample. The RPD results for the PSD of this replicate pair was within the range of those for the other sampling replicates collected from environmental sediment samples (table 4).

These results are similar to the quality-control results for replicate sandbar samples collected by previous USGS studies in Nebraska. Schaepe and Alexander $(2011$, p. 8) reported the 

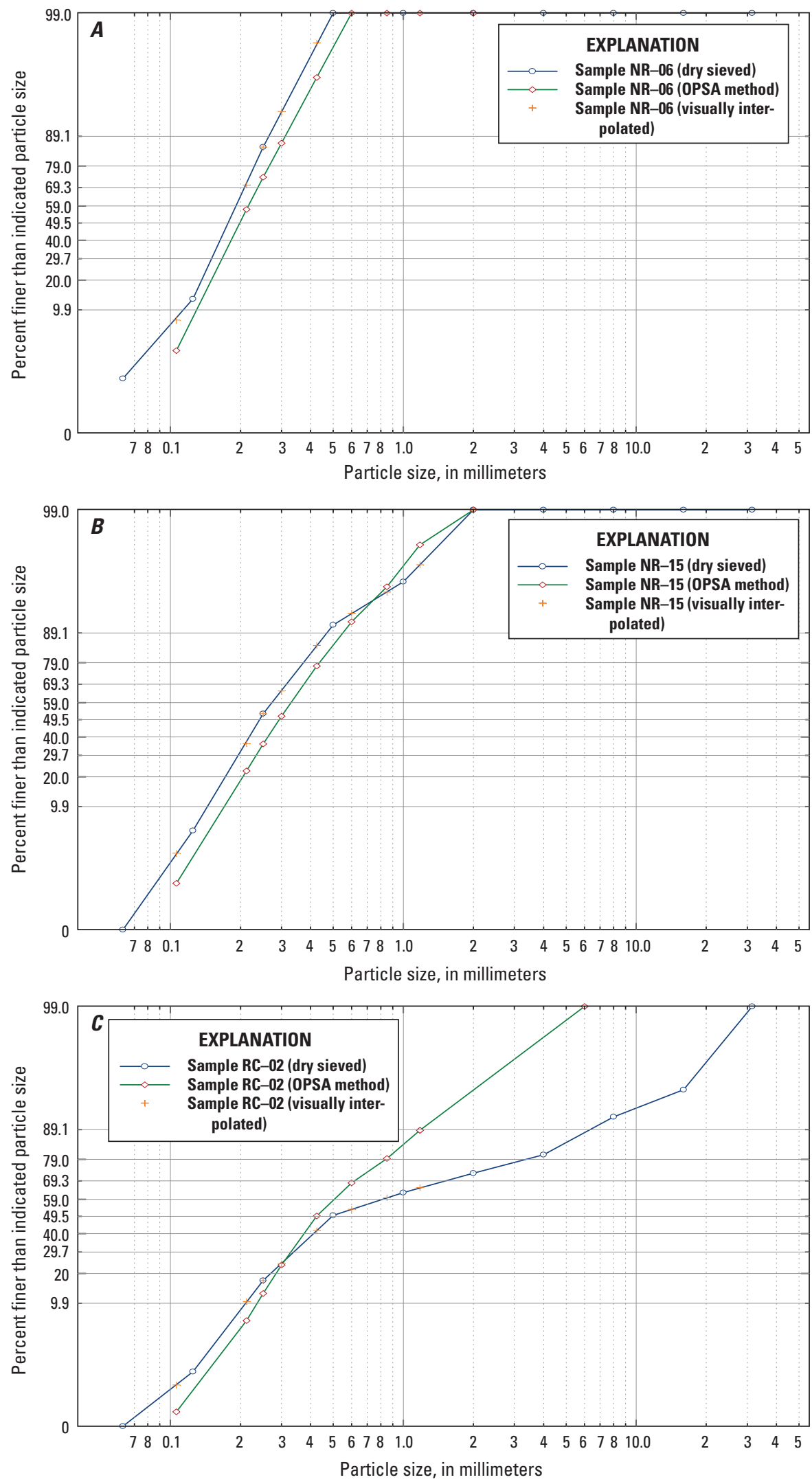

Figure 6. Particle-size distribution of selected sediment samples included in interlaboratory-comparison set showing results from dry-sieve method and optical imaging particle-size analyzer (OPSA; Camsizer ${ }^{\circledR}$ XT) method for sediment samples collected late May 2015 at Niobrara River sites, Nebraska. $A$, upstream from Eagle Creek (sample NR-06); $B$, upstream from Pischelville Bridge (sample NR-15); and C, Redbird Creek at county road 501st Avenue near Redbird (sample RC-02). 
following: "Except for the finest sieve size, the results for all samples were within 17 percent of the overall mean percentage finer than each indicated grain size, and variability was less than 6 percent for grain size of $0.5 \mathrm{~mm}$ or larger." Alexander and Schaepe (2014, p. 52) reported that root-mean-squared difference between replicates averaged less than 13 percent for sandbar samples and 7.5 percent for other streambed samples. Imprecision associated with sampling error in this study averaged 10 percent or less, and RPD between paired replicate results generally was less than 14 percent for size classes that contained more than 30 percent of sample volume (table 4); however, RPDs increased substantially for particle-size classes consisting of small parts of a sediment sample (generally less than 6 percent), with such classes being confined to the tails of the sample particle-size frequency distribution.

\section{Uncertainty Estimates from Interlaboratory Comparisons}

Mean size (as opposed to median size) was recommended by American Petroleum Institute and others (2008, p. 8) as the standard metric for characterizing the PSD of a proppant. Shown in figure $7 A$, the mean size determined by each laboratory was similar for five interlaboratory-sample pairs, with the plotted points near the line of equality (one-to-one line) and PD less than 14 percent. For the sixth, coarsest sediment sample (RC-02 from Redbird Creek), results were dissimilar although for the reconstructed prewash PSD the underestimation of mean size by the OPSA was less pronounced. Median absolute percent difference (MAPD) between the OPSA-based and dry-sieve-based mean sizes was 6.6 percent using the OPSA results for washed sediment samples. The mean sizes determined by each laboratory (table 5) were highly correlated ( $\operatorname{tau}=1.0, n=6, R=0.961, p=0.0023)$ when using the OPSA results for washed sediment samples. The attempt to reconstruct the prewash PSD resulted in better agreement (MAPD was 5.3 percent; five of six samples had RPD less than 10 percent) and a slightly stronger linear correlation $(R=0.981$, $p=0.0006)$. A threshold RPD of 10 percent was recommended by American Petroleum Institute and others (2008, p. 11), above which the difference between sieve sets (but herein, differences between laboratories and methods) would need to be considered when comparing and interpreting results.

Results of interlaboratory comparisons for the selected percentiles of the PSD are listed in table 5 (available for download as a Microsoft Excel ${ }^{\circledR}$ file at https://doi.org/10.3133/ sir20175105). Although the MAPD for the median size $\left(D_{50}\right)$ was 10.8 percent in the comparison with OPSA results from washed sediment samples, when the comparison was repeated using the reconstructed prewash PSD, the result improved such that all three percentiles had MAPD less than 7 percent. Given the disparate sample preparation and that the OPSA was never calibrated to the USGS ISL's sieve set, the typically modest difference in mean sizes and percentiles determined between OPSA-based methods and those from sieve-based results are within accepted limits; thus, interlaboratory sources of imprecision were not of further concern for this study. However, any potential bias would not be revealed by either correlation coefficients or absolute values of differences.

Interlaboratory comparison for relative composition in the API 40/70 size class again indicated a strong correlation between the two laboratories and methods ( $\operatorname{tau}=1.0$, $n=6, R=0.899, p=0.0147)$, with a linear relation indicated by the scatterplot (fig. $7 B$ ). But a sizable bias also is evident in the relation, with all six of the PD results being positive values for washed sediment samples, as well as for five of the reconstructed prewash PSDs, with median PD for the reconstructed PSD indicating a 19-percent positive bias. To better understand the bias, consider next the results for a similar variable, the sample percentage in the API 70/140 size class (fig. 7C). The bias consistently was in the opposite direction in the API 70/140 size class, with PD of all samples indicating underestimation greater than 15 percent for the OPSA results for washed sediment samples (table 5). When results for both size classes were considered together, the OPSA-based results underestimated the corresponding statistical result from dry sieving for measures of the fine sand class (percent API $70 / 140$, percent fine sand), but for size classes coarser than $0.25 \mathrm{~mm}$ (medium to coarse sand or API 40/70), either the PD magnitude was less than 5 percent or the bias was positive. The attempted reconstruction of prewash PSD failed to correct the negative bias of the fine sand class, which indicates that the washing procedure could have removed material from that size class and then the numerical attempt at reconstruction could have added it back to the "finer than $0.106 \mathrm{~mm}$ " size class (assuming that the washed-out material was of typical "wash load" sizes); this addition would have produced a positive bias in the very fine sand class (not shown). In future exploratory studies of potential sources of natural-sand proppant, developing a standard sample washing procedure or more specific guidance on preventing the loss of fine sand during the washing procedure may be useful.

The mass removed during the washing procedure at the PRG laboratory ranged from 1.7 to 30.3 percent among the interlaboratory sediment samples. The percentage mass removal was similar to that reported by Anderson (2011) for 10 North Dakota sediment samples (4.1-30 percent loss) but was not correlated significantly with the PD between labs in either the API 70/140 size class or percent of sample finer than 0.25 or $0.212 \mathrm{~mm}$ ( $\operatorname{tau}=-0.2, n=6, p$ greater than 0.5$)$, chiefly because of one Niobrara River sandbar sample (NR15 ) in which only 4 percent of mass was lost during the wash.

A second factor to recognize is that the OPSA was calibrated to the set of sieves used at the PRG laboratory and not to the sieves used at the USGS ISL. Sieves will vary slightly from their nominal mesh-opening size (ASTM International, 2004, p. 2), and the variance typically increases with repeated use over time. Quantification of the differing variances from a standard mesh that might characterize the sieves in use at the two laboratories was beyond the scope of this study, but such differences are a possible source of bias in the interlaboratory results. 

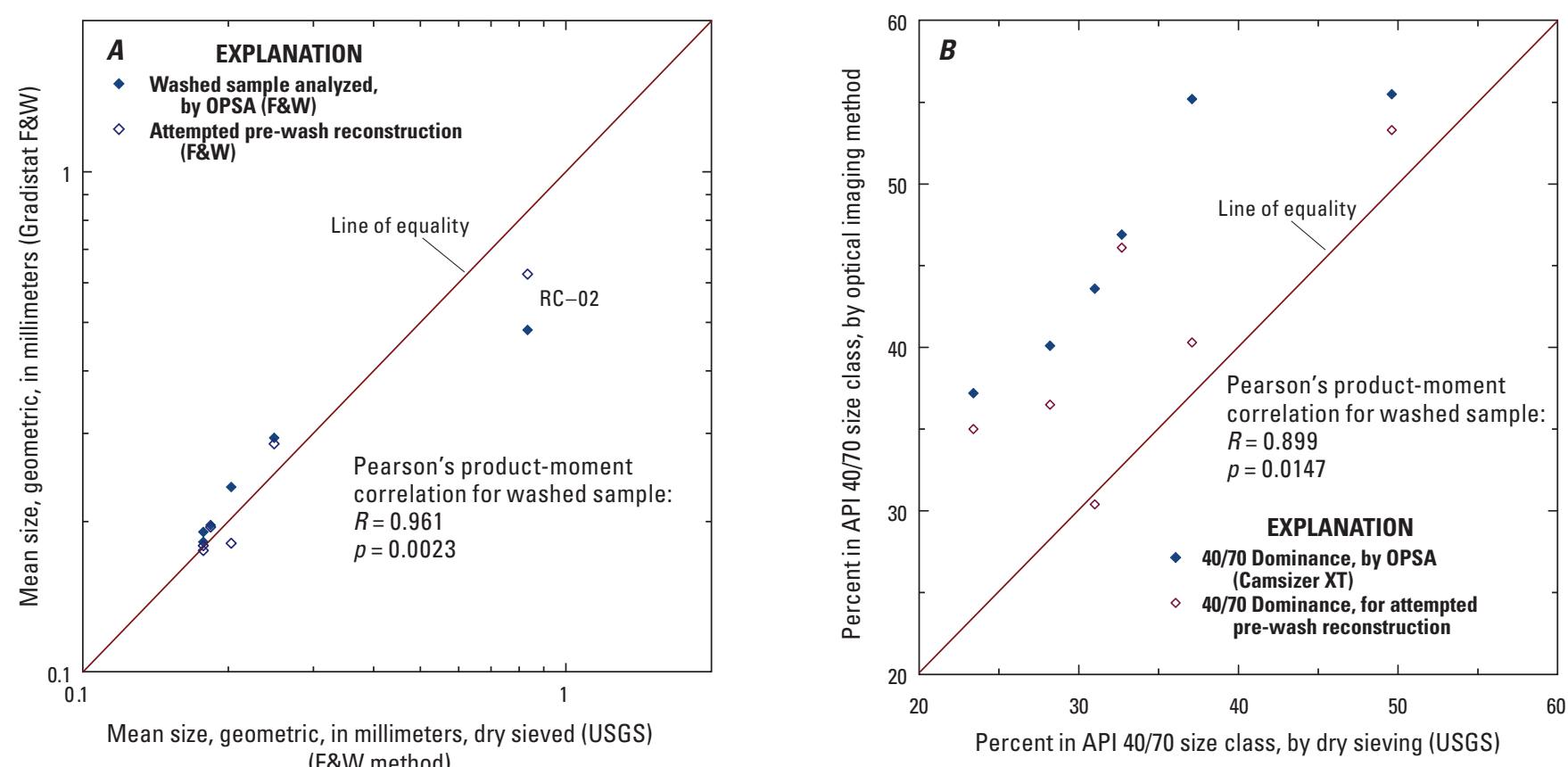

(F\&W method)

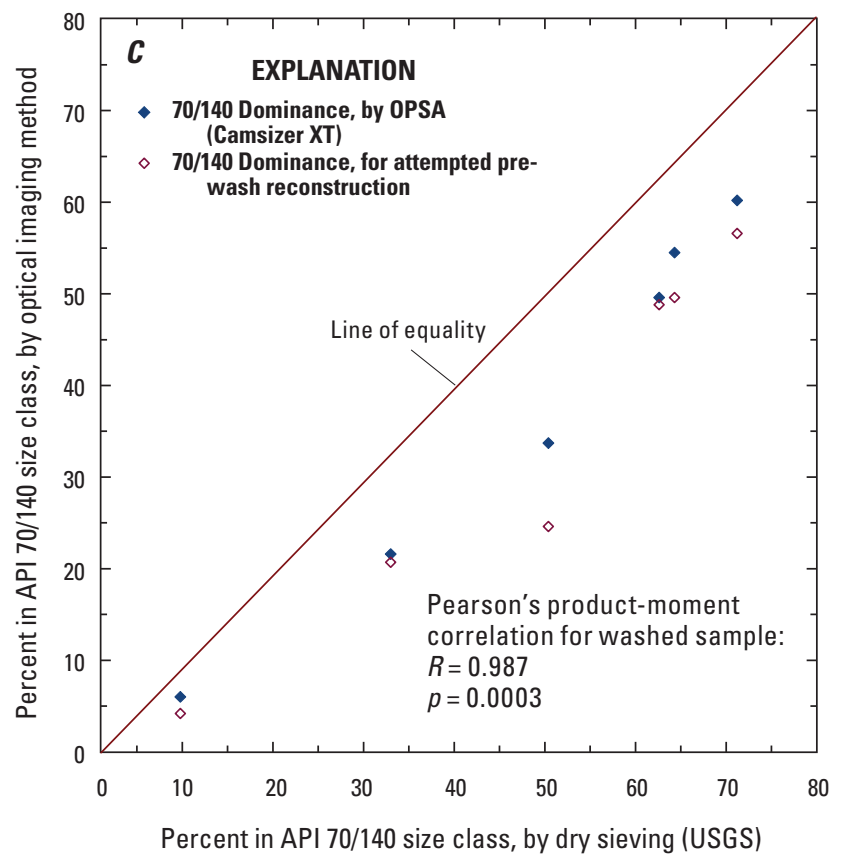

F\&W, Folk and Ward (1957) method implemented in GRADISTAT; USGS, U.S. Geological Survey method (Guy, 1969);

OPSA, optical imaging particle-size analyzer;

$R$, correlation coefficient;

API, American Petroleum Institute

Figure 7. Results of interlaboratory comparison between dry-sieved whole sediment samples analyzed at U.S. Geological Survey lowa Sediment Laboratory and washed sediment samples analyzed by optical imaging particle-size analyzer (OPSA; Camsizer ${ }^{\circledR}$ XT) method at Montana Tech. $A$, mean particle size; $B$, sample percentage in American Petroleum Institute 40/70 size class; $C$, sample percentage in American Petroleum Institute 70/140 size class. 
A third factor that might relate to bias in the interlaboratory differences involves differing resolutions of the particlesize classifications used by each laboratory. The standard size-classification system used for evaluating sand-size proppants (American Petroleum Institute and others, 2008) has more classes (that is, finer resolution) within the sand range of particle size (0.625-2 mm; Wentworth, 1922) than does the system (set of sieves) routinely used by USGS sediment laboratories for analyzing streambed samples. For five of the six interlaboratory samples, $61-88$ percent of the whole sample was in the size range between 0.125 and $0.30 \mathrm{~mm}$. Three standard proppant-size classes partly overlap the $0.125-0.30-\mathrm{mm}$ class: the 40/60, 40/70, and 70/140 sizes. Only two of the routine USGS bed-material size classes overlap this size range, and the single size class of $0.125-0.25 \mathrm{~mm}$ contained at least 64 percent of sample mass from four of the six interlaboratorycomparison samples.

The interlaboratory results for the six sediment samples indicated a substantial bias. This bias is not surprising given the differences in sample-preparation procedures, size classifications, and analytical technology (OPSA as compared to sieving). The environmental data analysis reported herein used the OPSA results from washed sediment samples because the paucity of dry-sieved results precluded attempted reconstructions of whole sediment samples; however, the raw, whole sediment samples likely were more enriched in fine sand than what OPSA results indicate.

\section{Other Quality-Assurance Review and Exploratory Data Analyses}

The mass of material removed during sample preparation was calculated as the percentage loss during the washing/sieving process. For the river delta samples, 1.3 to 42.4 percent of sample mass was removed during sample preparation of 69 samples, with an average loss of 10.8 percent (table $6 \mathrm{~A}$, available for download as a Microsoft Excel ${ }^{\circledR}$ file at https:// doi.org/10.3133/sir20175105). The overall average amount of mass removed was somewhat more than the average 9.3 percent reported for 10 sediment samples of North Dakota sands (Anderson, 2011), and the range of percent removal also was larger in this study than in the North Dakota study; however, a standard practice for the sample-preparation wash is not available. The largest percent removal in the Anderson (2011) study (30 percent) was for a sediment sample of an eolian sand dune that was finer than the material sampled for this study.

Of 28 sediment samples of sand sources along the lower Niobrara valley in which the 40/70 size class was dominant, the PSD results (presented in the "Suitability Assessment of Upstream Sources" section) indicated that nearly all (25) sediment samples did exceed 90-percent homogeneity in the 40/70 size class; moreover, average composition was 4.8 percent coarser than the U.S. No. 40 mesh size and 4.1 percent finer than the U.S. No. 70 mesh size. However, eight sediment samples (29 percent) had more than 5-percent fines (particles smaller than U.S. No. 70 mesh size). Of these eight sediment samples with an enriched level of fines before the crush test, two sediment samples had a size gradation that did not achieve a quality-control objective as a $40 / 70$ product ( 90 -percent homogeneity requirement). Those two sediment samples were reprocessed by the PRG laboratory to repeat the dry-sieving step to isolate the sediment subsample and repeat the crush test. One of the reprocessed sediment samples achieved the quality-control objective (SP-04-012-rerun) but the other sediment sample did not (SP-05-rerun achieved only 88.3-percent homogeneity). Thus, one sample (3.6 percent) of the size $40 / 70$ sediment subsamples from upstream sand sources that was tested for sphericity, roundness, and crush resistance had dominant size-class composition of less than 90 percent. Of the 50 regular samples from the Missouri River delta in which the 40/70 size class dominated, 32 (64 percent) samples met or exceeded 90-percent homogeneity in the 40/70 size class, and the remainder had at least 85 -percent dominance by the $40 / 70$ size class.

\section{Suitability Assessment of River Delta Sediment}

In this section of the report, the physical suitability of the river delta sediment samples for use as proppant is characterized on the basis of lithologic descriptions and results from measurements and tests at the Montana Tech PRG laboratory. A summary of the physical characteristics of all sediment samples is described followed by a comparison of characteristics between the four sandbar complexes. Further detail is given in subsections that describe the two most dominant API sizes classes - 40/70 and 70/140. The "Surface-Geophysical Reconnaissance" section describes the comparisons between the delta sediment samples and the CC resistivity profiles. Attempts were made to examine the vertical heterogeneity and estimate the marketable fraction of proppant within each sandbar complex.

\section{River Delta Sediment}

Of the 25 paired direct-push sediment cores, one core from each pair of cores was lithologically described. The sediment grain size, sorting, roundness of sand grains, Munsell color (Munsell Color, 1992), and presence of organic material or plant debris within each interval is tabulated in Hall and Hobza (2017). The presumed "best" sediment samples were chosen based on lithologic characteristics including roundness of grains, sorting, and appearance, which indicate only minor presence of sediments finer than sand. Generally, core intervals that were well sorted, had rounded grains, and were relatively free of fine-grained or organic matter were selected. A total of 71 sediment samples were selected for further analysis from the 25 paired direct-push delta sediment cores collected in the 
Missouri River delta (table 2). Results from selected laboratory analyses of each sample are listed in table 6 , available for download as a Microsoft Excel@ file at https://doi.org/10.3133/ sir20175105. The following is a summary of the analytical results.

From PSDs of the bulk washed sediment samples, the geometric mean size averaged $0.27 \mathrm{~mm}, 80$ percent of the sediment samples were predominantly sand in the API 40/70 size class, and 17 percent were predominantly sand in the API $70 / 140$ size class. Of the two remaining sediment samples, one each predominantly was in the API 20/40 and 30/50 size classes. For the 57 river delta sediment samples where a 40/70-size sand was dominant, an average 62 percent of the tested sample was in the dominant-size class. For the $12 \mathrm{sam}-$ ples where the 70/140 size was dominant, the average percentage of sediment within the dominant-size class was 72 percent.

Particle shape and crush resistance were measured using the sieved fraction corresponding to the dominant-size class of the washed sediment sample. American Petroleum Institute and others (2008) recommend that a minimum 90 percent of a tested proppant consist of particles within the nominal size class, meaning that for 40/70-sized sand, 90 percent would be finer than the first primary sieve (No. 40 sieve) but coarser than the second primary sieve (No. 70 sieve). For particle shape, all sediment samples surpassed the recommended minimum value of 0.6 units for sphericity and roundness, as measured by the OPSA using the Krumbein-Sloss scale (fig. 8). For proppant strength, crush resistance was tested at a predetermined level of stress ( $34.5 \mathrm{MPa}$, or $\left.5,000 \mathrm{lbf} / \mathrm{in}^{2}\right)$. To meet the American Petroleum Institute and others (2008) recommended minimum requirement, not more than 10 percent of the tested sample should be finer than the second primary sieve after the stress test. But for a natural sand proppant of API $40 / 70$ size tested for crush resistance at the $34.5-\mathrm{MPa}$ stress level, some industry experts (Bennetts, 2013; Zdunczyk, 2013) recommended that not more than 8-percent fines are generated and, for API 70/140 size, that not more than 6-percent fines are generated. Of 57 tested sediment samples of 40/70-sized sand, 23 (40 percent) passed the minimum criterion at $34.5 \mathrm{MPa}\left(5,000 \mathrm{lbf} / \mathrm{in}^{2}\right)$ but only 7 passed the more stringent criterion. Of 12 tested sediment samples of 70/140sized sand, 8 (67 percent) passed the API-recommended minimum criterion at $34.5 \mathrm{MPa}\left(5,000 \mathrm{lbf} / \mathrm{in}^{2}\right)$ and 8 passed the more stringent criterion of not more than 8-percent fines.

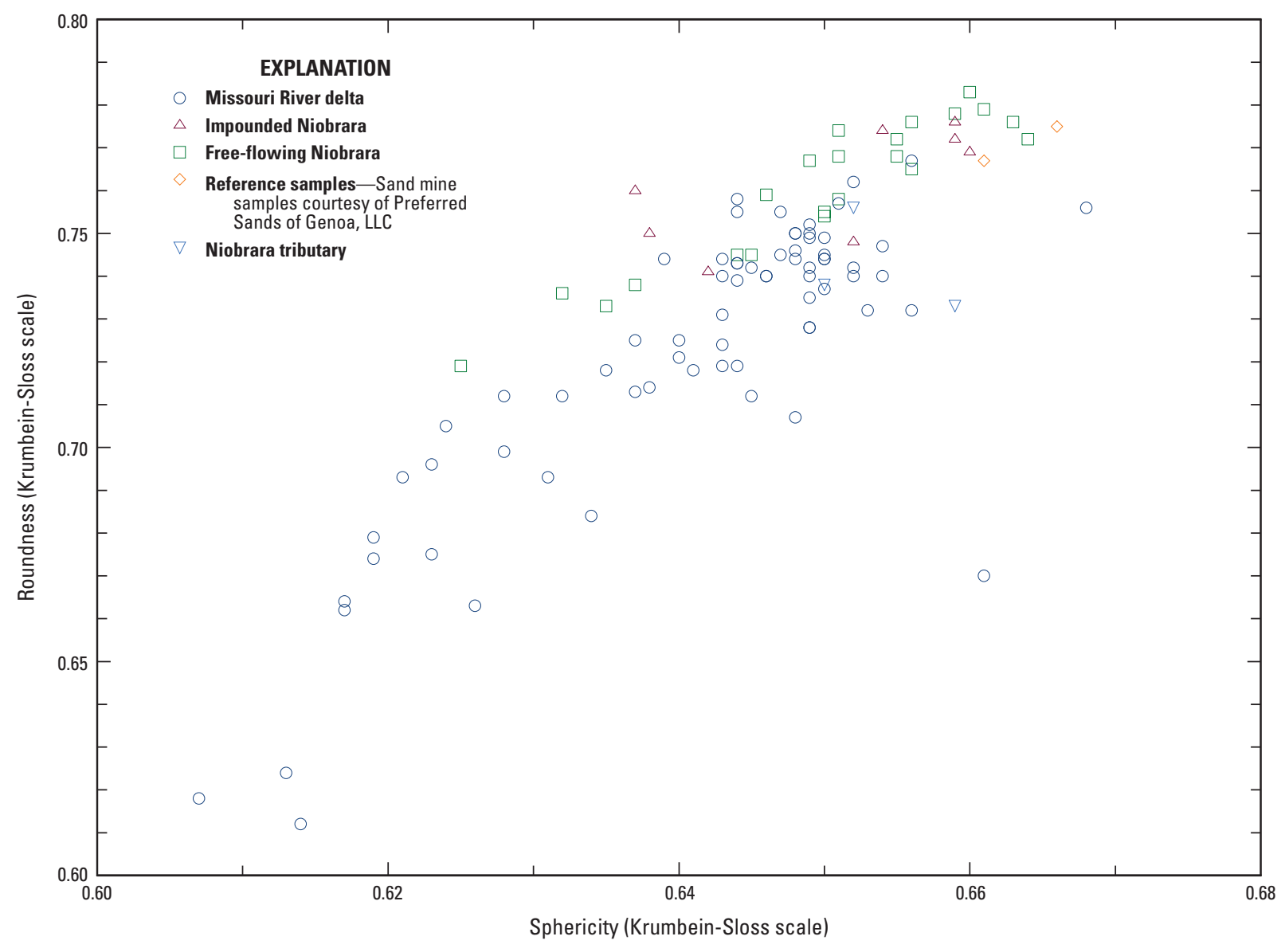

Figure 8. Scatterplot showing that particle roundness and sphericity were positively related and exceeded their respective minimum recommended values ( 0.6 units for each, on the respective Krumbein-Sloss scale) for suitability as proppant. Sediment samples collected from study area, Missouri River Delta, Nebraska and South Dakota, 2015. 
The physical characteristics of the four sandbar complexes (field identifiers of coring locations labeled as sandbar complex A, B, C, and D in figures $9 A-B$ ) were compared, including geometric mean size and crush-resistance test results. Sediment samples were not evenly distributed among the individual sandbar complexes; sandbar complexes A, B, C, and D were sampled at 4, 8, 8, and 5 locations, respectively (fig. 2). Distributions of geometric mean size among the four sandbar complexes were similar, but sediment samples collected from sandbar complex B had PSDs indicating slightly coarser deposits. The median geometric mean size was similar for each of the four sandbar complexes and ranged from 0.26 to $0.30 \mathrm{~mm}$, but sandbar complex B had the largest geometric mean size. Although grain-size characteristics were similar, crush-resistance test results were variable across the sandbar complexes (fig. 9B). Sandbar complex A had 67 percent of its sediment samples pass at least one of the two criteria for crush resistance at the $34.5 \mathrm{MPa}\left(5,000 \mathrm{lbf} / \mathrm{in}^{2}\right)$ threshold, which was more than sandbar complexes B, C, and D that had 50, 46, and 42 percent pass rates, respectively (table $6 B$ ). This difference in crush resistance was largely because sandbar complex A contained the largest percentage of the 70/140-dominated samples, which had a higher percentage of sediment samples passing the minimum crush-resistance criterion compared to coarser dominant-size classes.

This monotonic downstream pattern of decreasing suitability potential as proppant did not exactly correspond to the slight degree of downstream fining, notably among sandbar complexes B-D. The pattern of fining may be related to increased mixing of the sand load of the Niobrara River with that of the Missouri River as distance downstream from their confluence increases, or the pattern may be related to other unstudied processes or to increased mixing with historical deposits that are enriched in particles finer than medium sand.

\section{American Petroleum Institute 40/70 Dominant- Size Class}

For all sediment samples, initial exploratory analysis followed a sample wash, which removed the part of the sample presumably finer than the U.S. No. 200 mesh size. Materials coarser than $2 \mathrm{~mm}$ (U.S. No. 10 mesh) also were removed during sample preparation. For the 50 regular sediment samples dominated by the API 40/70 size class, the percentage by weight of bulk material lost from the raw sediment sample during the sample-preparation wash averaged 9.0 percent but ranged from 1.6 to 32.6 percent. The mass loss during the wash typically corresponds to the wash load of sediment in riverine transport; therefore, the mass loss may be expected to be removed (or lost) during the bulk-volume washing during processing of mine output in frac sand production (Anderson, 2011). Product-to-waste ratios were calculated using the postwash mass of the sample. Only 2 of the 50 regular sediment samples of the API 40/70 size had a composition by volume in the API 20/70 size class of at least 75 percent, which corresponds to a 3.0 ratio or greater for this most marketable size fraction. The mean 20/70-size product-to-waste ratio was 1.3 and values ranged from 0.4 to 3.5 .

The arithmetic mean particle size of the API 40/70-size sediment subsample used for resistance crush testing averaged $0.30 \mathrm{~mm}$. The average composition of tested material in the 50 regular sediment samples of API 40/70 size was 90.0 percent within the 40/70 class, which is the minimum criterion for this proppant size class. Particle shape measures were similar to those of the washed raw material, with an average roundness score of 0.73 and sphericity of 0.65 . The average values, as well as those for all individual sediment samples in this group, fully meet the API minimum requirements for proppant shape.

With respect to proppant strength, the average percentage of material finer than $0.212 \mathrm{~mm}$ (U.S. No. $70 \mathrm{mesh}$ ) following the crush-resistance test was 11.5 percent (table $6 B$ ). Of the 50 regular sediment samples of the $40 / 70$ size class, 14 samples (28 percent) passed the crush test at $34.5 \mathrm{MPa}(5,000 \mathrm{lbf} /$ $\mathrm{in}^{2}$ ) by having a postcrush fines less than 10 percent (table $6 B$ ). For the secondary criterion used in this study-proportional increase in fines percentage - only seven additional sediment samples passed the 80-percent threshold for this metric of proppant strength. A total of 21 regular sediment samples (42 percent) of the 40/70 size class indicated suitable strength for use as frac sand.

\section{American Petroleum Institute 70/140 Dominant- Size Class}

For samples with API 70/140 as the dominant-size class, the percentage by weight of bulk material lost from the raw sample during the sample-preparation wash averaged 18.3 percent but ranged from 3.3 to 42.4 percent. Not surprisingly, none of the 12 delta sediment samples dominated by the $70 / 140$ size class had sample composition that exceeded 30 percent in the API 20/70 size class. Consequently, the 20/70 product-to-waste ratio averaged only 0.25 for these 12 delta sediment samples.

For the 12 sediment subsamples of the API 70/140 size used for crush-resistance testing, the arithmetic mean particle size was $0.17 \mathrm{~mm}$, and an average 81.5 percent of tested material was within the API 70/140 size class (table $6 B$ ). Measures of particle shape had values similar to, but slightly less than, those of the washed raw material, with an average roundness score of 0.67 and sphericity of 0.62 . The average values, as well as those for all individual sediment samples in this group, fully meet the API minimum requirements for proppant shape.

With respect to proppant strength, the average percentage of material finer than $0.106 \mathrm{~mm}$ (U.S. No. $140 \mathrm{mesh}$ ) following the crush test was 7.6 percent for 12 delta sediment subsamples of the 70/140 size class (table $6 B$ ). Moreover, nine sediment samples ( 75 percent) passed the crush test at 34.5 MPa (5,000 lbf/in $\left.{ }^{2}\right)$ by having a postcrush fines composition ranging from 4.0 to 9.2 percent. None of the remaining 

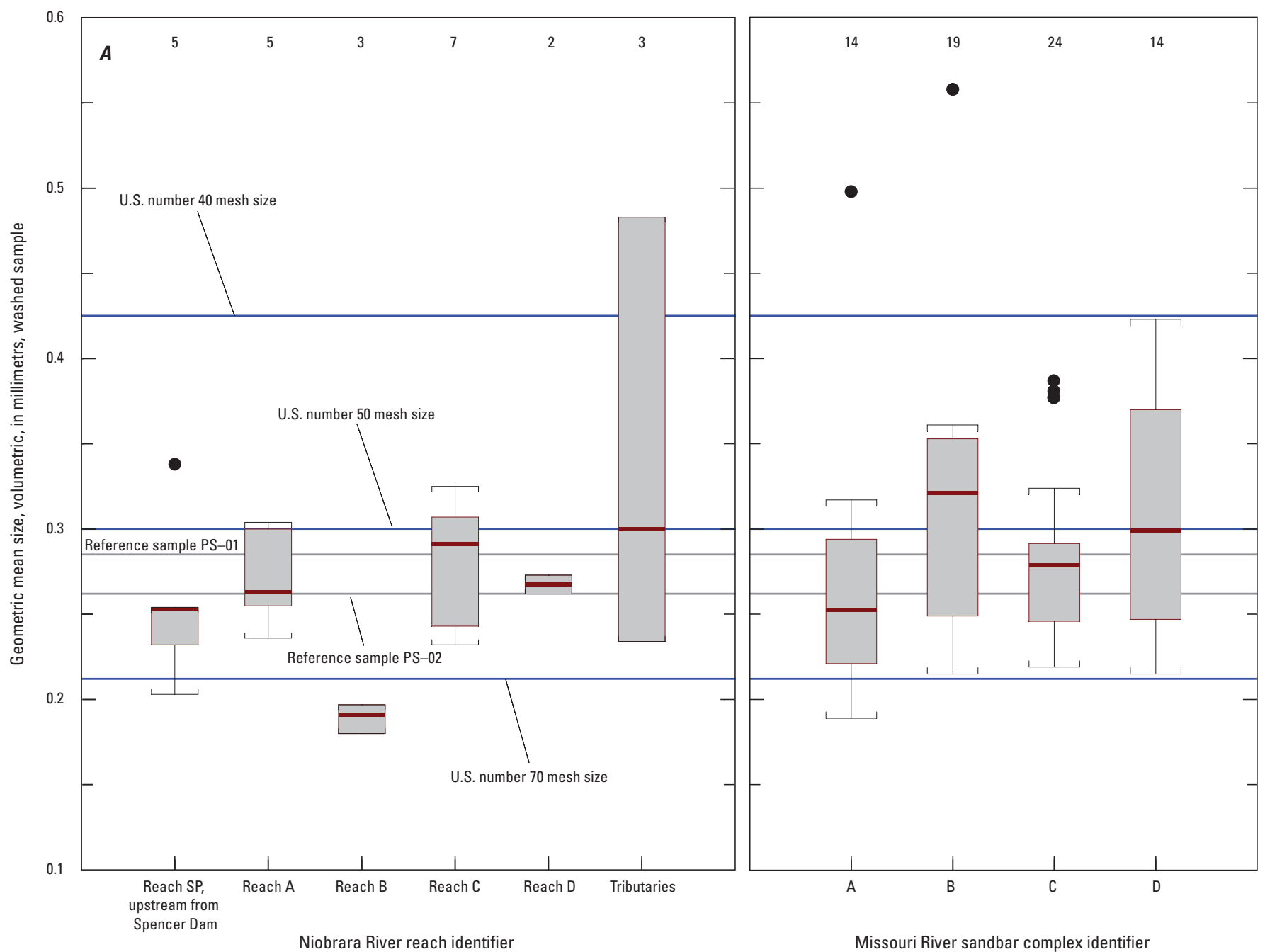

EXPLANATION

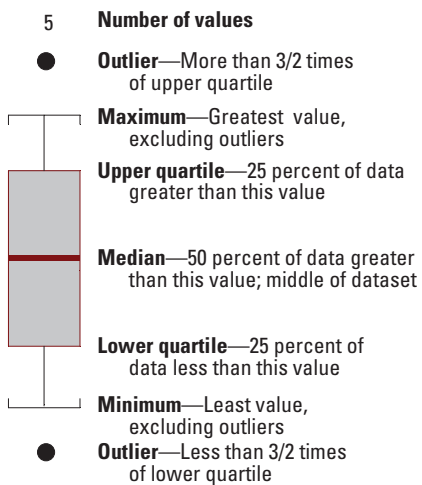

Figure 9. Sediment sample distributions by groups (Niobrara River reaches $S P, A, B, C$, and $D$, tributaries to the Niobrara River, and Missouri River Delta sandbar complexes $\mathrm{A}, \mathrm{B}, \mathrm{C}$, and D). $A$, geometric mean particle size; $B$, percent fine particles following crush-resistance test. (5,000 pounds-force per square inch equals 34.5 megapascals.) [PSG, Preferred Sands of Genoa mine output included for reference.] 


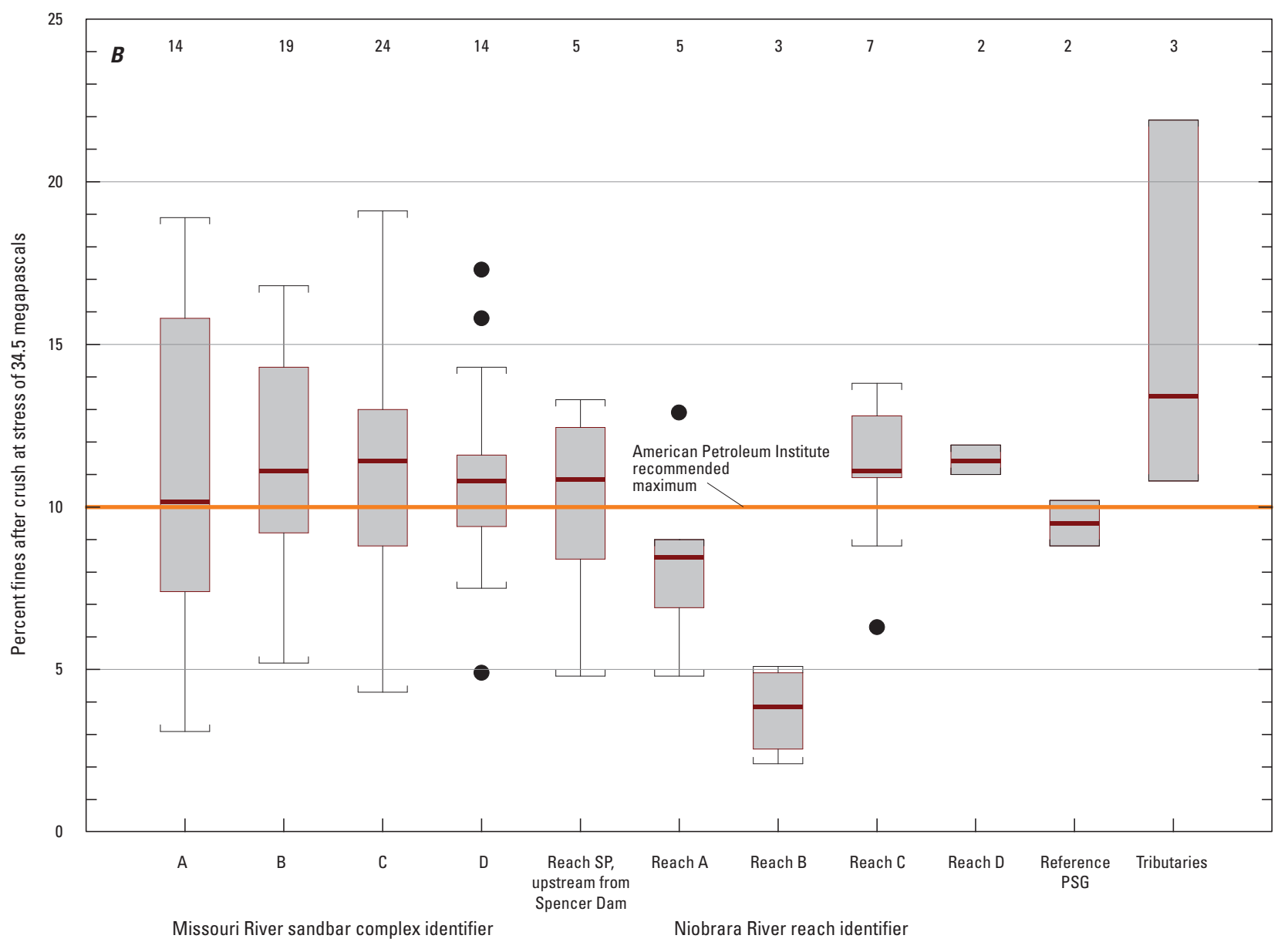

EXPLANATION

14 Number of values

Outlier-More than $3 / 2$ times of upper quartile

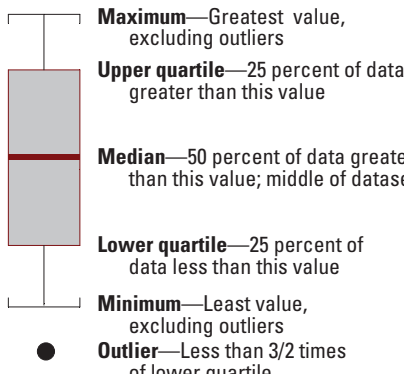

Figure 9. Sediment sample distributions by groups (Niobrara River reaches $S P, A, B$, , and $D$, tributaries to the Niobrara River, and Missouri River Delta sandbar complexes A, B, C, and D). A, geometric mean particle size; $B$, percent fine particles following crush-resistance test. $(5,000$ pounds-force per square inch equals 34.5 megapascals.) [PSG, Preferred Sands of Genoa mine output included for reference.]—Continued 
three sediment samples passed the secondary threshold indicator of crush resistance used in this study - less than an 80-percent proportional increase in fines. A total of nine regular sediment samples (75 percent) of the 70/140 size class indicated probable suitable strength for use as frac sand.

\section{Surface-Geophysical Reconnaissance}

Selected laboratory results from direct-push cores were plotted in three-dimensional space with the inverted CC resistivity data for comparative purposes and to evaluate the utility of the CC resistivity method as a reconnaissance tool for mapping and assessing potential proppant sources. The dominantsize class and the 10th percentile, mean, and median grain size for each sample listed in table 6 were plotted and compared to the inverted CC resistivity data and visually interpreted within the Profile Analyst program (Pitney Bowes Software, 2014).

An example inverted CC resistivity section, along with associated direct-push sediment core locations, are presented in figure 10. All other inverted CC resistivity sections are presented in Hall and Hobza (2017).

When compared to typical ranges for sand, the resistivity values of the inverted CC resistivity profiles (fig. 10) occupy a narrower range (typically $30-150 \mathrm{ohm}-\mathrm{m}$ ) than for alluvial sediments referenced in Loke (2009). Visual comparison with the lithologic descriptions given in Hall and Hobza (2017) indicated good agreement with the inverted CC resistivity sections. Generally, higher resistivity values are associated with coarse-grained deposits and lower resistivity values are associated with fine-grained deposits, although a few exceptions were noted. One such example is core D28, which was collected near the east end of the study reach along CC resistivity line L27Mar_40 (fig. 10). Throughout the reconnaissance survey, care was taken to collect data that would facilitate the best ground contact and, therefore, thick patches of Phragmites were avoided; however, one patch was crossed near the west end of line L27Mar_40. A resistive anomaly $(180 \mathrm{ohm}-\mathrm{m})$ coincident with the location of the Phragmites was present (Northings 4,736,150-4,736,200 m), but based on the lithologic description and lab analyses, the underlying delta sediment was fine to medium sand rather than a coarse sand or gravel that higher resistivity values normally indicate. Similarly, the lithology of core D28 agrees well with nearby areas along CC resistivity line L27Mar_20 (fig. 10), pointing to high likelihood that the resistivity-indicated coarse zone in line L27Mar_40 near D28 was a data acquisition artifact.

Other minor discrepancies in the $\mathrm{CC}$ resistivity data exist, such as with cores B7 and C22, which may be more of a function of lateral variability within the delta sediments. Core B7 was collected at the western end of CC resistivity profile L25Mar_30 (Hall and Hobza, 2017). Only one interval (sample 20; from 1.6 to $2.3 \mathrm{~m}$ ) was analyzed in the center of this resistive zone. The lithologic description of the sediment sample indicates a poorly sorted mixture of coarse sand and some gravel with lenses of fine-grained organic material, and the sediment sample was characterized by the API 40/70 dominant-size class. The resistive zone in line L25Mar_30 also is present in nearby CC resistivity line L25Mar_50 (Hall and Hobza, 2017), indicating that this unit was a somewhat laterally extensive subsurface feature. The resistivity value associated with this sediment sample $(150 \mathrm{ohm}-\mathrm{m})$ was the maximum value for all sediment samples within the API 40/70 dominant-size class. Sediment sample 24, near the bottom of core C22, was in the 70/140 size class; however, CC resistivity profile 26Mar_90upper indicated that at this depth there was a high resistivity zone (172 ohm-m). The resistivity value associated with this sample was $172 \mathrm{ohm}-\mathrm{m}$, which was nearly double the resistivity value of the next highest sample in the 70/140 size class. This discrepancy cannot be explained and is attributed to lateral variability in the delta deposits; therefore, this sample was excluded from further analyses.

The inverted CC resistivity profiles provided additional information to identify marketable proppant including API 40/70 and 70/140 size classes. Resistivity values were extracted from inverted CC resistivity profiles, specifically, for bins that corresponded to soil boring sample locations but the sediment samples mentioned above from cores $\mathrm{C} 22$ and D28 were excluded. The frequency distribution of resistivity values for the $40 / 70$ size class overlaps with that for the $70 / 140$ size class, with the mode of the coarser, 40/70 size class being slightly offset toward higher resistivity values (fig. 11). Based on these comparisons, 78 percent of the sediment samples in the 40/70 and 70/140 size classes had resistivity values between 60 and $100 \mathrm{ohm}-\mathrm{m}$, with substantial overlap between the two size classes. Given the low productto-waste ratios, the overlap of the resistivity ranges of the $40 / 70$ and 70/140 dominant-size classes is not surprising considering the high percentage of sediment that was finer or coarser than the dominant-size class. Resistivity values within the $90-100 \mathrm{ohm}-\mathrm{m}$ range generally correspond to a sediment sample dominated by medium sand within the $40 / 70$ size class. Two other sediment samples were characterized within two other coarser dominant size classes (30/50 and 20/40). These dominant-size classes had resistivity values of 108 and $109 \mathrm{ohm}-\mathrm{m}$, respectively. Because each class only had one sample, the range and distribution of resistivity values could not be fully described.

Given the fact that resistivity values between the 60 and $100 \mathrm{ohm}-\mathrm{m}$ range correspond to the marketable $40 / 70$ and $70 / 140$ size fractions, CC resistivity could be used as a viable tool to estimate the spatial extent and potentially the volume of minable proppant. Attempts were made to estimate a total volume of marketable sand within the four studied sandbar complexes. Because of the local heterogeneity, creating a reliable three-dimensional model with the 2015 dataset, which was acquired as a reconnaissance survey for this pilot study, is not feasible. The inverted resistivity models consist of seven discrete layers of varying thicknesses, with layer thickness increasing with depth. Roughly 56 percent of the profile areas 


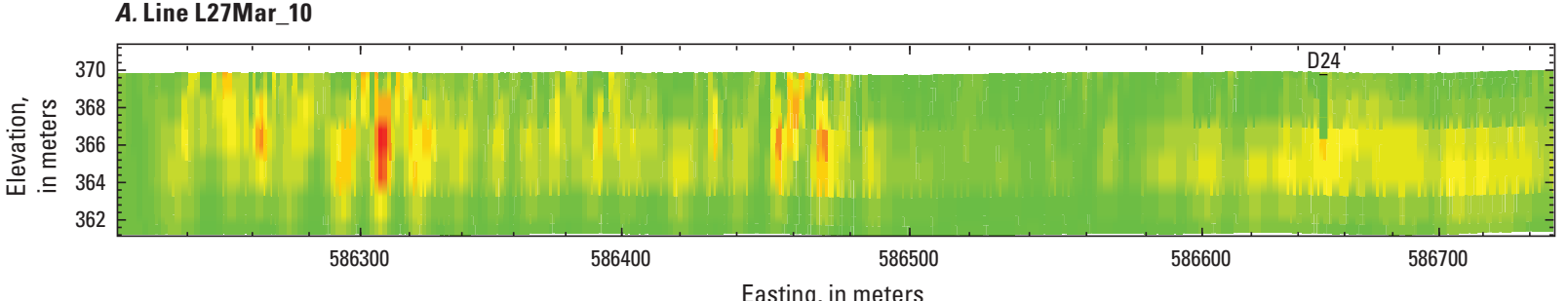

B. Line L27Mar_20
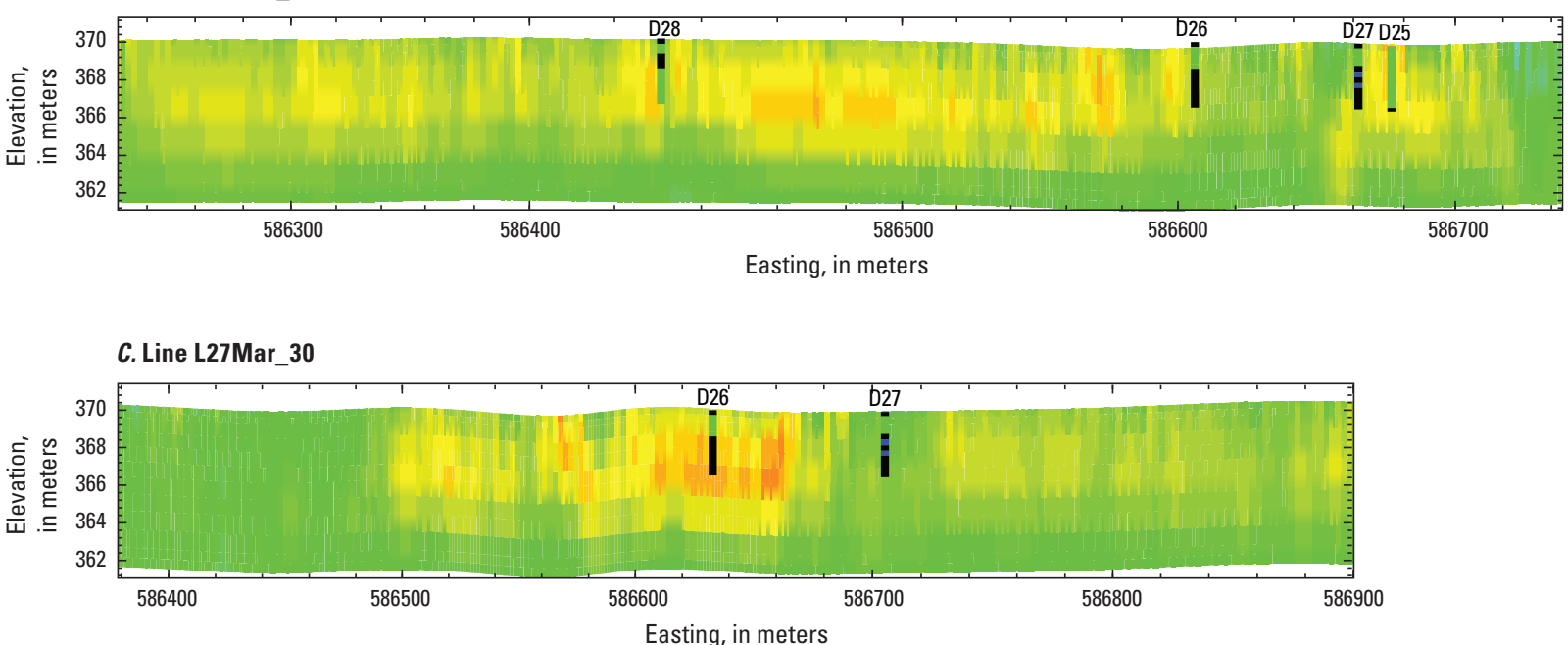

D. Line L27Mar_40

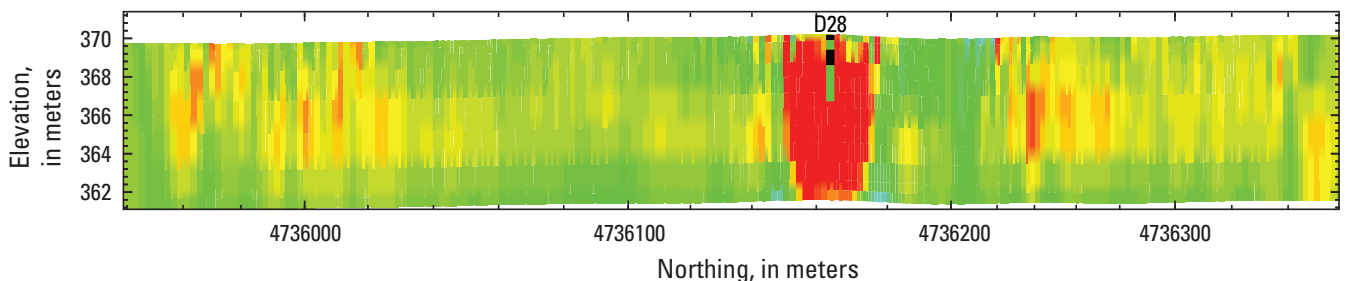

Figure 10. Vertical sections of surveyed lines showing surface-geophysical results from capacitively coupled resistivity and dominant American Petroleum Institute (API) size class in boreholes, Missouri River delta sandbar complexes near Running Water, South Dakota, 2015. $A$, line L27Mar_10; $B$, line L27Mar_20; C, line L27Mar_30; D, line L27Mar_40.
Easting, in meters

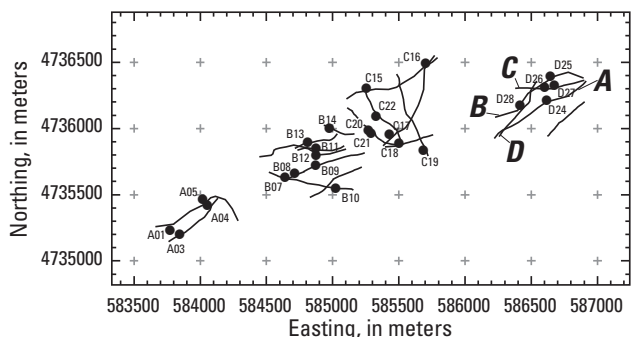

\section{EXPLANATION}

\begin{tabular}{|c|c|}
\hline $\begin{array}{l}\text { Borehole-Field identifier } \\
\text { [table 2] above symbol }\end{array}$ & $\begin{array}{l}\text { Resistivity_In } \\
\text { ohm-meters }\end{array}$ \\
\hline $20 / 40$ & \\
\hline & 100 \\
\hline $30 / 50$ & 80 \\
\hline $40 / 70$ & 60 \\
\hline $70 / 140$ & 40 \\
\hline No sample & \\
\hline
\end{tabular}

NOTE: Horizontal coordinates are referenced to Universal Transverse Mercator grid, zone 14 north. Elevation refers to height above North American Vertical Datum of 1988.

Northing, in meters 


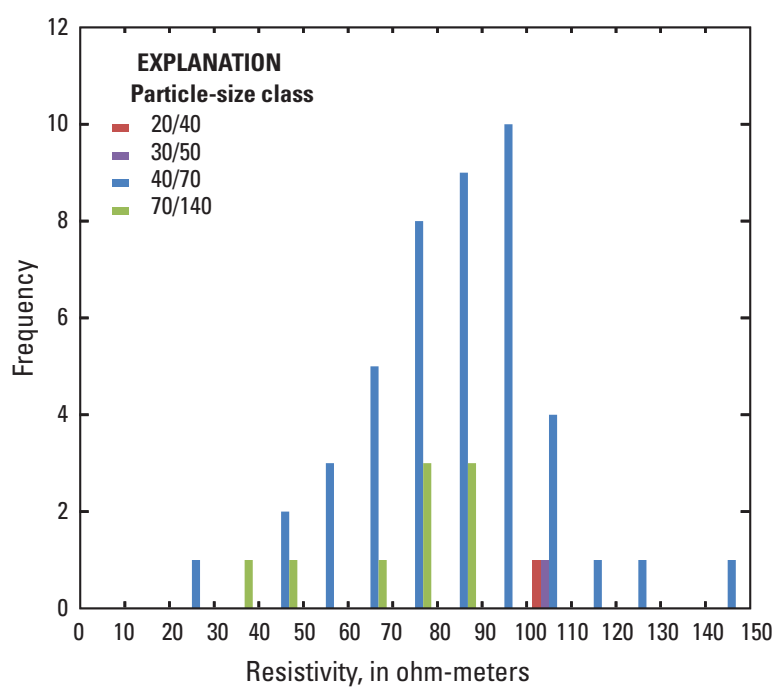

Figure 11. Frequency distribution of apparent resistivity values extracted from inverted capacitively coupled profiles at locations coincident with sediment samples from direct-push coring of Missouri River delta sandbar complexes, Nebraska and South Dakota, 2015.

were in the $60-100 \mathrm{ohm}-\mathrm{m}$ range, indicating the area underlying each profile contains a substantial portion of potentially marketable material, which is dominated by API size classes $40 / 70$ and 70/140. Roughly 6 percent of the area underlying the surveyed profiles was indicated to have $\mathrm{CC}$ resistivity in the $90-100 \mathrm{ohm}-\mathrm{m}$ range, which is likely dominated by the API 40/70 size class (fig. 11).

Comparisons of the inverted $\mathrm{CC}$ resistivity profiles with the core logs and sediment sample analysis results indicated that delta sediments are an unstratified mixture of sand and silt. Further examination of the inverted CC resistivity profiles was used to examine vertical heterogeneity and to determine which depths seemed to host the largest percentage of marketable proppant. Summary statistics were computed for each depth layer and are listed in table 7. The standard deviation of apparent resistivity was used to describe the overall variability of each layer. Overall, the intermediate layers ( 2 and 3 ) had more variability compared with layers near the bottom of the profile (5 and 6). Because samples submitted for laboratory analysis came exclusively from vertical layers 0,1 , and 2 , the study results cannot indicate whether those higher standard deviations of resistivity correspond to poorer sorting statistics or to higher product-towaste ratios.

Visual interpretation of the inverted CC resistivity profiles alone does not conclusively indicate which depth has the largest percentage of areas within the $60-100 \mathrm{ohm}-\mathrm{m}$ range, which is indicative of potentially marketable material dominated by API 40/70 and 70/140 size classes (table 7). Percentages ranged from 45 percent to 68 percent, and layer 4 had the largest percentage. Areas within the $90-100 \mathrm{ohm}-\mathrm{m}$ resistivity range generally are indicative of a medium sand within the API 40/70 dominant-size class. Layer 3 had the largest percentage within that range at 22.3 percent of its cross-sectional area.

\section{Mineralogy}

Of the 111 sediment samples collected for this study, 12 were submitted for mineralogy analysis by XRD including 8 Missouri River delta sediment samples. Sediment samples were analyzed for percentages of quartz (silica), plagioclase feldspar, alkali feldspar (includes potassium feldspar), pyroxene, clays, and micas.

Results from the XRD analyses are listed in table 8. Not surprisingly, the mineralogy of the eight Missouri River delta sediment samples was similar to the upstream source sediment samples. With one exception (sediment sample D24), sediment samples were typically dominated by quartz with lesser percentages of feldspar, which is typical of sedimentary deposits derived from a granitic source rock (Blatt and Tracy, 1996). The quartz content for the eight delta sediment samples ranged from 41 to 79 percent and averaged 67 percent. The percentage of feldspars (plagioclase plus alkali feldspars) ranged from 20 to 55 percent for sediment samples collected within the delta. Using the sandstone classification systems of Folk (1968) and McBride (1963), the sediment samples would be classified as either subarkose or arkose. The mineral composition of sediment samples in table 8 are comparable to eolian deposits in the Nebraska Sand Hills as described by Ahlbrandt and Fryberger (1980), who estimated that their sampled dune-sand deposits were 50-75 percent quartz, with

Table 7. Statistical summary of resistivity values at specific depth intervals from inverted capacitively coupled resistivity profiles, Missouri River delta sandbars, Nebraska and South Dakota, 2015.

[Depths measured from surface of sediment deposit (river sandbar complex); profile area refers to cross-sectional, two-dimensional area]

\begin{tabular}{ccccc}
\hline $\begin{array}{c}\text { Layer } \\
\text { number }\end{array}$ & $\begin{array}{c}\text { Depth } \\
\text { interval, } \\
\text { in meters }\end{array}$ & $\begin{array}{c}\text { Percentage of area } \\
\text { of profiles with } \\
\text { resistivity between } \\
\mathbf{6 0} \text { and 100 ohm- } \\
\text { meters }\end{array}$ & $\begin{array}{c}\text { Percentage of area } \\
\text { of profiles with } \\
\text { resistivity between } \\
\mathbf{9 0} \text { and 100 ohm- } \\
\text { meters }\end{array}$ & $\begin{array}{c}\text { Standard } \\
\text { deviation, in } \\
\text { ohm-meters }\end{array}$ \\
\hline 0 & $0-0.35$ & 50.4 & 8.9 & 24.16 \\
1 & $0.35-1.91$ & 52.1 & 10.5 & 25.45 \\
2 & $1.91-3.47$ & 52.0 & 18.8 & 36.83 \\
3 & $3.47-5.18$ & 57.0 & 22.3 & 48.32 \\
4 & $5.18-7.06$ & 67.9 & 12.5 & 25.19 \\
5 & $7.06-8.56$ & 54.1 & 0.9 & 12.86 \\
6 & $8.56-9.07$ & 45.3 & 0.5 & 11.00 \\
\hline
\end{tabular}


Table 8. Sediment sample mineralogy by $\mathrm{x}$-ray diffraction for selected sediment samples of deltaic or riverine sand deposits, Missouri and Niobrara Rivers, 2015.

[R-profile, a dimensionless measure of how well the refinement fits the diffraction pattern; $\mathrm{T}$, (trace) less than 1 percent]

\begin{tabular}{|c|c|c|c|c|c|c|c|}
\hline \multirow[b]{2}{*}{$\begin{array}{l}\text { Sample field } \\
\text { identifier } \\
\text { (tables } 1 \text { and 2) }\end{array}$} & \multicolumn{6}{|c|}{$\mathrm{X}$-ray diffraction result, in percent by weight } & \multirow[b]{2}{*}{ R-profile } \\
\hline & $\begin{array}{c}\text { Quartz } \\
\text { (percent) }\end{array}$ & $\begin{array}{c}\text { Feldspar, } \\
\text { plagioclase } \\
\text { (percent) }\end{array}$ & $\begin{array}{c}\text { Feldspar, } \\
\text { orthoclase } \\
\text { (percent) }\end{array}$ & $\begin{array}{l}\text { Pyroxene } \\
\text { (percent) }\end{array}$ & $\begin{array}{c}\text { Clay } \\
\text { (percent) }\end{array}$ & $\begin{array}{c}\text { Mica } \\
\text { (percent) }\end{array}$ & \\
\hline \multicolumn{8}{|c|}{ Missouri River delta sandbar samples } \\
\hline A1 & 62 & 24 & 11 & 2 & $\mathrm{~T}$ & 1 & 11.5 \\
\hline A4 & 70 & 26 & 2 & 2 & 0 & 0 & 11.0 \\
\hline B13 & 69 & 29 & 0 & 2 & $\mathrm{~T}$ & $\mathrm{~T}$ & 12.1 \\
\hline B14 & 73 & 17 & 8 & 2 & 0 & 0 & 10.9 \\
\hline B9 & 77 & 15 & 7 & 1 & 0 & 0 & 10.8 \\
\hline $\mathrm{C} 16$ & 79 & 14 & 6 & 1 & $\mathrm{~T}$ & $\mathrm{~T}$ & 9.0 \\
\hline D24 & 41 & 51 & 4 & 4 & $\mathrm{~T}$ & $\mathrm{~T}$ & 11.3 \\
\hline D28 & 69 & 16 & 12 & 3 & 0 & 0 & 9.8 \\
\hline \multicolumn{8}{|c|}{ Niobrara River sand deposit samples } \\
\hline NR-16-A & 68 & 20 & 7 & 5 & 0 & 0 & 10.3 \\
\hline NR-45 & 72 & 21 & 6 & 1 & 0 & 0 & 11.1 \\
\hline SP-03R-013 & 76 & 21 & 3 & 1 & 0 & 0 & 8.1 \\
\hline SP-06-013 & 67 & 30 & 2 & 1 & 0 & 0 & 11.2 \\
\hline
\end{tabular}

${ }^{1}$ A good fit has a value of approximately 10 ; lower values are more accurate and higher values are less accurate.

about equal amounts of potassium feldspar (9-25 percent) and plagioclase feldspar (5-24 percent), chert (3-9 percent), rock fragments (1-4 percent), and clay (trace- 4 percent).

The American Petroleum Institute and others (2008) specifications for proppants did not state a minimum quartz composition threshold for frac sand; however, for a premium sand proppant, 99-percent quartz was the criterion widely stated. Mineralogy results were clear in confirming that the Missouri River delta is not capable of producing premium frac sand, which was consistent with the results from crushresistance testing.

Contemporaneous sampling of the surface of sandbar deposits along the Missouri River delta, including reaches upstream and downstream from the Niobrara River confluence, was reported by the USD (M. Sweeney, University of South Dakota, written commun., 2016). Those sediment samples were analyzed using X-ray fluorimetry methods. The results indicated that the total silica content along the delta peaked at about 88.4 percent near the Missouri River sandbar complex A that was sampled for this USGS study. Beyond providing additional confirmation that the study area is unlikely to provide sand with quartz content at the level of premium frac sand, the USD results also indicate that the sandbar complexes A-C and sand deposits near the Niobrara River confluence were the optimal locations for sampling sand enriched in quartz or silica content.

\section{Suitability Assessment of Upstream Sources}

This section is organized to allow the reader who is mainly interested in suitability of the dominant-size fraction of sand deposits for potential use as proppant to readily access that material for either the dam-impounded deposits or those along the free-flowing reaches downstream. Other sections are included to provide insight on potential marketability and waste management considerations or to give some geomorphic context to the sample locations and present a downstream trend that emerged in results for the reaches upstream from the Eagle Creek confluence (fig. 1).

A total of 22 main-stem sampling locations along the lower Niobrara River (table 1) contributed sediment samples to the following overall summary of sediment characteristics and test results. The lower Niobrara River main stem includes all of the upstream sampling sites except three tributary streams. The impounded reach SP at Spencer Dam is included.

For PSD of bulk washed sediment samples, geometric mean size averaged $0.26 \mathrm{~mm}$, an average of 61 percent was sand in the API 40/70 size class, and 28 percent was sand in the API 70/140 size class (table $9 \mathrm{~A}$, available for download as a Microsoft Excel® file at https://doi.org/10.3133/ sir20175105). Average composition was 48 percent medium 
sand, 38 percent fine sand, 7.5 percent very fine sand, and 6.0 percent coarse sand (table $9 A$ ). Average sorting falls into the moderately well-sorted category of Folk and Ward (1957).

American Petroleum Institute and others (2008) recommend that a minimum 90 percent of a tested proppant consist of particles within the nominal size class, meaning that for 40/70-sized sand, 90 percent would be finer than the first primary sieve (the No. 40 sieve) but coarser than the second primary sieve (the No. 70 sieve). For the 25 lower Niobrara River sediment samples that were dominated by $40 / 70$-sized sand, composition by the $40 / 70$ size averaged 91 percent and 88 percent had the recommended homogeneity (table $9 B$, available for download as a Microsoft Excel® file at https:// doi.org/10.3133/sir20175105). For the remaining four sediment samples, a 70/140-sized sand was dominant; however, the average composition by that size class was 80 percent and none of these sediment samples met the recommended quality criterion of 90 percent purity. For particle shape, all sediment samples from the lower Niobrara River surpassed the recommended minimum value of 0.6 units for sphericity and roundness, as measured by the OPSA using the Krumbein-Sloss scale (table $9 B$ ).

For proppant strength, crush resistance was tested at a predetermined level of stress ( $34.5 \mathrm{MPa}$, or $\left.5,000 \mathrm{lbf} / \mathrm{in}^{2}\right)$. To meet the minimum requirement, not more than 10 percent of the tested sediment sample should be finer than the second primary sieve after the stress test. But for a natural sand proppant of API 40/70 size, some industry experts (Bennetts, 2013; Zdunczyk, 2013) recommended that not more than 8-percent fines are generated at the 34.5-MPa stress level. Of the 25 tested Niobrara River sediment samples of 40/70-sized sand, 9 sediment samples passed the minimum criterion at $34.5 \mathrm{MPa}$ $\left(5,000 \mathrm{lbf} / \mathrm{in}^{2}\right)$, or 11 samples passed if the 2 samples that passed using the percentage increase in fines threshold are included, but only 4 sediment samples passed the more-stringent criterion of 8-percent postcrush fines (table 9B). All four $70 / 140$ sand samples tested passed the minimum criterion at $34.5 \mathrm{MPa}\left(5,000 \mathrm{lbf} / \mathrm{in}^{2}\right)$, with postcrush fines at 5.1 percent or less (table $9 B$ ), but these represent only three sampling sites.

Mineralogical analyses were available for only 4 of the 22 Niobrara River sediment sampling sites. Results from the $\mathrm{XRD}$ analyses are listed in table 8 . Without exception, sediment samples were dominated by quartz with lesser percentages of feldspar, typical of sedimentary deposits derived from a granitic source rock (Blatt and Tracy, 1996). The range of quartz content of the upstream source sediment samples was 67-76 percent, with an average of 71 percent. Even with such a small sample size, mineralogy seems to confirm that these channel deposits will not yield premium frac sand, which would be at least 99-percent quartz (Zdunczyk, 2013); however, a great deal of sand used as proppant has a silica content of 95-99 percent (Benson and Wilson, 2015b). The silica content was similar to that in a single sediment sample collected by USD from the most downstream segment (88.6 percent) of the Niobrara River, a sediment sample that was analyzed by x-ray fluorimetry methods (M. Sweeney, University of
South Dakota, written commun., 2016). By comparison with the results from the Missouri River delta, the results from upstream sand sources were more uncertain because the sediment sample set was too small for definitive conclusions; however, results indicate that mineralogy was similar though more homogeneous than the Missouri River delta sediment samples.

Geomorphically, bed sediment texture generally exhibits a gradually fining trend in the downstream direction along most rivers (Knighton, 1998, p. 136). The sediment characteristics and test results for the lower Niobrara River sites will be discussed in the following subsections beginning at the upstream, western end of the study area and concluding at the mouth of the river.

\section{Deposits Impounded by Spencer Dam}

The average results for five coring sites in deposits impounded by Spencer Dam were calculated as the weighted average of eight OPSA-analyzed sediment samples (table 9), in which sediment samples from sites with a single sediment sample (SP-01 and SP-05) were double weighted and the remaining sediment samples were single weighted. Recall that rerun results were used for the two sediment samples for which a laboratory rerun was requested. Hereinafter, the sampled reach corresponding to the Spencer Dam impoundment is commonly referred to as reach SP.

\section{Results for Washed Sediment Samples}

The percentage by weight of bulk material lost from the raw sediment sample during the sample-preparation wash averaged 9.8 percent for the samples from the impoundment but ranged from 3.0 to 20.8 percent. The mass loss during the wash typically corresponds to the wash load of sediment in riverine transport and, therefore, may be expected to be removed (or lost) during the bulk-volume washing during processing of mine output in frac sand production (Anderson, 2011).

The resulting weighted-average mean particle sizes for the washed sediment samples were $0.281 \mathrm{~mm}$ (arithmetic mean) and $0.256 \mathrm{~mm}$ (geometric mean), with, on average, more than 85 percent of sediment sample bulk composition in the fine-to-medium sand size class (table $9 A$ ). The mean size at the sampled locations in the Spencer Dam impoundment may be on average slightly coarser than that of the dune sand of the Nebraska Sand Hills, where mean size was predominantly finer than $0.25 \mathrm{~mm}$ (Ahlbrandt and Fryberger, 1980). This difference in mean size likely reflects the progressively greater sediment-trapping efficiency of the impoundment for each progressively coarser size fraction (Brune, 1953; Gill, 1979) that, in combination with the impoundment's small ratio of storage capacity to sediment inflow, allows some percentage of the finest fraction of Sand Hills sediment to be transported past Spencer Dam between the periods of flushing. 
The outer deciles reported by the OPSA indicate that on average 80 percent of sediment sample composition was in the size range from 0.163 to $0.410 \mathrm{~mm}$ (table $9 A$ ). On average, sediment samples contained more than 60 percent by volume in the API 40/70 size class and more than 70 percent in the API 20/70 size class, which is the most marketable size fraction when multiple products are included. Of the five sampling sites, three sites seem to have potential to yield sand of marketable size classes at a product-to-waste ratio (defined as percent 20/70 size divided by the complementary percentage) of at least 3.0 (sites SP-02, SP-03, and SP-05), although the replicate sample from site SP-03 was short of that ratio value (table 9A).

The average PSD for the sediment sampled in the Spencer Dam impoundment was similar to that of sediment sample NR-01-B (table $9 A$; arithmetic mean $0.284 \mathrm{~mm}$, geometric mean $0.255 \mathrm{~mm}$, and 87 percent fine-to-medium sand), a 56-cm thick sediment sample collected $0.5 \mathrm{~km}$ downstream from Spencer Dam. The difference in corresponding percentile values between sediment sample NR-01-B and the weighted mean for the impoundment averaged less than $0.01 \mathrm{~mm}$ (table $9 A$ ). This difference indicates that the set of sediment samples from the impoundment was representative of the sand deposited in the impoundment that is likely to be released to the river downstream when the gates are opened for a flush.

The mean sizes for the first five sampling sites along the Niobrara River downstream from Spencer Dam were approximately 6 percent coarser on average than the corresponding mean sizes of the reach SP sediment samples. The sediment samples from the impoundment are enriched in very fine to fine sand relative to the sediment samples from the river downstream, as one would expect given the different currentvelocity regimes upstream and downstream from a dam. The weighted-mean sizes of the sediment sampled in the Spencer Dam impoundment (arithmetic mean $0.281 \mathrm{~mm}$ and geometric mean $0.256 \mathrm{~mm}$ ) were finer than those of the sand mined from Loup River dredge spoil (sediment samples PSG-01 and PSG-02), which had a geometric mean size $(0.274 \mathrm{~mm})$ that was approximately 7 percent coarser than the respective size of the impoundment sand. The weighted-mean PSD of the sediment sampled in the Spencer Dam impoundment was similar to the PSD of sediment sample PSG-02 because at both locations similar percentages of very fine, fine, and medium sand were present (very fine sand was 8.3 and 8.0 percent, respectively; fine sand was 37.7 and 34.6 percent, respectively; and medium sand was 47.9 and 46.4 percent, respectively), resulting in similar values for the geometric mean size and 10th- and 50th-percentile sizes (table 9A). The coarse quartile of the PSDs differed, however, when the impoundment's weighted-average PSD was compared with that of the PSG sediment samples.

Particle shape metrics for the washed sediment samples indicate that all sediment samples from the Spencer Dam impoundment had roundness exceeding 0.7 units on the
Krumbein-Sloss index and sphericity of 0.64 or greater. A roundness index exceeding 0.7 is considered "well-rounded" and comfortably exceeds the 0.6 minimum criterion for proppant roundness. Compared with the PSG sediment samples, the sampled sand from the Spencer Dam impoundment was slightly less spherical but equally well-rounded.

\section{Results for Dominant Proppant Size Class}

For the 40/70-size subset used for crush testing, the mean particle size was a medium sand with weighted-average size of $0.307 \mathrm{~mm}$ and an average 91.5 percent of tested material in the API 40/70 size class (table 9B). In the final dataset, only one sediment sample (SP-05 rerun) had less than 90-percent homogeneity with respect to the $40 / 70$ size class. Particle shape measures were similar to those of the washed raw material, with average roundness score of 0.76 and sphericity of 0.65 (table $9 B$ ). The average values, as well as those for all individual sediment samples in this group, fully meet the API requirements for proppant shape.

With respect to proppant strength, the weighted-average percentage of material finer than $0.212 \mathrm{~mm}$ (U.S. No. 70 mesh size) following the crush test was 9.5 percent for the impoundment sediment samples (table 9B). Individual sediment samples from three of the five coring locations passed the crush test at $34.5 \mathrm{MPa}\left(5,000 \mathrm{lbf} / \mathrm{in}^{2}\right)$ by having a postcrush fines result ranging from 4.8 to 8.6 percent. For the secondary criterion used in this study - proportional increase in fines percentage - only the sediment samples from sites SP-02 and SP-03 failed to pass the 80-percent threshold for this metric of proppant strength.

\section{Sandbar Deposits along the Lower Niobrara River Downstream from Spencer Dam}

The average results for 17 sampled sand deposits along the lower Niobrara River downstream from Spencer Dam were calculated as the weighted average of 22 OPSA-analyzed samples (table 9A). Sediment samples from sites with a single sample were double-weighted and the remaining sediment samples were single-weighted. Thus, a site with a replicate pair is represented by the average of the paired values, and likewise in the case of site NR-14 where sediment samples of the vertically upper and lower parts of the deposit were separately analyzed. With respect to the two pairs of sediment samples that gave some insight on spatial variability within a deposit, the samples from NR-49 were each single-weighted; however, sample NR-01-A was zero-weighted (excluded) because the sediment sample included only the upper $12 \mathrm{~cm}$ of a high, dry sandbar that presumably had undergone deflation and, therefore, was not comparable with the other sediment samples that better represented the vertical thickness of the river sandbars. With sample NR-01-A excluded, sediment sample NR-01-B was double-weighted. 


\section{Results for Washed Sediment Samples}

The percentage of bulk material lost from the raw sediment sample during the sample-preparation wash ranged from 1.7 to 36.6 percent for 22 main-stem sediment samples downstream from Spencer Dam, with a weighted-average loss of 16.7 percent (table $9 A$ ). The range of percentage losses is comparable to that reported for 10 sediment samples of North Dakota sand or disaggregated sandstone, which had fines losses of 4.1-30 percent during the preparatory wash, with an average loss of 9.3 percent (Anderson, 2011); however, the average loss in this study was almost twice as large as that in the North Dakota study. This difference may underscore the interpretation that interlaboratory results (see the "Quality Assurance and Quality Control" section) indicate the likelihood of negative bias in fine sand composition that may have been introduced by the preparatory wash.

Overall, the arithmetic mean size for washed sandbar sediment samples from 17 sites averaged $0.29 \mathrm{~mm}$ (weighted average of 22 samples). The geometric mean size for the 17 sediment sampling sites along the Niobrara River downstream from Spencer Dam averaged $0.26 \mathrm{~mm}$ (table 9A). This mean size was slightly finer than that of two sediment samples of mine output from Loup River dredge spoil (sediment samples PSG-01 and PSG-02), which had an average geometric mean size of $0.27 \mathrm{~mm}$ and arithmetic mean size of $0.32 \mathrm{~mm}$. Median size for the 17 main-stem sites $(0.264 \mathrm{~mm}$ as weighted average) also was slightly finer than the average median size of the PSG sediment samples $(0.281 \mathrm{~mm})$. Mainstem sites had an overall average 54.1 percent bulk composition of medium to coarse sand; however, both PSG sediment samples were at least 56.1 percent medium to coarse sand.

\section{Downstream Trend from Spencer Dam to Eagle Creek}

Sediment samples collected from Niobrara River sandbars had PSDs that became finer with distance downstream from Spencer Dam until the confluence with Eagle Creek $(8.65 \mathrm{~km})$ was reached at the end of reach B (fig. 1). The four sediment samples from the three sandbar sites in reach B were the finest of all sediment samples collected along the lower Niobrara River for this study and were the only sediment samples not dominated by the API 40/70 size class (fig. 12). Within this upper reach of the sampled river segment, the PSD results indicate two distinct reaches with contrasting PSDs. Results for these two reaches (A and B) are discussed in the subsequent two subsections of this report, respectively.

\section{Reach A-Where Medium Sand is Dominant}

Sandbar sediment samples from sites NR-01 through NR-05 had coarseness similar to the sediment samples from the impoundment upstream from Spencer Dam that also had a 90th-percentile size $\left(d_{90}\right)$ greater than $0.4 \mathrm{~mm}$. Although a trend of downstream fining is indicated along this 3-km reach, all of these sediment samples were dominated by the API 40/70 size class, which was the size class selected for crush-resistance testing for all six sediment samples (table 9B). Areally extensive and thick sand deposits along alternate banks of the Niobrara River downstream from Spencer Dam were observed in October 2014 during a sediment-flushing release from the dam (Schaepe and others, in press). In 2014 aerial photography (Google, Inc., 2015), these thick, shelf-type deposits extended at least $2.75 \mathrm{~km}$ downstream from Spencer Dam (fig. 3; $0.35 \mathrm{~km}$ beyond site NR-05), and photographs taken on site by sampling crews in 2015 document that the thick shelf deposits also were present in May 2015. The steep hydraulic gradient extending from Spencer Dam for several hundred meters downstream (mean energy slope of 0.004 meter per meter $[\mathrm{m} / \mathrm{m}]$ from the impoundment to site NR-05) produces swift currents that transport sand as bedload and in suspension (for example, during sediment releases from Spencer Dam, suspended sand concentrations exceeded 10,000 milligrams per liter in several October 2014 samples [Schaepe and others, in press]). Also, at three different places in reach $\mathrm{A}$, the channel narrows to less than $100 \mathrm{~m}$, which also tends to accelerate the current and keep sand moving. Thereafter, the channel widens and its gradient becomes gentler (slope of 0.0013 $\mathrm{m} / \mathrm{m}$ between sites NR-05 and NR-07; fig. 1). The energy gradient decrease along the upstream 6-km reach downstream from Spencer Dam enables depositional sorting of the transported load (conceptually described by Knighton, 1998), resulting in much of the coarsest fraction of the flushed sand being deposited closer to the dam, but finer sand is carried farther downstream.

The PSD of sediment samples from the five sites within the upstream, 3-km reach below Spencer Dam was, on average, dominated by the API 40/70 size class, with an average 67.5 percent in that class and 54.9 percent as medium sand (table $9 \mathrm{~A}$ ). Average geometric mean and median sizes of the washed raw material were 0.27 and $0.28 \mathrm{~mm}$, respectively; an average 40 percent of each sediment sample was coarser than $0.3 \mathrm{~mm}$; and 88 percent was fine-to-medium sand, on average. With an average of 78 percent of sediment sample composition in the API 20/70 size class, the sand shelf deposits within the first $3 \mathrm{~km}$ downstream from Spencer Dam are likely to contain marketable sizes of sand at a product-to-waste ratio of at least 3-to-1. Compared with the PSG sediment samples derived from Loup River sand, the sampled sand from the reach downstream from Spencer Dam was enriched in medium sand, poorer in coarse and very fine sand, and thus was more well sorted - differing by at least 10 percent on each measure of sorting listed in table $9 \mathrm{~A}$. Geometric mean sizes agreed to within about 1 percent when the PSG averages were compared with averages for sites NR-01 through NR-05.

For comparison, Anderson (2011) reported that washed bulk material for two sand samples from North Dakota had a mean size of $0.135-0.174 \mathrm{~mm}$ and bulk compositions dominated by the API 70/140 size class (61-78 percent composition). One sample from the North Dakota study was eolian sand of Holocene age, and the other sample was bedrock of Tertiary age (Paleocene); however, another sample, labeled 

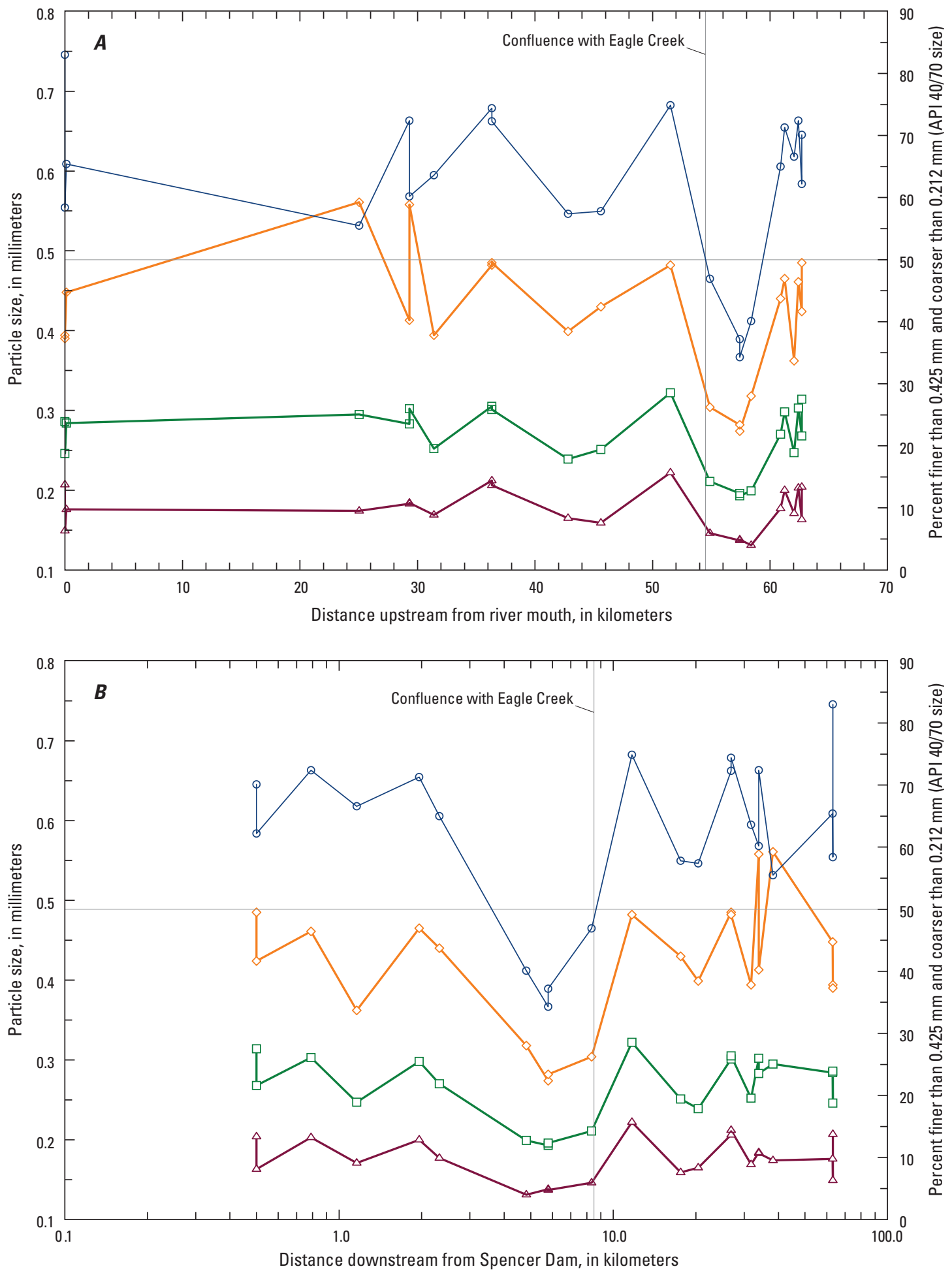

EXPLANATION

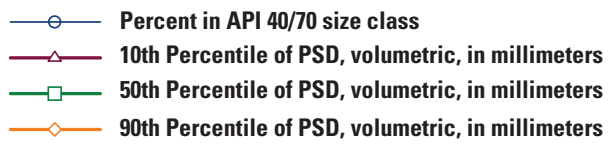

Figure 12. Graphs showing longitudinal distribution of percentiles of the particle-size distribution (PSD) and percentage of washed raw material in American Petroleum Institute (API) 40/70 size class, lower Niobrara River, Nebraska. $A$, upstream distance; $B$, logarithm of downstream distance. (See table 1 for upstream distance coordinates of sampled stations.) 
Missouri River channel sand (not crush tested), had a median size of just larger than $0.3 \mathrm{~mm}$ (Anderson, 2011).

The average values of particle shape indicators for sediment samples from these same five sites also exceed the minimum values for proppant as recommended by American Petroleum Institute and others (2008), and these values were slightly larger (better) than the averages for the sediment samples from the upstream impoundment. Compared with the PSG sediment samples, the washed sand from samples of the reach downstream from Spencer Dam was within 1 percent on the sphericity index but was about 3 percent more wellrounded (table 9A).

\section{Reach B-Where Fine Sand is Dominant}

In contrast with reach A, the fine sand and API 70/140 size classes dominated the PSDs of sediment samples from reach B (sites NR-06 through NR-08), geometric mean sizes were less than $0.2 \mathrm{~mm}$, and $d_{90}$ sizes were finer than $0.32 \mathrm{~mm}$ (fig. 9A; table 9A). No lower Niobrara River sediment samples other than those from reach B were as enriched in fine sand (greater than 15 percent by volume). Sediment from reach $\mathrm{B}$ also was better sorted than that from reach $\mathrm{A}$, with the replicate sediment samples from site NR-07 characterized as having the best sorting metrics among all sediment samples from the lower Niobrara River.

Although the washed raw material from reach B does achieve the minimum requirements for roundness and sphericity, this sand is not as well-rounded as the deposits in reach A or the upstream impoundment.

\section{Reach C-Between Eagle Creek and Streamgaging Station 06465500}

The single sediment sample from Eagle Creek contains sand coarser than reach B sandbars and perhaps similar to some sites from reach A; for example, sediment samples NR-02 and NR-04 have similar PSD measures to those of sandbar sediment sample EC-01 from lower Eagle Creek. Downstream from the Eagle Creek confluence, Niobrara River sandbars had coarser PSDs than those from reach B (table $9 A$ ). Geometric mean sizes varied between 0.23 and $0.33 \mathrm{~mm}$ through reach C, likely in response to local tributary deliveries of coarser sand loads alternating with subsequent downstreamfining trends. For example, the series of sampled main-stem sandbars coarsened downstream from Eagle Creek; however, downstream from the Redbird Creek confluence, no coarsening of the main-stem bed material was observed at the next sandbar sampled (NR-11). The sandbar at NR-11 was near the south bank a short distance from where Louse Creek delivered its somewhat finer sand load. The PSDs of sediment sample NR-11 and Louse Creek sediment sample LC-02 were similar in most respects (table $9 A$ ). Farther downstream, sandbars were not observed in the gravel-bed tributaries (not sampled), but the sampled sandbars in the main stem remained at least as coarse as sediment sample NR-11, being dominated by the API 40/70 and medium-sand size classes.
As a group, the reach $\mathrm{C}$ main-stem sediment samples were slightly coarser than those from reach A but generally less well sorted. The fraction coarser than $0.6 \mathrm{~mm}$ was more abundant in reach $\mathrm{C}$ sediment samples, whereas, on average, the fraction finer than $0.25 \mathrm{~mm}$ was distributed almost identically in reaches A and C. The average PSD for reach C sediment samples was similar to that of the PSG samples in the central tendency of the size distribution, but reach $\mathrm{C}$ sediment samples had 8 percent more medium sand than PSG sediment samples (expressed as an RPD). Moreover, the PSG sediment samples were enriched in both tails of the PSD relative to reach C sediment samples. Hence, the PSG material was not as well sorted as the reach $\mathrm{C}$ samples, but both groups were quite similar in roundness and sphericity.

\section{Reach D-At the Niobrara River Mouth}

Considerable uncertainty is inherent when making generalizations from only three sediment samples that were submitted for testing by the PRG laboratory, although the minimum sampled thickness of $29 \mathrm{~cm}$ was greatest for reach D among all the summarized sediment sample groups. Better sorted and more well-rounded than the samples from reach $\mathrm{C}$, the reach $\mathrm{D}$ averages for percent medium sand (55.4 percent), fine sand (32.7 percent), and very fine sand (5.9 percent) also were each larger than their reach $C$ counterparts. The median particle size $(0.275 \mathrm{~mm})$ and average PSD for reach D was similar to that of reach A, but reach D had the largest percentages of API 40/70 and medium-sand size classes among the sediment sample groups along the lower Niobrara River. The average 77.0-percent composition from the API 20/70 size class for reach $\mathrm{D}$ exceeded the threshold for a 3-to-1 ratio of marketable product to waste. These results for the downstream reach of the Niobrara River are similar to what Coker and others (2009) reported - the coarsest part of the sediment load entering Lewis and Clark Lake settles onto the delta, which has an overall median particle diameter of about $0.28 \mathrm{~mm}$.

The PSD in reach D was finer than that of the PSG sediment samples, particularly so for measures of the coarse tail of the distribution. However, the central tendencies of particle size and shape (roundness and sphericity) were similar for both groups of sediment samples.

\section{Results for Dominant Proppant Size Class}

For lower Niobrara River sand samples dominated by the API 40/70 size, 9 of the 25 nonzero-weighted main-stem samples tested for crush resistance passed the American Petroleum Institute and others (2008) minimum criterion (less than 10-percent fines in postcrush PSD) (table 9B). The average pretest characteristics of these 9 sediment samples included mean size of $0.32 \mathrm{~mm}$; median size of $0.30 \mathrm{~mm}$; 10th and 90th percentile sizes of 0.24 and $0.39 \mathrm{~mm}$, respectively; sphericity of 0.66 ; roundness of 0.77 ; and bulk density of 1.51 grams per cubic centimeter $\left(\mathrm{g} / \mathrm{cm}^{3}\right)$. These characteristic averages were similar to those of the sediment samples of Loup River 
Power Canal dredge spoils near Genoa, Nebr., except that the sediment samples of mined dredge spoils had particle-size statistics that were $0.01-0.025 \mathrm{~mm}$ coarser.

All sediment samples from the lower Niobrara River that were dominated by the 40/70 size class had sphericity and roundness values exceeding API-recommended values for proppant. Sphericity ranged from 0.64 to 0.66 and averaged 0.65 units on the Krumbein-Sloss scale. Roundness ranged from 0.74 to 0.78 and averaged 0.76 units (well-rounded). Results for the four samples dominated by the 70/140 size class correspond to the reach $\mathrm{B}$ results that are discussed in the "Reach B-Where Fine Sand is Dominant" subsection of this report. The remainder of this section of the report presents results for the dominant-size class by reach for the four sampled main-stem reaches downstream from Spencer Dam.

\section{Reach A-Where Medium Sand is Dominant}

The weighted-average API mean size of the tested sediment subsamples was $0.314 \mathrm{~mm}$ for the reach A sediment samples sieved to retain the API 40/70 size class. The sieved sediment subsamples acceptably achieved at least 90.9-percent homogeneity for the 40/70 nominal size range, averaging a 92-percent compositional purity. All sediment samples were well-rounded and had sphericity scores greater than 0.65 , and sediment samples for four of the five sampled locations passed the crush-resistance test at $34.5 \mathrm{MPa}\left(5,000 \mathrm{lbf} / \mathrm{in}^{2}\right)$. No additional sediment samples passed the fines proportional-increase criterion. Hence, 80 percent of the locations sampled in reach A were sand with physical characteristics supporting their apparent potential as sources of natural sand suitable for use as proppant. The planimetric area of the sampled sand deposits was 16.1 square hectometers (39.7 acres), as measured using a geographic information system with aerial photography from September 2014 that preceded the October 2014 sediment flush from Spencer Dam that likely rebuilt these sand deposits; thus, the measured area of the deposits may be considered a conservative estimate of the extent of these deposits in May 2015. Similarly, a conservative thickness for these sand deposits was estimated using four sampled vertical intervals that averaged $54 \mathrm{~cm}$ thick, but with the knowledge that these sampled intervals did not extend below the water surface. A conservative, acknowledged underestimate (minimum estimate) of sand volume calculated from the planimetric area and thickness was about 86,000 cubic meters, but the handful of sediment samples collected for this pilot reconnaissance study is insufficient for an unbiased estimate of the total volume of upstream sand sources within reach A.

Results for crush testing of two API 40/70-size sand samples from the North Dakota study were reported by Anderson (2011) as having crush-resistance $K$ values of less than 13.8 $\mathrm{MPa}\left(2,000 \mathrm{lbf} / \mathrm{in}^{2}\right)$, which is the stress level given in American Petroleum Institute and others (2008, p. 26) as the minimum guideline for frac sand. The North Dakota sand samples had quartz mineralogical composition of 84-85 percent and mean sizes not coarser than 0.245 mm (Anderson, 2011).
The API 40/70 size fraction of reach A sediment samples was considerably more suitable as a proppant source than the finer, less crush-resistant eolian sand from North Dakota. Relative to the crush-resistance test results for the API 40/70 size fraction of sediment samples of mined Loup River settling-basin dredge spoils from near Genoa, Nebr., four of five reach A sediment sample locations compared favorably - the four had increases in fines composition of 1.6-5.9 percentage points, whereas fines in the PSG mine sediment samples increased by an average 6.8 percentage points.

\section{Reach B-Where Fine Sand is Dominant}

The tested sediment subsamples from reach B had a weighted-average API mean size of $0.174 \mathrm{~mm}$ as sieved to retain the API 70/140 size class. None of the four sieved sediment subsamples achieved 90-percent homogeneity for the 70/140 nominal size range, averaging only 78.9-percent compositional purity. All sediment samples were well-rounded but sphericity averaged 0.63 , a little less than the average for upstream reaches A and SP. All four sediment samples tested passed the crush-resistance test at the $34.5-\mathrm{MPa}(5,000 \mathrm{lbf} /$ $\mathrm{in}^{2}$ ) stress level. Of the three sandbars sampled, two had no more than 3-percent fines after the crush test, easily meeting not only the API guidelines but surpassing even more stringent criteria for crush resistance (Bennetts, 2013) that accept a maximum of 6-percent fines following the crush test for the API 70/140 size class. None of the reach B samples passed the fines proportional-increase criterion.

The reach B sediment samples with not more than 3-percent fines following crush testing had proportional increases in percent fines of 150-200 percent relative to precrush condition; therefore, with a similar proportional increase in fines, those two sediment samples might pass a higher-stress crushresistance level. The API 70/140-size proppant commonly is crush tested at stress levels as high as $82.7 \mathrm{MPa}(12,000 \mathrm{lbf} /$ $\left.\mathrm{in}^{2}\right)$.

In summary, although sampled reach B deposits may satisfy minimum criteria for potential use as sources of natural sand suitable for use as proppant, the tested sediment subsamples that were nominally of the 70/140 size class were not adequate in class purity for results to be representative or conclusive. Moreover, the sampled reach B deposits were not predominantly composed of the size classes in high demand as proppant. Therefore, the areal extent of sand deposits in reach $\mathrm{B}$ was not determined.

\section{Reach C—Between Eagle Creek and Streamgaging Station 06465500}

The tested sediment subsamples from reach $\mathrm{C}$, as sieved to retain the dominant API 40/70 size class, had a weightedaverage API mean size of $0.325 \mathrm{~mm}$ (table $9 B$ ). Of the nine sieved sediment subsamples, seven achieved 90 -percent homogeneity for the 40/70 nominal size range, averaging 90.3-percent compositional purity. All sediment samples were well-rounded but sphericity averaged 0.65 , suitable for frac 
sand. Only two of the reach $\mathrm{C}$ sediment samples tested passed the crush-resistance test at the $34.5-\mathrm{MPa}\left(5,000 \mathrm{lbf} / \mathrm{in}^{2}\right)$ stress level; however, the increase in fines during the crush test was limited to not more than 7.8 percentage points for three additional sediment samples. Although none of the reach $\mathrm{C}$ sediment samples passed the fines proportional-increase criterion, if the tested sediment subsamples had been prepared so as to minimize their precrush fines composition in the 40/70size sediment subsample, five of the nine reach $\mathrm{C}$ sediment samples potentially could have produced a passing result at the 34.5-MPa stress level. Nevertheless, only seven sampling locations are represented among the reach $\mathrm{C}$ sediment samples, and the results indicate that only three sampled deposits were likely to yield sand suitable for proppant.

The dilution of higher-quality sand supplies upstream from reach C, where Sand Hills sources predominate, with mixed loads of sand and gravel from tributaries downstream from the Eagle Creek confluence seems to be a key factor limiting the potential for reach $\mathrm{C}$ to consistently produce channel deposits suitable for frac sand; therefore, the areal extent of sand deposits in reach $\mathrm{C}$ was not determined. Relative to the PSG Loup River sand samples, reach C sediment samples on average were finer, which was particularly evident in percentage composition in the size fraction between 0.212 and $0.30 \mathrm{~mm}(50 / 70$ size $)$.

\section{Reach D-At the Niobrara River Mouth}

The tested sediment subsamples from reach D represent only two locations of what might be arguably considered a single extensive deposit. As sieved to retain the dominant API 40/70 size class, sediment subsamples had a weighted-average API mean size of $0.312 \mathrm{~mm}$ (table $9 B$ ) and particle-size statistics reflected net downstream fining across the unsampled interval between reaches $\mathrm{C}$ and $\mathrm{D}$. All three sieved sediment subsamples achieved 90-percent homogeneity for the 40/70 nominal size range, averaging 91.8-percent compositional purity. All sediment samples were well-rounded and sphericity averaged 0.65 , which is suitable for frac sand.

None of the tested reach D sediment samples passed the crush-resistance test at the $34.5-\mathrm{MPa}\left(5,000 \mathrm{lbf} / \mathrm{in}^{2}\right)$ stress level; however, for one of the sampled locations, the increase in fines during the crush test was only 6.7 percentage points. Although none of the reach D sediment samples passed the fines proportional-increase criterion, if sediment subsamples from location NR-49 could have been prepared carefully, so as to halve their precrush fines composition, the probability of passing the crush-resistance test criterion at $34.5 \mathrm{MPa}$ seems likely. As was the case for reach C, reach D sediment samples were finer on average than the PSG Loup River sand samples, and this was particularly evident in percentage composition in the size fraction between 0.212 and $0.30 \mathrm{~mm}$ (50/70 size). Therefore, the areal extent of sand deposits in reach $\mathrm{D}$ was not determined.

\section{Summary and Conclusions}

Sediment management is a challenge faced by reservoir managers who have several potential options, including dredging, for mitigating the loss of storage capacity to sedimentation. As sediment is removed from reservoir storage, potential use of the sediment for socioeconomic or ecological benefits could defray some costs of its removal. Rivers that transport a sandy sediment load will deposit the sand load along a reservoir-headwaters reach where the current of the river slackens. Given a combination of factors, a reservoir deposit of alluvial sand has potential to be suitable for use as proppant for hydraulic fracturing in unconventional oil and gas development. In 2015, the U.S. Geological Survey began a program of researching nontraditional sources of fracture sand (hereinafter referred to as frac sand) from reservoirs, with an initial focus on the Missouri River subbasins that receive sand loads from the Nebraska Sand Hills. This pilot effort was a case study to identify and test methodologies that might be used, modified, and improved for similar work at other impoundments across the Midwest and other regions.

This report documents the methods and results of assessments of the suitability of river delta sediment as frac sand for a case study area in the delta headwaters of Lewis and Clark Lake, Nebraska and South Dakota. Additionally, the U.S. Geological Survey collected samples of upstream sand sources in the lower Niobrara River valley. Despite the study being a general reconnaissance-level study, one goal was to test the methodology for assessing sand deposits as to physical suitability for proppant and selected factors affecting potential development of the resource. Study goals also included attainment of the following evaluation endpoints:

- comparison of resulting sand properties with those of sand suitable for use as proppant, to include direct comparisons for the dominant-size fraction of each sample;

- distribution within each sand body of the analyzed physical properties of sediment, to include particle-size distribution (PSD), roundness/sphericity, hardness (crush resistance), and stratigraphy; and

- estimation of the volume of evaluated sand bodies in the river delta, along with their estimated spatial extent.

This report describes the physical characteristics and assesses the suitability of river delta sand deposits of the Missouri River near the head of Lewis and Clark Lake for use as a proppant feedstock resource in unconventional oil or gas production. Additionally, the spatial extent and volume of sampled delta sand bodies are estimated; and the Missouri River delta sand is compared with sand samples collected from selected upstream source areas along the lower Niobrara River from the Spencer Dam impoundment to the confluence with the Missouri River. 
Within the Missouri River delta, the four sandbar complexes that were sampled for this study are contained in a 3.5-kilometer reach that extends downstream from immediately south of the town of Running Water, S. Dak.; the sandbar complexes are identified herein as A (most upstream) through D (most downstream). At each of 25 locations, two cores (3.8-centimeter diameter) were collected to a depth of 3.7 meters $(\mathrm{m})$. Each set of cores was collected approximately $0.5 \mathrm{~m}$ apart. Of the 25 paired direct-push sediment cores, one core from each pair of cores was lithologically described. Generally speaking, core intervals that were well sorted, had rounded grains, and were relatively free of silt and organic matter were selected for further analysis. In total, 71 samples were selected from the direct-push sediment cores collected in the Missouri River delta.

For this study, all sampling sites used to characterize potential upstream sources were along the lower Niobrara River valley, which is consistent with the present understanding that the Niobrara River is the source of nearly threefourths of the sand load entering the Missouri River delta. Upstream sand deposits of three types were identified as likely having contrasting physical characteristics and were targeted as separate sampling strata for representing the following upstream sources of sand: (1) impounded main-stem sediment (reach SP), (2) downstream main-stem channel deposits (reaches A-D in downstream order), and (3) channel sandbar deposits of selected tributary streams.

Spencer Dam impoundment was sampled using a Universal push corer to bore into the distributary channel deposits to a target depth ranging from about 0.4 to $0.6 \mathrm{~m}$. Bore depth was limited by refusal or the $0.7-\mathrm{m}$ length of open core barrel affixed to the sampler head. Cores of bottom sediment from the impoundment behind Spencer Dam were collected as three pairs of boring locations along the sampled transect. Of the six coring sites, one did not yield a sufficient mass of sand-sized material for submittal to the laboratory; therefore, laboratory results are available only for five of the cored locations (eight samples were analyzed overall, including two replicate pairs).

Samples of free-flowing channel deposits were collected from medial bars and sand shelves, using one of two methods dependent on whether the hand-pushed corer could penetrate to softer, fully saturated sand near the water level in the sandbar. When the sampled interval was mostly saturated material, a manual push-coring method was used; cores were retrieved after sealing the barrel top manually with a test plug to create suction. A second method, used to sample unsaturated material, involved collection of a bank-scrape sample using a trowel or scoop. In total, 25 samples (including 2 replicates) from free-flowing reaches were analyzed.

Exploratory analysis of natural sand for determining its suitability as a proppant involved application of a subset of the protocols known as American Petroleum Institute (API) Recommended Practice 19C (RP19C). The Proppant Research Group at Montana Tech analyzed the sand samples using their standard (modified API RP19C) protocol. Raw samples were weighed, prepared for analysis (washed, dried, and sieved/ disaggregated), and reweighed. An optical imaging particlesize analyzer (OPSA) measured the continuous PSD of the sample and also measured particle shape (sphericity and roundness). The OPSA uses dynamic digital-image processing to analyze the size and shape in images from a twocamera system collecting more than 275 images per second of dispersed particle shadows to achieve a 1-micron resolution. Gravity dispersion (free fall) was used with the dry, pourable sand samples. The OPSA's measurement range includes the full range of sand sizes $(0.0625-2$ millimeters $[\mathrm{mm}])$ and beyond.

Based on the PSD measured with the OPSA, the dominant sand size was identified from among the standard proppant size classes specified in API RP19C. The washed sample was split and then sieved to separate the dominant-size class. A representative aliquot of the sieved subsample was tested for crush resistance at a predetermined level of stress (34.5 megapascals [MPa], or 5,000 pounds-force per square inch $\left.\left[\mathrm{lbf} / \mathrm{in}^{2}\right]\right)$. The resulting material was weighed and its PSD was reanalyzed with the OPSA. The fraction of the material smaller than the finer bounding sieve size of the tested size class was reported as the percent fines, an indication of the percentage that was not crush resistant at that stress level. Samples that meet the API minimum requirement for proppant have a postcrush percent fines of not more than 10 percent by weight.

Imprecision associated with sampling error in this study averaged 10 percent or less, and the relative percent difference (RPD) between paired replicate values generally was less than 14 percent for size classes that contained more than 30 percent of sample volume. However, RPDs increased substantially for particle-size classes consisting of small parts of a sample (generally less than 6 percent), with such classes being confined to the tails of the sample frequency distribution. The modest differences in mean sizes and percentiles determined between OPSA-based methods and sieve-based results were within accepted limits; thus, laboratory imprecision was not a concern for this study. However, the interlaboratory-comparison results for six samples indicated a substantial bias. The environmental data analysis reported herein used the OPSA results for washed samples because the paucity of dry-sieved results precluded attempted reconstructions of whole samples; however, the raw, whole samples likely were more enriched in fine sand than what OPSA results indicate.

Results from surface-geophysical surveys (inverted capacitively coupled resistivity profiles) were compared with core logs and laboratory analysis results. Comparisons indicated that delta sediments were unstratified mixtures of sand and silt. Apparent-resistivity values in the $60-100 \mathrm{ohm}-$ meters (ohm-m) range corresponded to proppant sizes 40/70 and 70/140; 78 percent of the samples in the $40 / 70$ and 70/140 size classes had resistivity values between 60 and $100 \mathrm{ohm}-\mathrm{m}$. Resistivity values within the $90-100 \mathrm{ohm}-\mathrm{m}$ range generally correspond to samples dominated by medium sand and the 40/70 size class of proppant. Resistivity surveys could be a viable tool to estimate the spatial extent and potentially the 
volume of minable proppant. Attempts were made to estimate a total volume of marketable sand within the four sampled sandbar complexes. The inverted resistivity models divided the cross-sectional area of each profile into a grid with seven discrete layers of varying thicknesses. Roughly 56 percent of the profiled cross-sectional areas were in the $60-100 \mathrm{ohm}-\mathrm{m}$ range, indicating materials underlying each profile contain a substantial volume of potentially marketable sizes of sand dominated by $40 / 70$ and 70/140 proppant size classes. About 6 percent of the cross-sectional area underlying the profiles was in the $90-100 \mathrm{ohm}-\mathrm{m}$ range, which is likely dominated by the API 40/70 dominant-size class.

From PSDs of the bulk washed samples, the geometric mean size averaged $0.27 \mathrm{~mm}, 80$ percent of the samples were predominantly sand in the API 40/70 size class, and 17 percent were predominantly sand in the API 70/140 size class. The two remaining samples were in the API 20/40 and 30/50 size classes. Distributions of geometric mean size among the four sandbar complexes were similar, but samples collected from sandbar complex B had PSDs indicating slightly coarser deposits. The average geometric mean sizes among the four sandbar complexes were similar and ranged from 0.26 to $0.30 \mathrm{~mm}$. For particle shape, all samples surpassed the recommended minimum value of 0.6 units for sphericity and roundness as measured by the OPSA using the KrumbeinSloss scale.

For proppant strength, of 57 crush-resistance tested samples of 40/70-sized sand, 23 (40 percent) were interpreted as meeting the minimum criterion at $34.5 \mathrm{MPa}\left(5,000 \mathrm{lbf} / \mathrm{in}^{2}\right)$. Of 12 tested samples of 70/140-sized sand, 9 ( 75 percent) had less than 10 percent fines by volume following crush testing, interpreted as achieving the minimum criterion at $34.5 \mathrm{MPa}$ $\left(5,000 \mathrm{lbf} / \mathrm{in}^{2}\right)$.

Crush resistance for delta samples was strongest at sandbar complex A, where 67 percent of tested samples met the 10-percent fines criterion at the $34.5 \mathrm{MPa}\left(5,000 \mathrm{lbf} / \mathrm{in}^{2}\right)$ threshold. This frequency was higher than was indicated by samples from sandbar complexes B, C, and D that had rates of 50, 46, and 42 percent, respectively. The group of sandbar complex A samples also contained the largest percentage of the samples dominated by the API 70/140 size class, which overall had a higher percentage of samples meeting the minimum percent-fines criterion compared to samples dominated by coarser size classes. However, samples from sandbar complex A that had the API 40/70 size class tested also had a higher rate for meeting the minimum criterion (57 percent) than did samples from sandbar complexes B, C, and D $(50,43$, and 40 percent, respectively).

A total of 22 main-stem sampling locations along the lower Niobrara River contributed samples to the following overall summary of sediment characteristics and test results. For PSD of bulk washed samples, geometric mean size averaged $0.26 \mathrm{~mm}$, an average 61 percent was sand in the API 40/70 size class, and 28 percent was sand in the API 70/140 size class. Average composition was 48 percent medium sand, 38 percent fine sand, 7.5 percent very fine sand, and
6.0 percent coarse sand. Average sorting was in the moderately well-sorted category.

For the 25 upstream sources samples that were dominated by $40 / 70$-sized sand, 88 percent had the recommended homogeneity of at least 90 percent. For the remaining four samples, a 70/140-sized sand was dominant, but percent composition by that size class was substandard, averaging 80 percent. For particle shape, all 29 samples surpassed the recommended minimum score of 0.6 for sphericity and roundness.

For proppant strength, crush resistance was tested at a predetermined level of stress ( $34.5 \mathrm{MPa}$, or $\left.5,000 \mathrm{lbf} / \mathrm{in}^{2}\right)$. To meet the minimum requirement, not more than 10 percent of the tested sample should be finer than the second primary sieve after the stress test. Overall, of the 25 tested samples of 40/70-sized sand, 9 samples passed the minimum criterion at $34.5 \mathrm{MPa}\left(5,000 \mathrm{lbf} / \mathrm{in}^{2}\right)$, but only 4 samples passed the more-stringent criterion of 8-percent postcrush fines. All four $70 / 140$ sand samples tested passed the minimum criterion at 34.5 MPa $\left(5,000 \mathrm{lbf} / \mathrm{in}^{2}\right)$, with postcrush fines percentage of at most 5.1 percent.

For two reaches (A and B) of the lower Niobrara River, where hydraulic sorting was energized artificially by the hydraulic head drop at and immediately downstream from Spencer Dam, suitability of channel deposits for potential use as frac sand was confirmed by test results. All reach A washed samples were well-rounded and had sphericity scores above 0.65 , and samples for four of the five ( 80 percent) sampled locations met the crush-resistance criterion at the $34.5 \mathrm{MPa}$ $\left(5,000 \mathrm{lbf} / \mathrm{in}^{2}\right)$ stress level. A conservative lower-bound estimate of sand volume in the reach A deposits calculated from the planimetric area and minimum thickness was about 86,000 cubic meters. All reach B samples were well-rounded but sphericity averaged 0.63 , a little less than the average for upstream reach A. All four samples tested passed the crushresistance test at the $34.5-\mathrm{MPa}\left(5,000 \mathrm{lbf} / \mathrm{in}^{2}\right)$ stress level. Of the three reach B sandbars sampled, two had no more than 3-percent fines after the crush test. All four samples of 70/140sized sand met not only the API minimum guidelines, but surpassed even more stringent criteria for crush resistance that accept a maximum of 6-percent fines following the crush test for the API 70/140 size class.

About one-half of the $40 / 70$ size sand samples from the three remaining reaches of the lower Niobrara River valley had characteristics and test results indicating minimal suitability for use as frac sand; these were reaches (SP, C, and D) where sand deposits exhibited fairly typical river sorting of sediment from mixed sources. For impounded reach SP, size $40 / 70$ sand samples from three of the five coring locations passed the crush test at $34.5 \mathrm{MPa}\left(5,000 \mathrm{lbf} / \mathrm{in}^{2}\right)$ by having postcrush fines of $4.8-8.6$ percent. Not more than 50 percent of samples from reaches $\mathrm{C}$ and $\mathrm{D}$ met the crush-resistance criterion at the tested stress level.

Relative to the crush-resistance test results for the API 40/70 size fraction of two samples of mine output from Loup River settling-basin dredge spoils near Genoa, Nebr., four of five reach A sample locations compared favorably. The 
samples from these four sites had postcrush increases in fines composition of 1.6-5.9 percentage points, whereas fines in the two tested Preferred Sands of Genoa mine samples increased by an average 6.8 percentage points.

\section{References Cited}

Abireddy, C.O.R., and Clayton, C.R.I., 2009, A review of modern particle sizing methods: Proceedings of the Institution of Civil Engineers, Geotechnical Engineering, v. 162, p. 193-201.

Advanced Geosciences, Inc., 2008, Instruction manual for EarthImager 2D, version 2.3.0-Resistivity and IP inversion software: Austin, Tex., Advanced Geosciences, Inc., 139 p.

Ahlbrandt, T.S., and Fryberger, S.G., 1980, Eolian deposits in the Nebraska Sand Hills: U.S. Geological Survey Professional Paper 1120-A, 24 p.

Alexander, J.S., and Schaepe, N.J., 2014, Sedimentologic and bed-material budget analyses of sandbars, lower Platte River, eastern Nebraska, 1970 to 2011: appendix C of U.S. Army Corps of Engineers, Lower Platte River Cumulative Impact Study Phase III Summary Report: [Omaha, Nebr.] U.S. Army Corps of Engineers report prepared for the Lower Platte River Corridor Alliance, 95 p.

American Petroleum Institute (API), 1983, Recommended practices for testing sand used in hydraulic fracturing operations [Recommended Practice 56]: Washington, D.C., API Publishing, $13 \mathrm{p}$.

American Petroleum Institute (API), 1989, Recommended practices for testing high strength proppants used in hydraulic fracturing operations [Recommended Practice 60]:

Washington, D.C., API Publishing, 21 p.

American Petroleum Institute (API), American National Standards Institute (ANSI), and International Organization for Standardization (ISO), 2008, Measurement of properties of proppants used in hydraulic fracturing and gravel-packing operations; ANSI/API Recommended Practice 19C, part 2 of Petroleum and natural industries - Completion fluids and materials (ISO 13503): Washington, D.C., API Publishing, $30 \mathrm{p}$.

Anderson, F.J., 2011, Investigation of sand resources in North Dakota-Sedimentological characterization of surficial sand deposits for potential use as proppant: Bismarck, North Dakota Geological Survey Report of Investigation 110, $77 \mathrm{p}$.

ASTM International, 2004, Standard specification for wire cloth and sieves for testing purposes (E11-04): West Conshohocken, Pa., ASTM International, 5 p., accessed January 4, 2008, at http://www.astm.org/Standards/E11.htm.
Ball, L.B., Kress, W.H., Steele, G.V., Cannia, J.C., and Andersen, M.A., 2006, Determination of canal leakage potential using continuous resistivity profiling techniques, Interstate and Tri-State Canals, western Nebraska and eastern Wyoming, 2004: U.S. Geological Survey Scientific Investigations Report 2006-5032, 53 p., accessed February 2016 at http://pubs.usgs.gov/sir/2006/5032/.

Beckwith, Robin, 2011, Proppants-Where in the world: Journal of Petroleum Technology, v. 63, no. 4, p. 36-41.

Bennetts, A.C., 2013, Understanding frac sand requirements, in Frac Sand Insider Conference, Pittsburgh, 2013, Conference Program and Session Archives: Denver, Mining Media International, accessed September 25, 2015, at http:// www.fracsandinsider.com/mmi_ConferenceDL/2013FSI/ FSIThurAlan\%20Bennetts\%20(2).pdf.

Benson, M.E., and Wilson, A.B., 2015a, Frac sand in the United States-A geological and industry overview: U.S. Geological Survey Open-File Report 2015-1107, 78 p., accessed December 11, 2015, at http://dx.doi.org/10.3133/ ofr20151107.

Benson, M.E., and Wilson, A.B., 2015b, Frac sand sources in the United States: Rock Products, v. 118, no. 5, p. 34, accessed June 26, 2015, http://www.rockproducts.com/fracsand/14379-frac-sand-sources-in-the-united-states.html.

Blatt, Harvey, and Tracy, R.J., 1996, Petrology-Igneous, sedimentary, and metamorphic ( $2 \mathrm{~d}$ ed.): New York, W.H. Freeman and Company, $529 \mathrm{p}$.

Blott, S.J., 2010, GRADISTAT, Grain size analysis program, Version 8.0 for Excel: Berkshire, U.K., Kenneth Pye Associates, Ltd., spreadsheet software add-in macro, accessed January 28, 2016, at http://www.kpal.co.uk/gradistat.html.

Blott, S.J., and Pye, K., 2001, GRADISTAT-A grain size distribution statistics package for the analysis of unconsolidated sediment: Earth Surface Processes and Landforms, v. 26 , p. $1237-1248$.

Bridge, J.S., 2003, Rivers and floodplains-Forms, processes, and sedimentary record: Malden, Mass., Blackwell, 491 p.

Brune, G.M., 1953, Trap efficiency of reservoirs: Transactions, American Geophysical Union, v. 34, p. 407-418, accessed February 20, 2016, at http://dx.doi.org/10.1029/ TR034i003p00407.

Butler, D.K, ed., 2005, Near-surface geophysics; Investigations in geophysics, No. 13: Tulsa, Okla., Society of Exploration Geophysicists, 732 p.

Chicago and North Western Railway, 1882, Correct map of Dakota compiled from United States and Territorial surveys Nov. 1, 1882: Chicago, Rand-McNally, 1 sheet, scale 1:1,500,000, accessed December 16, 2015, at http://www. loc.gov/resource/g4181p.rr003700/. 
Coker, E.H., Hotchkiss, R.H., and Johnson, D.A., 2009, Conversion of a Missouri River dam and reservoir to a sustainable system-Sediment management: Journal of the American Water Resources Association, v. 45, p. 815-827, accessed September 15, 2015, at http://dx.doi.org/10.1111/ j.1752-1688.2009.00324.x.

Courtney, Phillip, 2014, Frac sand potential on selected state trust lands: Denver, Colorado Department of Natural Resources, State Land Board, 11 p.

Cowman, T., Sweeney, M., Dixon, M., Campbell, M., Geary, N., and Boever, C., 2013, Historical and future sediment accumulation in the Niobrara River delta and Lewis and Clark Lake headwaters: Vermillion, S. Dak., University of South Dakota Missouri River Institute, slide presentation, $34 \mathrm{p}$.

Dolley, T.P., 2016, Sand and gravel (industrial), in Mineral Commodity Summaries 2016: U.S. Geological Survey, p. 144-145, accessed June 2016 at http://dx.doi. org/10.3133/70140094.

Economides, M.J., Hill, A.D., Ehlig-Economides, C., and Zhu, D., 2013, Petroleum production systems (2d ed.): Upper Saddle River, N.J., Prentice Hall, 730 p.

Engineering and Hydrosystems, Inc., 2002, Conceptual analysis of sedimentation issues on the Niobrara and Missouri Rivers, South Dakota and Nebraska: Omaha, U.S. Army Corps of Engineers, $19 \mathrm{p}$.

Esswein, E.J., Breitenstein, M., Snawder, J., Kiefer, M., and Siebeer, W.K., 2013, Occupational exposures to respirable crystalline silica during hydraulic fracturing: Journal of Occupational and Environmental Hygiene, v. 10, p. 347356, DOI: 10.1080/15459624.2013.788352, accessed March 23, 2016, at http://digitalcommons.unl.edu/publichealthresources/281.

Folk, R.L., 1968, Petrology of sedimentary rocks: Austin, University of Texas Hemphills Publication, 170 p.

Folk, R.L., and Ward, W.C., 1957, Brazos River bar-A study in the significance of grain size parameters: Journal of Sedimentary Petrology, v. 27, p. 3-26.

Freedonia Group, 2015, Proppants in North America: Cleveland, Ohio, Freedonia Group, study 3302, 251 p.

Geiver, Luke, 2014, Entering the frack sand industry: The Bakken Magazine, 3 p., accessed December 14, 2015, at http://www.thebakken.com/articles/602/entering-the-fracksand-industry.

Geometrics, 2001, OhmMapper TR1 operation manual, rev. F: San Jose, Calif., Geometrics, Inc., 147 p., accessed February 2016 at ftp://geom.geometrics.com/pub/GeoElectric/Manuals/OhmMapper-Manual-TRN-2004.PDF.
Geometrics, 2009, DataMap ${ }^{1}$ user guide 2.0: San Jose, Calif., Geometrics, Inc., DataMap (24890-01) OhmMapper manual 29007-01, rev. A, 75 p., accessed July 7, 2017, at ftp:// geom.geometrics.com/pub/GeoElectric/Manuals/DATMAPM.PDF.

Getty, J.C., 2013, Overview of proppants and existing standards and practices, in ASTM Subcommittee D18.26 Hydraulic Fracturing, Jacksonville, Florida, 2013: ASTM International, 20 p., accessed December 14, 2015, at http:// www.astm.org/COMMIT/images/6D_Getty_ProppantTestingStandards_ASTM_Mtg18.26_Jan2013V2.pdf.

Getty, J.C., Krzywosz, N.V., and McDonald, Catherine, 2016, SNaP; A survey of native proppant resources within Montana; Final report: Montana Department of Natural Resources and Conservation, Board of Oil and Gas Conservation, Exhibit 2 for Board meeting of February 10, 2016, 45 p., 5 appendices, accessed February 2016 at http://bogc. dnrc.mt.gov/Hearings/2016/2016_02/2016_02_Exhibits\%20 2-5r.pdf.

Gill, M.A., 1979, Sedimentation and useful life of reservoirs: Journal of Hydrology, v. 44, p. 89-95, accessed February 22, 2016, at http://dx.doi.org/10.1016/00221694(79)90148-3.

Google, Inc., 2015, Google Earth ${ }^{\circledR}$ imagery: Mountain View, Calif., Google, digital aerial imagery dated February 20, 2014.

Gordon, J.D., Newland, C.A., and Gagliardi, S.T., 2000, Laboratory performance in the sediment laboratory qualityassurance project, 1996-98: U.S. Geological Survey WaterResources Investigations Report 99-4184, 39 p.

Gutentag, E.D., Heimes, F.J., Krothe, N.C., Luckey, R.R., and Weeks, J.B., 1984, Geohydrology of the High Plains aquifer in parts of Colorado, Kansas, Nebraska, New Mexico, Oklahoma, South Dakota, Texas, and Wyoming: U.S. Geological Survey Professional Paper 1400-B, 63 p.

Guy, H.P., 1969, Laboratory theory and methods for sediment analysis: U.S. Geological Survey Techniques of WaterResources Investigations, book 5, chap. C1, 58 p.

Hall, B.M., and Hobza, C.M., 2017, Streambed sediment data for Missouri and Niobrara Rivers, Nebraska and South Dakota, 2015: U.S. Geological Survey data release, accessed November 2017 at https://doi.org/10.5066/ F79W0CQB.

Helsel, D.R., and Hirsch, R.M., 2002, Statistical methods in water resources: U.S. Geological Survey Techniques of Water Resources Investigations, book 4, chap. A3, 522 p.

\footnotetext{
${ }^{1}$ DataMap is exactly the same software as Geometrics MagMap96 software (Geometrics, 2009, p. 8).
} 
Holditch, S.A., 2007, Hydraulic fracturing, chap. 8 of Clegg, J.D., ed., Petroleum Engineering Handbook, Vol. IV, Production operations engineering: Society of Petroleum Engineers, p. 323-366, accessed June 2016 at http://petrowiki. org/PEH\%3AHydraulic_Fracturing\#In-Situ_Stresses.

Houston, Everett, [1938], How R. R. came to Niobrara, Nebraska: New Mexico, U.S. Work Projects Administration, Federal Writers' Project, 3 p., retrieved from the Library of Congress, accessed December 15, 2015, at https://www.loc. gov/item/wpalh001206/.

Houseworth, James, 2014, Advanced well stimulation technologies, Sect. 2 of Advanced well stimulation technologies in California-An independent review of scientific and technical information: Sacramento, California Council on Science and Technology, p. 47-87, accessed December 16, 2015, at http://2fwww.ccst.us/publications/2014/2014wst2.pdf.

Jacobson, R.B., Blevins, D.W., and Bitner, C.J., 2009, Sediment regime constraints on river restoration-An example from the Lower Missouri River, in James, L.A., Rathburn, S.L., and Whittecar, G.R., eds., Management and restoration of fluvial systems with broad historical changes and human impacts: Denver, Geological Society of America, Special Paper 451, p. 1-22.

KELRIK LLC, and PropTester, Inc., 2016, 2015 Proppant market report: Cypress, Tex., PropTester, Inc., and KELRIK LLC, accessed July 5, 2016, at http://www.proppantmarketreport.com/.

Knighton, David, 1998, Fluvial forms and processes-A new perspective: London, Arnold, 383 p.

Kondolf, G.M., Gao, Y., Annandale, G.W., Morris, G.L., Jiang, E., Zhang, J., Cao, Y., Carling, P., Fu, K., Guo, Q., Hotchkiss, R., Peyeuil, C., Sumi, T., Wang, H.-W., Wang, Z., Wei, Z., Wu, B., Wu, C., and Yang, C.T., 2014, Sustainable sediment management in reservoirs and regulated riversExperiences from five continents: Earth's Future (AGU), v. 2, no. 5, p. 256-280, DOI:10.1002/2013EF000184, accessed December 9, 2015, at http://onlinelibrary.wiley. com/doi/10.1002/2013EF000184/epdf.

Krumbein, W.C., 1938, Size frequency distributions of sediments and the normal phi curve: Journal of Sedimentary Petrology, v. 8, no. 3, p. 84-90.

Krumbein, W.C., and Sloss, L.L., 1963, Stratigraphy and sedimentation (2d ed.): San Francisco, W.H. Freeman, 660 p.

Loke, M.H., 2009, RES2DINV, ver. 3.58, manual—Rapid 2D resistivity and IP inversion using the least-squares method: Penang, Malaysia, Geotomo Software, 151 p., accessed May 2009 at http://www.geotomosoft.com/downloads.php.
Lucius, J.E., Abraham, J.D., and Burton, B.L., 2008, Resistivity profiling for mapping gravel layers that may control contaminant migration at the Amargosa Desert Research Site, Nevada: U.S. Geological Survey Scientific Investigations Report 2008-5091, 30 p. [Also available at http://pubs.usgs. gov/sir/2008/5091/.]

Marshall, T.R., Johnson, D.J., Chadima, S.A., Schulz, L.D., Fahrenbach, M.D., and Herrig, K.G., 2014, Assessment of South Dakota's sand and alumina resources for use as proppant: Vermillion, University of South Dakota, Geological Survey, Oil and Gas Investigation 5, 33 p.

McBride, E.F., 1963, A classification of common sandstones: Journal of Sedimentary Petrology, v. 33, p. 664-669.

McManus, J., 1988, Grain size determination and interpretation, in Tucker, M., ed., Techniques in sedimentology: Oxford, Blackwell, p. 63-85.

Munsell Color, 1992, Munsell soil color charts: New York, Macbeth, Division of Kollmorgen Instruments Corp., Munsell Color, loose-leaf (continually updated resource).

National Research Council, 2011, Missouri River planning - Recognizing and incorporating sediment management: Washington, D.C., National Academies Press, 164 p., accessed February 24, 2016, at http://www.nap.edu/catalog. php?record_id=13019.

Nebraska Department of Roads, 2016, Niobrara East and West, Highway N-12; Alternative A8-New: Nebraska Department of Roads, Preliminary Plan, Project No. S-125(1011); CN 31674, Knox County, 1 p., accessed at http:// www.roads.nebraska.gov/projects/future-projects/niobraraeast-west/.

OmniSTAR, 2005, OmniSTAR HP subscription service: Houston, Tex., OmniSTAR, Inc., website, accessed April 2013 at http://www.omnistar.com/Support/FAQs.aspx.

Pacific GeoScience, 1998, Missouri River erosion update, 1941-1998 - Yankton Sioux Reservation, Marty, South Dakota: San Anselmo, Calif., Pacific GeoScience [variously paged].

Perkey, D.W., Smith, S.J., and Wadman, H.M., 2013, Physical processes of heterogeneous, cohesive sediments at Lewis and Clark Lake, South Dakota: USACE Engineer Research and Development Center, Letter Report, 18 p., appendices.

Piatak, N.M., Dulong, F.T., Jackson, J.C., and Folger, H.W., 2014, Powder X-ray diffraction laboratory, Reston, Virginia: U.S. Geological Survey Fact Sheet 2014-3063, 2 p., http:// dx.doi.org/10.3133/fs20143063.

Pitney Bowes Software, 2014, Encom Profile Analyst: North Sydney, Australia, accessed January 17, 2014, at http:// www.encom.com.au/template2.asp?pageid $=16$. 
Powers, M.C., 1953, A new roundness scale for sedimentary particles: Journal of Sedimentary Petrology, v. 23, no. 2, p. 117-119.

Preferred Sands, 2016, Products-Materials specification and quality control, Preferred Sands of Genoa: Radnor, Pa., Preferred Sands, 2 p., accessed March 23, 2016, at http://www. preferredsands.com/products/nebraska.html and http:/www. preferredsands.com/products/control.html.

Reinicke, Andreas, Rybacki, Erik, Stanchits, Sergei, Huenges, Ernst, and Dresen, Georg, 2010a, Hydaulic fracturing stimulation techniques and formation damage mechanismsImplications from laboratory testing of tight sandstoneproppant systems: Chemie der Erde, v. 70, p. 107-117, accessed November 19, 2016, at http://doi.org/10.1016/j. chemer.2010.05.016.

Reinicke, Andreas, Zimmermann, Gunter, Blocher, G., Naumov, D., Stanchits, S., Dresen, G., and Huenges, E., 2010b, Mechanical and hydraulic aspects of rock-proppant systems - Experimental approaches and implications for reservoir treatments, in World Geothermal Congress, Bali, Indonesia, 2010, Proceedings: Bochum, Germany, International Geothermal Association, 9 p., accessed March 2, 2016, at https://www.geothermal-energy.org/pdf/IGAstandard/WGC/2010/3146.pdf.

Retsch Technology, 2015, Particle analyzer CAMSIZER ${ }^{\circledR}$ XT: Haan, Germany, Retsch Technology brochure 980.2005/ E-02-2015, 12 p., accessed December 11, 2015, at http:// www.retsch-technology.com/rt/products/dynamic-imageanalysis/camsizer-xt/.

Reynolds, J.M., 1997, An introduction to applied and environmental geophysics: Chichester, England, Wiley, 796 p.

Rietveld, H.M., 1969, A profile refinement method for nuclear and magnetic structures: Journal of Applied Crystallography, v. 2, no. 2, p. 65-71, accessed December 20, 2016, at https://doi.org/10.1107/S0021889869006558.

Rock Products, 2012, Study-Well stimulation materials to rise through 2016: Rock Products, Frac Sand Newsletter, August 29, 2012, accessed at http://www.rockproducts.com/ frac-sand/analysis/11650-study-well-stimulation-materialsto-rise-through-2016.html.

Schaepe, N.J., and Alexander, J.S., 2011, Sediment samples and channel-geometry data, lower Platte River watershed, Nebraska, 2010: U.S. Geological Survey Data Series 572, $22 \mathrm{p}$.

Schaepe, N.J., Zelt, R.B., and Coleman, A.M., in press, Niobrara River suspended-sediment and bed-sediment data collected during hydroelectric dam flush near Spencer, Nebr., October through November, 2014: U.S. Geological Survey data release.
Sharma, P.V., 1997, Environmental and engineering geophysics: Cambridge, England, Cambridge University Press, $475 \mathrm{p}$.

Smart Sand, Inc., 2016, Proppant industry overview, in Form S-1 registration statement as filed with Securities and Exchange Commission, October 25, 2016: Washington, D.C., Securities and Exchange Commission, Registration no. 333-213692, p. 72-77, accessed January 2017 at https:/www.sec.gov/Archives/edgar/ data/1529628/000119312516745690/d219314ds1a.htm.

Tibor, Bodi, 2014, Propping agents and transport proppant in the fracture, chap. 5 of Geothermal reservoirs: Hungary, University of Miskolc, Earth Resources MFKOT5058, web curriculum, accessed March 2, 2016, at http://www.tankonyvtar.hu/hu/tartalom/tamop412A/2011_0059_SCORM MFKOT5058-EN/adatok.html.

Timofeev, V.M., Rogozinski, A.W., Hunter, J.A., and Douma, M., 1994, A new ground resistivity method for engineering and environmental geophysics, in Symposium on the Application of Geophysics to Engineering and Environmental Problems, Boston, Mass., 1994, Proceedings: Denver, Colo., Environmental Engineering Geophysical Society, p. 701-715.

U.S. Army Corps of Engineers, 1977, Missouri River, South Dakota, Nebraska, North Dakota, Montana-Review report for water resources development: U.S. Army Corps of Engineers Missouri River Division, vol. 1-3 [variously paged].

U.S. Army Corps of Engineers, 2001, Niobrara and Missouri Rivers, South Dakota and Nebraska, Sediment StrategiesSection 905(B) (WRDA 86) Analysis, Reconnaissance Report: Omaha, U.S. Army Corps of Engineers Omaha District, Civil Works Branch, 43 p., accessed December 2014 at http://www.cityofyankton.org/yankton/topics/sedimentation-study-web.pdf.

U.S. Army Corps of Engineers, 2004, Gavins Point Dam/ Lewis and Clark Lake master plan, Missouri River, Nebraska and South Dakota_-Updated: Omaha, U.S. Army Corps of Engineers Design memorandum MG-123 [variously paged].

U.S. Army Corps of Engineers, 2011, Lewis and Clark LakeHistory of delta growth: Omaha, U.S. Army Corps of Engineers, Omaha District report-Reconnaissance assessment, $8 \mathrm{p}$.

U.S. Army Corps of Engineers, 2012, Lewis and Clark Lake sediment management study: Omaha, U.S. Army Corps of Engineers fact sheet, $2 \mathrm{p}$. 
U.S. Army Corps of Engineers, 2013a, Lewis and Clark Lake sediment management study (LCLSMS) — Part I. Summary Report on evaluating hydraulic transport of Missouri River delta sediments: Omaha, U.S. Army Corps of Engineers, $23 \mathrm{p}$.

U.S. Army Corps of Engineers, 2013b, Sedimentation conditions at Lewis and Clark Lake, October 2013: Omaha, U.S. Army Corps of Engineers Missouri River Basin (M.R.B.) Sediment Memorandum 29, 106 p., appendices.

U.S. Army Corps of Engineers, 2013c, Survey of sand resources at four U.S. Army Corps of Engineers, St. Paul District's dredge material placement sites for potential use as proppants: St. Paul, U.S. Army Corps of Engineers, 10 p., appendices.

U.S. Fish and Wildlife Service, 2000, Biological opinion on the operation of the Missouri River main stem reservoir system, operation of the Missouri River bank stabilization and navigation project, and operation of the Kansas River reservoir system: U.S. Fish and Wildlife Service, 244 p., accessed December 14, 2015, at http://www.fws.gov/midwest/mussel/documents/april_2000_biological_opinion.pdf.

U.S. Fish and Wildlife Service, 2003, 2003 Amendment to the 2000 biological opinion on the operation of the Missouri River main stem reservoir system, operation of the Missouri River bank stabilization and navigation project, and operation of the Kansas River reservoir system: U.S. Fish and Wildlife Service, 308 p., accessed December 19, 2014, at http://www.fws.gov/feature/pdfs/FinalBO.pdf.

U.S. Geological Survey, Branch of Quality Systems, 2014, Sediment Laboratory Quality-Assurance Project-Study results-Study 2, 2014: U.S. Geological Survey Branch of Quality Systems web page, accessed January 12, 2016, at https://bqs.usgs.gov/slqa/frontpage_study_results.htm.

U.S. Geological Survey, Branch of Quality Systems, 2015, Sediment Laboratory Quality-Assurance Project-Study results_-Studies 1 and 2, 2015: U.S. Geological Survey Branch of Quality Systems web page, accessed January 12, 2016, at https://bqs.usgs.gov/slqa/frontpage_study_ results.htm.
U.S. Silica, 2014, 40/70 Ottawa: Frederick, Md., U.S. Silica, Product data sheet, 2 p., accessed December 14, 2015, at http://www.ussilica.com/sites/ussilica.com/uploads/files/ product-data-sheets/industry/oil-and-gas/USS_4070_ Ottawa.pdf.

University of North Dakota, Energy and Environmental Research Center, 2014, Beyond the boom-Completion and stimulation: Grand Forks, University of North Dakota, Energy and Environmental Research Center, 2 p., accessed December 14, 2015, at https:/www.undeerc.org/Bakken/ completionstimulation.aspx.

Wentworth, C.K., 1922, A scale of grade and class terms for clastic sediments: Journal of Geology, v. 30, no. 5, p. $377-$ 392.

Zdunczyk, Mark, 2007, The facts of frac: Industrial Minerals Journal, no. 1, p. 58-61, accessed June 2016 at http://www. everythingredwing.com/nosand/literature/frac-sand-info/ DrillingMinerals-FactsOfFrac-Jan2007.pdf.

Zdunczyk, M.J., 2013, Hydraulic fracturing sand (frac sand): Mining Engineering, v. 65, no. 7, p. 68-70.

Zdunczyk, M.J., and Nicholls, S., 2014, National Instrument 43-101 Technical Report, Inferred Frac Sand Resource Estimate for the Firebag Property, Northeastern Alberta, Canada: Edmonton, Alberta, Athabasca Minerals, 111 p., accessed June 2016 at http://www.athabascaminerals.com/i/ pdf/Firebag-InferredResource-43-101.pdf.

Zimmermann, Gunter, and Reinicke, Andreas, 2010, Hydraulic stimulation of a deep sandstone reservoir to develop an enhanced geothermal system - Laboratory and field experiments: Geothermics, v. 39, p. 70-77, DOI: 10.1016/j. geothermics.2009.12.003, accessed March 2, 2016, at http:// gfzpublic.gfz-potsdam.de/pubman/item/escidoc:240269:1/ component/escidoc:240268/14609.pdf. 



\section{Glossary}

40/70 size class This standard proppant size class includes particles coarser than U.S. Number 70 mesh ( 0.212 millimeters) and finer than U.S. Number 40 mesh $(0.425$ millimeters).

70/140 size class This standard proppant size class includes particles coarser than U.S. Number 140 mesh (0.106 millimeters) and finer than U.S. Number 70 mesh (0.212 millimeters).

bulk density The unit mass of an untapped or unsettled proppant that will occupy a specific known volume (for example, grams per cubic centimeter). Bulk density includes the mass of the proppant and the mass of air occupying the interstitial spaces between proppant particles (Courtney, 2014).

\section{closure stress (fracture-closure pres-}

sure) The pressure that closes the fracture after the hydraulic fracturing pressure is relieved (Holditch, 2007).

crush resistance The measure of strength of a mass of screened, fines-free dry proppant to force applied over a fixed cross-sectional area, providing an equivalent stress to the proppant under test (Courtney, 2014).

crush-resistance test A laboratory test to determine the amount of proppant crushed at a given stress; the test uses samples that have been sieved so that all particles tested are within a specified size range. The mass of proppant to be tested is a function of its bulk density and the specified loading rate of 1.95 grams per square centimeter. The load is applied in a controlled rate of 13.8 megapascals per minute and held at the final test stress level for 2.0 minutes. The tested sample is resieved to determine the mass of fines generated by the applied stress (American Petroleum Institute and others, 2008).

delta A mound of sediment deposited where a stream enters a body of water and delivers more sediment than can be transported by currents in the water body (Bridge, 2003). frac sand See fracture sand.

fracture conductivity A fluid mechanical property calculated as the product of fracture permeability and fracture aperture (that is, gap width; Zimmermann and Reinicke, 2010).

fracture sand A specialized sand added to the fluids that are injected into unconventional oil and gas wells during hydraulic fracturing. Fracture sand includes processed naturally occurring sand or industrially coated sand that meets strict mineralogical and physical specifications such that frac sand is effective as a proppant.

hydraulic fracturing A process used by oil and gas companies to increase production from wells that would otherwise have low production rates and low overall production totals. Hydraulic fracturing involves using a pressurized slurry of a fluid, typically water and dilute chemicals, with a solid proppant to fracture the rock emanating from the borehole. This increases the effective fluid conductivity of the formation and improves the connectivity of the formation to the borehole, allowing increased hydrocarbon production (University of North Dakota, Energy and Environmental Research Center, 2014).

mineral resources Mineral resources are not mineral reserves and do not have demonstrated economic viability.

proppant Propping agent; solid granular material that "props" open a bedrock fracture after the hydraulic fracture fluid pressure is released to allow a flow path for oil or gas to reach the well bore (Houseworth, 2014). Proppants include sand, ceramic media, resincoated proppants, and other materials used for hydraulic fracturing (American Petroleum Institute and others, 2008). Together with water and chemicals, proppants are injected under high pressure into a fine-textured bedrock formation to widen existing or create new fractures and then keep them open. 

For more information about this publication, contact Director, USGS Nebraska Water Science Center 5231 South 19th Street

Lincoln, NE 68512

(402) 328-4100

For additional information visit https://ne.water.usgs.gov

Publishing support provided by the

Rolla Publishing Service Center 
